\title{
Common Country Assessment for the Islamic Republic of Afghanistan
}
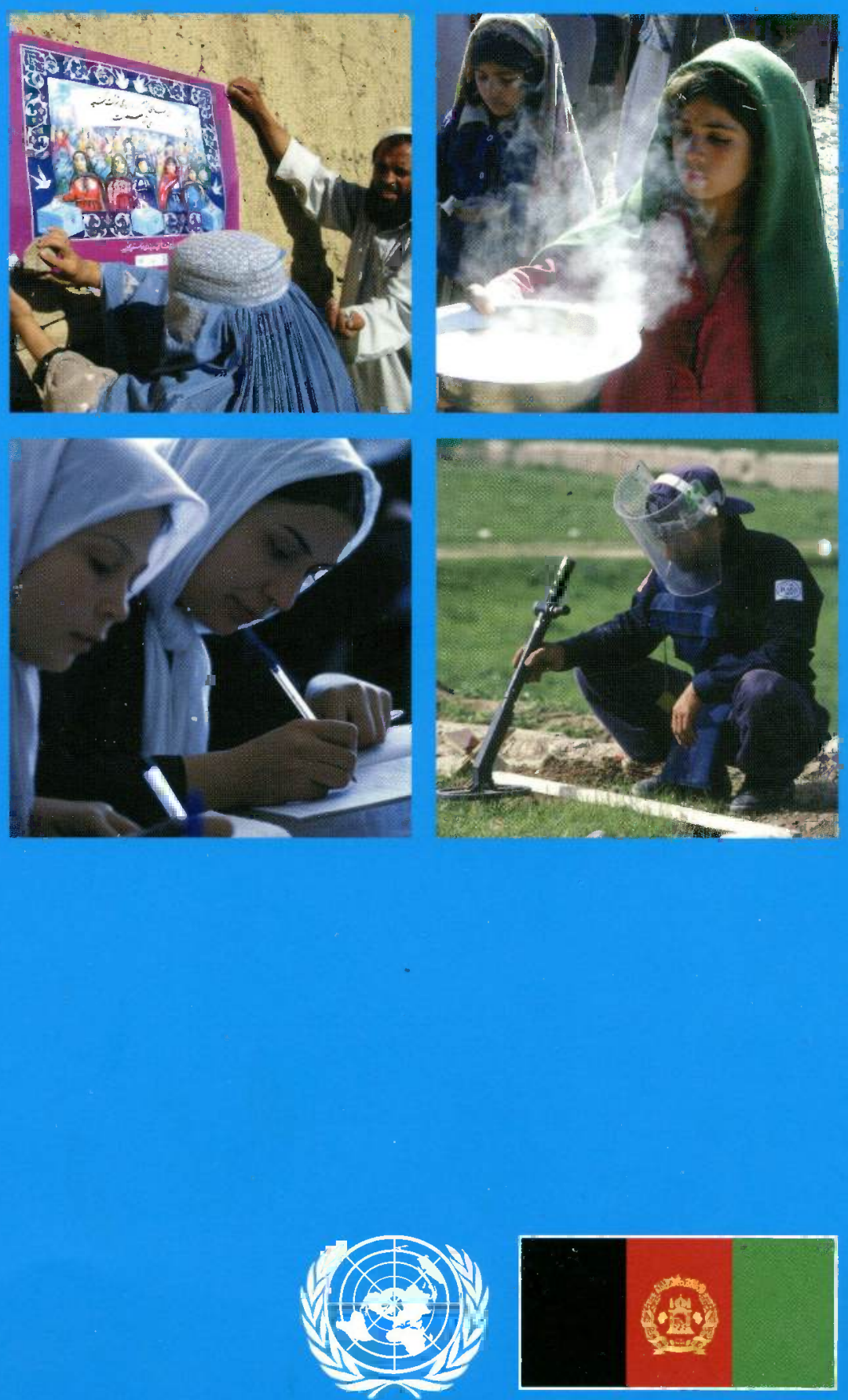

United Nations System, Kabul, October 2004 


\section{Foreword}

The Common Country Assessment (CCA) for the Islamic Republic of Afghanistan is the work of a large number of individuals within the Government, the United Nations System and other organisations. In a dynamic process begun six months ago, these individuals worked together to carry out the essential first phase of data collection and analysis for the future United Nations Development Assistance Framework 2006-2008 (UNDAF). This, we believe, has been an important learning tool for the entire United Nations System staff.

It is with pleasure that we, the United Nations Country Team, present this first CCA for Afghanistan, in the hope that it will prove a useful source of information for better coordination and programming of United Nations support in the country. May our common efforts continue to bear fruit in the years to come.

Ameerah Haq

Deputy Special Representative of the Secretary-General, UNAMA and Resident Coordinator of the United Nations System
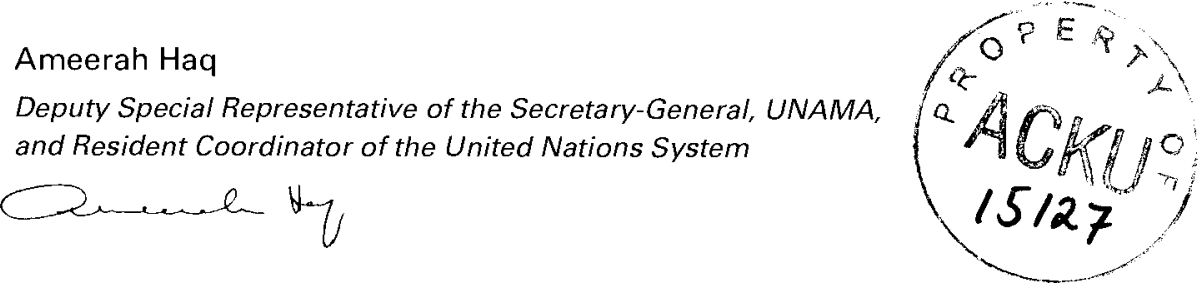

Serge Verniau, FAO

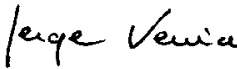

Lalith Lankatilleke, UN-Habitat

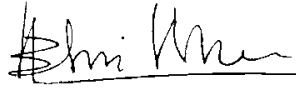

Shengjie Li, ILO

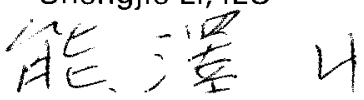

Matt Huber, IOM

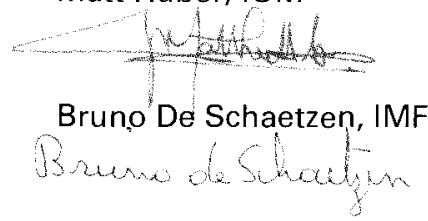

Karen Jorgensen, UNDP

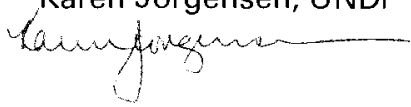

Asif ZaidinUNEP

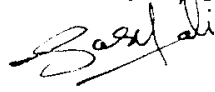

Malama Meleisea, UNESCO

Nel Mus

Athanase Nzokirishaka, UNFPA

$$
A-0.2
$$

Jacques Mouchet, UNHCR

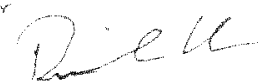

Sally Cooper, UNIRIN

Bernt Aasen, UNICEF

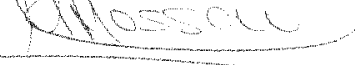

Ryoko Hosono, UNIDO

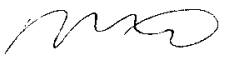

Meryem Aslan, UNIFEM

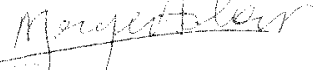

Dan Kelly UNMACA

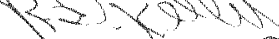

Doris Buddenberg, UNODC

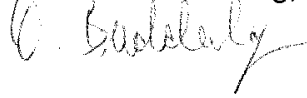

Gary Helseth, UNOPS

Susana Rico, WFP

YUMA

Riyad Ausa WHO

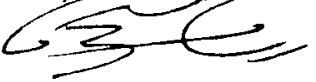

Uean Mazurelle, World Bank

wiolowe

V. N. Gnanathurai, ADB 


\section{Contents}

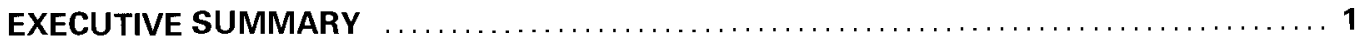

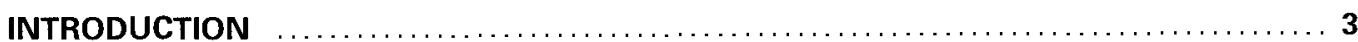

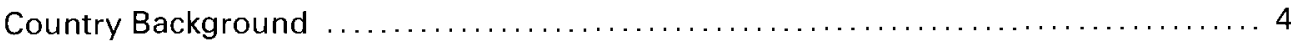

Objective and Scope of the Common Country Assessment $\ldots \ldots \ldots \ldots \ldots \ldots \ldots \ldots, 5$

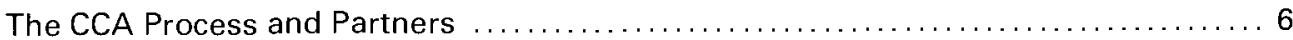

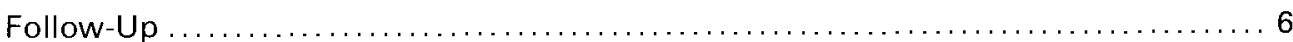

I. GOVERNANCE AND INSTITUTIONAL DEVELOPMENT $\ldots \ldots \ldots \ldots \ldots \ldots \ldots \ldots \ldots$

The Situation in Afghanistan $\ldots \ldots \ldots \ldots \ldots \ldots \ldots \ldots \ldots \ldots \ldots \ldots \ldots \ldots \ldots \ldots \ldots \ldots, 10$

Analysis of Key Issues and Underlying and Root Causes $\ldots \ldots \ldots \ldots \ldots \ldots \ldots \ldots \ldots \ldots \ldots \ldots$

Democratic Accountability and the Rights of the Citizen $\ldots \ldots \ldots \ldots \ldots \ldots \ldots 13$

Participation in Political Processes and Social Inclusion ................... 14

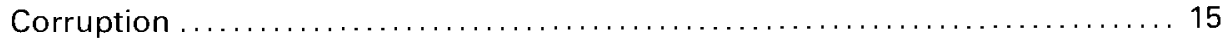

Public Administration Reform ................................... 1

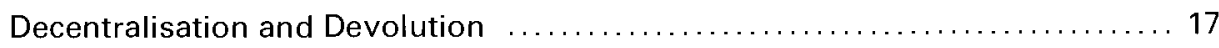

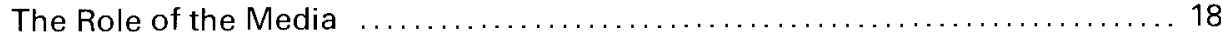

What Does Success Depend On? . . . . . . . . . . . . . . . . . . . . . . . . . . . 19

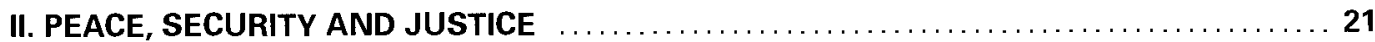

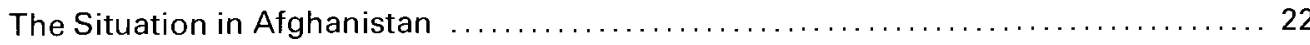

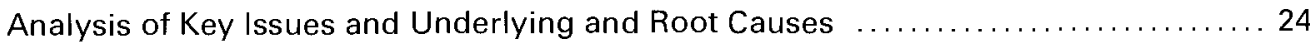

Explosive Remnants of War: Landmines, Unexploded Ordnance ............. 25

Continued Influence of Non-Statutory Armed Forces and Persistence

of Incidents of Armed Violence ............................ 26

Contested Allocation of Resources . . . . . . . . . . . . . . . . . . . . . . . . . 28

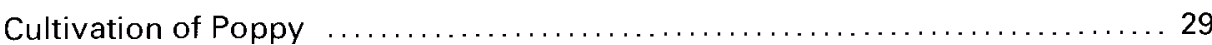

Dysfunctional Formal Justice System and Preference for Traditional

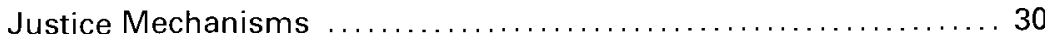

Social Violence and Lack of Social Protection ........................ 33

What Does Success Depend On? . . . . . . . . . . . . . . . . . . . . . . . . . . . 34

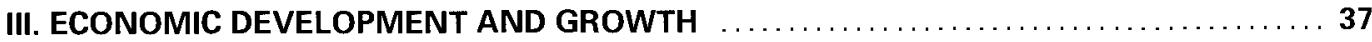

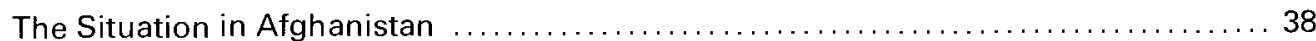

Analysis of Key Issues and Underlying and Root Causes ..................... 40

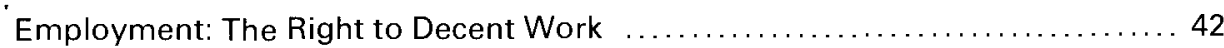

Distributive Justice: The Right to Human Dignity and Gender Equality ....... 44

Using Natural Resources Sustainably, Managing Disaster Risks Effectively .... 47

What Does Success Depend On? ...................................... 48 


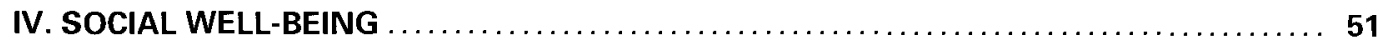

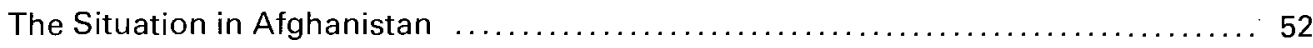

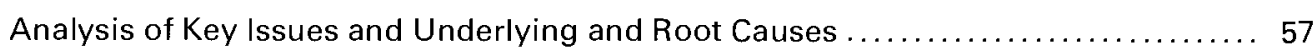

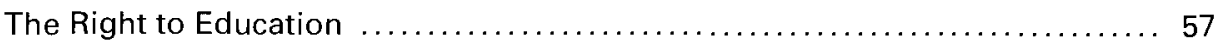

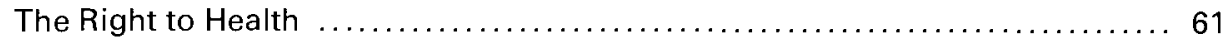

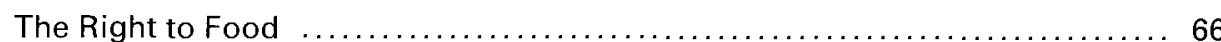

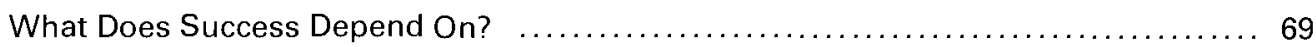

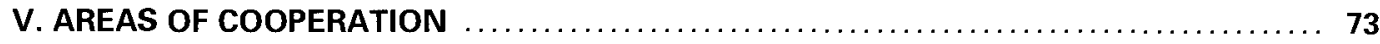

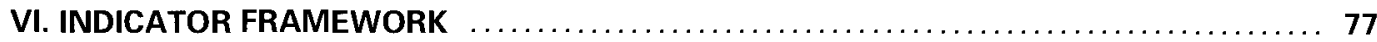

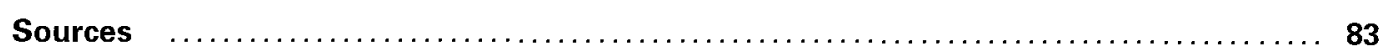

Annex A Major Findings of the Common Country Assessment $\ldots \ldots \ldots \ldots \ldots \ldots \ldots \ldots \ldots$

Annex B International Agreements Concluded Between Afghanistan

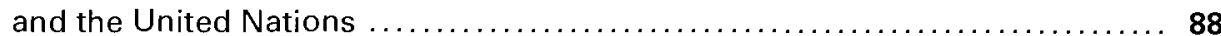

\section{Boxes}

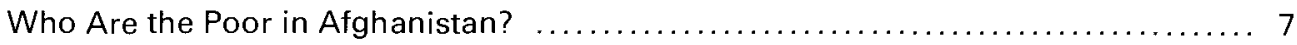

Governance and Institutional Development: National Policies and Priorities ....... 11

Governance and Institutional Development: International Context and Commitments . 20

Governance and Institutional Development: Significant Data Gaps $\ldots \ldots \ldots \ldots \ldots .20$

Peace, Security and Justice: National Policies and Priorities $\ldots \ldots \ldots \ldots \ldots \ldots \ldots \ldots 23$

Peace, Security and Justice: International Context and Commitments .......... 35

Peace, Security and Justice: Significant Data Gaps $\ldots \ldots \ldots \ldots \ldots \ldots \ldots \ldots \ldots \ldots \ldots$

Economic Development and Growth: National Policies and Priorities ........... 39

Economic Development and Growth: International Context and Commitments .... 50

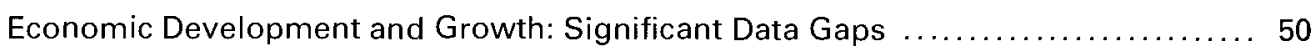

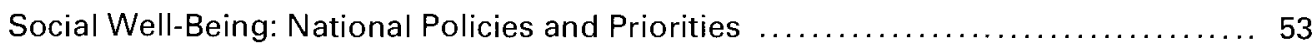

Social Well-Being: International Context and Commitments $\ldots \ldots \ldots \ldots \ldots \ldots \ldots \ldots 71$

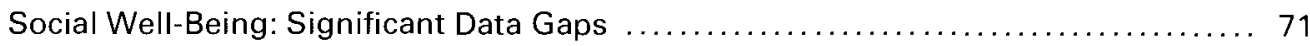




\section{Executive Summary}

The Common Country Assessment (CCA) reviews and analyses Afghanistan's development situation to begin to answer the question: Where can the United Nations System have the greatest impact between 2006 and 2009 toward the overall goal of poverty reduction? In identifying development challenges requiring priority attention during its harmonised programme cycles, the United Nations System and its partners clustered themes for analysis into four closely interrelated groups:

- Governance and Institutional Development

- Peace, Security and Justice

- Economic Development and Growth

- Social Well-Being

All themes are key to helping Afghanistan achieve the Millennium Development Goals (MDGs) for 2015, which Afghanistan has endorsed. For each thematic area, this document presents a strategic analysis, identifies root and underlying causes of key issues, and assesses the factors for success, providing recommendations for future areas of cooperation and underscoring the urgency of acting now. A crosscutting issue of note lies in conflict prevention, post-conflict reconciliation and peace building, which underpins all four thematic areas and must be mainstreamed in each.

In the area of Governance and Institutional Development, key issues included:

- Democratic Accountability and the Rights of the Citizen

- Participation in Political Processes and Social Inclusion

- Corruption

- Public Administration Reform

- Decentralisation and Devolution

- Ensuring a Positive Role for the Media

Under Peace, Security and Justice, issues that were assessed included:

- Explosive Remnants of War

- Continued Power and Influence of Non-Statutory Armed Forces, Along With the Persistence of Incidents of Armed Violence

- Contested Allocation of Resources

- Cultivation of Poppy

- Dysfunctional Formal Justice System and Preference for Traditional Justice Mechanisms

- Social Violence and Lack of Social Protection

Economic Development and Growth analysed issues of:

- Employment: The Right to Decent Work

- Distributive Justice: The Right to Human Dignity and Gender Equality

- Using Natural Resources Sustainably, Managing Disaster Risks Effectively

Lastly, Şocial Well-Being looked at availability of, and access to:

- The Right to Education

- The Right to Health

- The Right to Food

Overall, root causes of these key issues were traced to the following:

- Underdeveloped human rights culture, along with lack of traditions of democracy, state-building and civil society participation 
- Young governance structures still in the process of establishment and/or early.stages of development, and unable to curb political insecurity

- Shortage of human resources that can propel democratic, economic and social reforms

- Wide variations in socio-economic indicators, by gender, region and rural-urban divide

- Weakened social infrastructure

- Socio-cultural traditions that result in widespread marginalisation based on gender, social status or ethnicity

- Culture of unsustainable resource use that must be reversed

- Obsolete industrial and agricultural techniques and practices that harm the environment

A complete summary of the findings of the CCA is available in Annex A. Based on the analysis, three broad areas have emerged in which support for the transition of Afghanistan can be concentrated. These are:

- Human Rights and Peace Building

- Good Governance and Participatory Development

- Basic Social Services and Environmental Sustainability

The main criteria for proposing these areas of cooperation are: priority needs; potential for long-term impact on national goals and priorities; lessons learnt and good practices; and opportunities to strengthen both national capacities and international cooperation. The three areas will be coherently reflected by individual Agencies in their mandated activities within the UNDAF.

The focus of Human Rights and Peace Building will not be on emergencies as such, but rather, on longer-term peace-building. "This can include support to creating the knowledge, skills and values for a human rights culture; significantly improving gender equality; expanding counter-narcotics measures; enhancing the rule of law; and ensuring a more equitable allocation of resources, particularly through enhancing conflict resolution mechanisms and access for the poor and vulnerable. Building national ownership and national capacities, both within Government and civil society, will be emphasised.

Meanwhile, different concepts of good governance can be accommodated within a durable structure of pluralist democracy grounded in civic rights. The latter also constitute a vehicle for ensuring minority rights. Through Good Governance and Participatory Development, the United Nations System can assist in this process both by helping to solidify the governance agenda as well as by supporting a number of initiatives to consolidate democracy in the course of the Afghan transition. This can include support for the fight against corruption; strengthening of civil society; institution building and civil service reform; enhanced propoor policy frameworks; and accountability and monitoring of the public sector.

Finally, under Basic Social Services and Environmental Sustainability, the United Nations System will support measures essential to allow people to lead long, healthy and creative lives, to enjoy decent living standards and freedoms, and to possess dignity, self-respect and respect for others. These can include education; health, family planning and nutrition; the environment; mitigation of natural disasters; and social protection. Consequently, as the. United Nations System moves forward with development of the UNDAF, the focus on the poor and vulnerable - as well as on duty bearers, including the State - will be more deliberate. This approach also will be highlighted in United Nations involvement in the World Bank-led Poverty Reduction Strategy (PRSP) process. What this implies is a more concerted, explicit engagement of domestic and international partners - non-Government organisations (NGOs) and civil society, families, local Governments and communities, the business community, the media and academia. In so doing, the United Nations System can help Afghanistan stand firmly among democracies of the 21 st Century.

1 Peace-building is used in this context as "aimed at preventing the outbreak, the recurrence or continuation of armed conflict and therefore encompasslingl a wide range of political, developmental, humanitarian and human rights programmes and mechanisms." United Nations Security Council, Presidential Statement, 20 February 2001, para. 5 
Introduction 

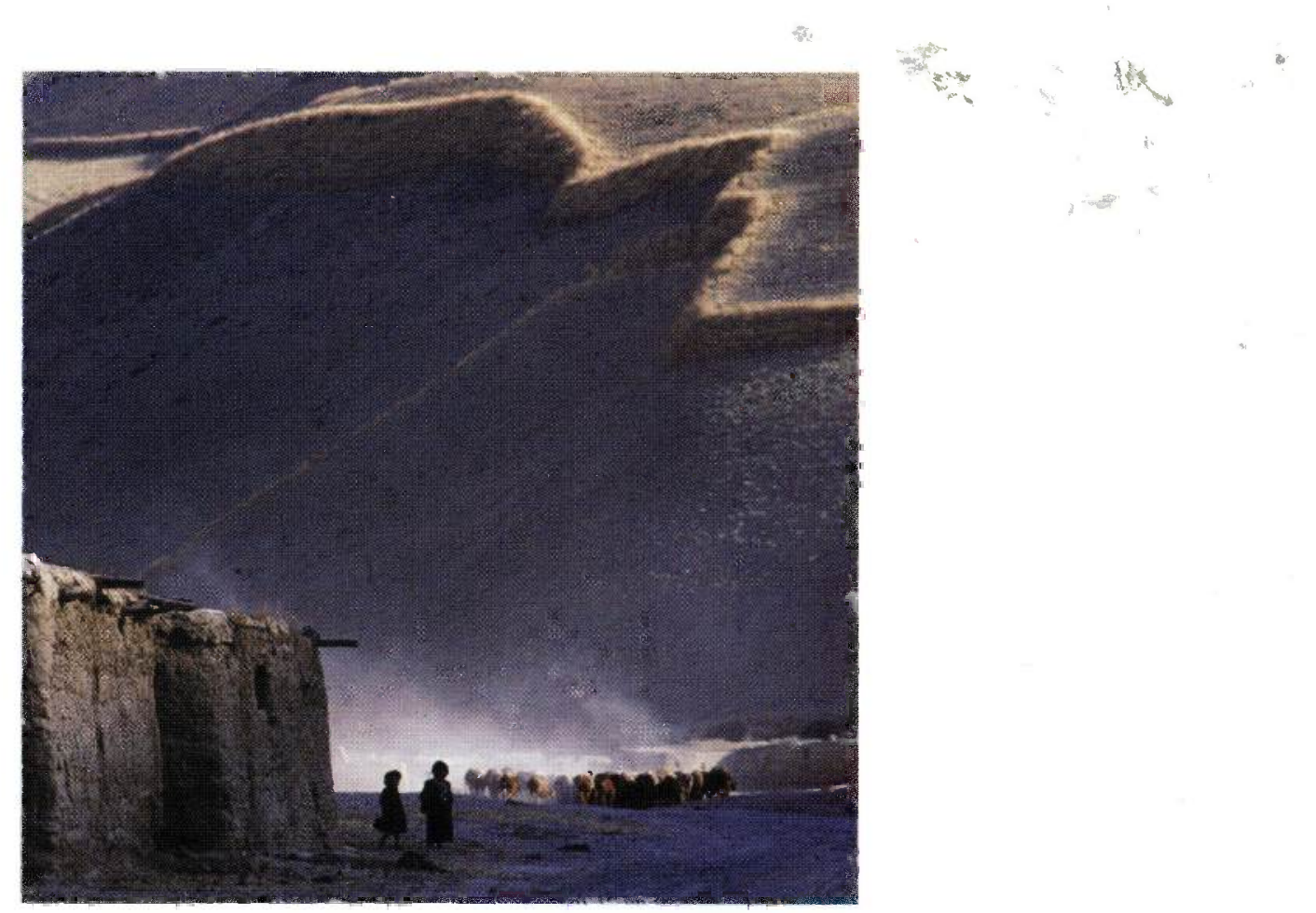

\section{Country Background}

Afghanistan's geopolitical role as the centre of global interchange was well established more than a century ago, and it is a strategic role that continues to exercise considerable influence today. This starkly beautiful country's recent history - marked by civil war, Soviet occupation, mujahidin resistance, fragmentation of power, the rise of Islamic extremism and a continued military coalition presence - still makes it a pivot for international relations. Thus, the entire world has a strong interest in Afghanistan's reconstruction, longer-term development and avoidance of further conflict.

Following the last quarter-century of turbulence, Afghanistan is working to rebuild a secure state that can reduce poverty for its people. It is a powerful yet urgent challenge: In the new National Human Development Report, Afghanistan ranks as the world's seventh-poorest nation, a devastating figure ${ }^{2}$. Moreover, its poverty is deeply entrenched. Even before the 1979 Soviet invasion, the country's development indicators were very low. Now, human security, based on the full realisation of the human rights of the Afghan people, must be significantly expanded so stability may thrive: Low incomes, socio-cultural traditions that severely restrict women's opportunities, poor quality of education, continued threats from the burgeoning drug economy and criminality are mutually reinforcing. In response, eliminating vulnerability, improving social services delivery, strengthening democratic institutions, establishing participatory development - all will lead to a more stable Afghanistan. This will help not only to formulate pro-poor poverty reduction strategies but also to fulfil human security.

\footnotetext{
${ }^{2}$ National Human Development Report, UNDP, 2004, p.

2. Afghanistan's Human Development Index value is 0.346 , at the bottom of the low human development countries. With a Gender Development Index (GDI) of only 0.300 , reflecting the level of equality or inequality between women and men, Afghanistan ranks just above one country.
}

Despite a myriad of challenges before stability is assured, Afghanistan has hope. Education is again a priority for girls as well as boys, with 4 million children thronging back to school. With an improved political situation, an estimated 3.6 million refugees have returned - nearly one-fifth of the population - and 700,000 Internally Displaced Persons (IDPs) have come back to their homes. Large-scale infrastructure projects have been undertaken to stimulate economic growth. Perhaps most importantly, a path toward democratic selfgovernment has been laid out, starting at the Bonn Conference in 2001. A new Constitution was signed in January 2004, and the nation's first presidential elections were held in 
In pursuit of human Gevelopment, 189 United Nations Member States. including Afghanistan, have adopted the Millennium Declaration, setting out key development challenges facing humanity and outlining measures for gauging performance. Eight time-bound goals have been identified for combating poverty, hunger, disease, illiteracy, discrimination against women and environmental degradation. The Millennium Declaration also pays special heed to all nations' responsibility to protect the vutnerable, particularly chidren and civilian populations.
${ }^{3}$ Securing Afghanistan's Future: Accomplishments and the Strategic Path Forward; Transitional Islamic State of Afghanistan, Asian Developmen Bank, United Nations Assistance Mission in Afghanistan, United Nations Development Programme World Bank, March 2004, p. 107.

4 Afghanistan is a party to six of seven major intemational human rights instruments but, given decades of conflict, it has not been able to fulfil its reporting obligations under the ratified human rights treaties. The Govemment has, however, recendy committed to reporting and has prominently incorporated human rights in the new Constitution. For a full listing of international agreements concluded between Afghanistan and the United Nations, see Annex $\mathrm{B}$
October 2004. All these developments, properly managed, contribute to the overarching. goal of poverty reduction.

At the same time, Afghan women and girls continue to struggle to exercise fundamental rights to health, education, work, freedom of expression and freedom of movement. Considerable disparities among different social groups and across different regions of the country bring the continuing need for vigilance in development to the forefront. Huge amounts of external assistance are required to help Afghanistan's reconstruction - estimated at US\$27.6 billion over the next seven years ${ }^{3}$ - if meaningful poverty reduction is to occur. In the long run, the experience of Afghanistan may show whether the international community can sustainably assist a fragile country as it rises from the aftermath of conflict. Equally important, the capacities and potential of the poor themselves must be fully tapped to unlock the potential of Afghanistan as a whole. Only then will Afghan voices be heard as they should.

\section{Objective and Scope of the Common Country Assessment}

The Common Country Assessment (CCA) reviews and analyses Afghanistan's development situation to begin to answer the question: Where can the United Nations System have the greatest impact between 2006 and 2008 toward the overall goal of poverty reduction? The multidimensional character of poverty indicates that its incidence in Afghanistan remains high, although specific data remain scarce and variations among regions are wide [see also Who Are the Poor in Afghanistan?]. While the CCA identifies the key challenges to tackle poverty reduction, the United Nations Development Assistance Framework (UNDAF), which follows it, will put forward a common response to a select number of those challenges. Both processes are intended to strengthen the contribution of the United Nations System toward achieving the global Millennium Development Goals (MDGs) and maximising the potential of Afghanistan's women, men and children.

Because poverty most often results from the denial of human rights ${ }^{4}$ - through discrimination, marginalisation or unequal access to education, health or resources - the guiding principle behind this CCA is rights-based human development. Those living in poverty are often vulnerable to further human rights violations. Therefore, a focus on human rights will help ensure that key concerns of the poor become, and remain, key concerns of poverty reduction strategies. The legal obligations for duty bearers, particularly the State, that this involves in turn enable the people to demand accountability, strengthening good governance and the rule of law. In particular, the CCA examines impediments to fulfilment of rights to survival, livelihood, protection and participation for the poor and vulnerable. It then lays out opportunities required to guarantee basic rights for all Afghans and identifies the United Nations System's niche.

In identifying areas requiring priority attention during its harmonised programme cycles, the United Nations System and its partners have built on national development priorities, the global MDGs and the United Nations' experience and proven competitive advantage. The most crucial themes for analysis have been clustered into four closely interrelated groups:

- Governance and Institutional Development

- Peace, Security and Justice

- Economic Development and Growth

- Social Well-Being

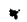


For each thematic area, this document presents a strategic analysis; identifies root and underlying causes of key issues; and assesses the factors for success. It provides recommendations for future areas of cooperation and underscores the urgency of acting now. A crosscutting issue of note lies in conflict prevention, post-conflict reconciliation and peace building, which underpins all four thematic areas and must be mainstreamed in each. Meanwhile, the Government committed to the MDGs in March 2004 and has progressed in key areas of the Millennium Declaration, such as gender equity; expanding the base of political and social freedoms; and revival of the media.

Moreover, its key policy document Securing Afghanistan's Future takes an explicitly MDGbased approach. Afghanistan has the potential to meet 10 of 11 MDG targets ${ }^{5}$, although the state of the supportive policy environment is weak to fair in relevant areas ${ }^{6}$. This must be further qualified, however, by the prerequisites of attaining human security and continuing strong international assistance for at least the next 10 years. Full compliance with commitments to the major international conventions signed and ratified by the Government also will promote greater respect for the rights of all.

5601517

Gopening Doors to Opportunity: Afohanistan's Milenntum Development Goals, UNDP 2004 p. 46 .

7 Answers were recelved from International Fund for Agricultural Develoment, mtemational Marthe Oranisation, UNADS. Unted Nations Contarence on Trade and Development, United Natons Hich Commissioner for Human Pights. United Nations institute for Disamament Research, United Nations institute for Traing and Research. United Natons htemational Pesearch and Traning Instirute for the Advancement of Women. Universal Postal Union and Word Intellectuas Propery Organisation.

3 The indicator framework, which was approved by the Unted Nations Develoomen Grouo (UNOG) as an integral part of the CCAUNDAF guidelines, comprises five components: (a) indicators reloting to development goals and objectives set in Unted Nations

Conferences, Conventions.

Declarations and Summits

bulding on existing established

globallists, especialy that used for the olobal montoring of MDGs; (b) Conterence and Convention indicators relating to govemance. democracy justice adminstration, and security and protection of the person; (c) Basio contextual indicators relating to the demographic and economio conditions of the country, which provide the necessary background for understanding develoment and socio-cultural concems; (d) hicators used for monitorng MDG 8. "Develop a global partnership for development"; and (e) Thematio indicators to provide further insights into issues of major concen for development. including specific county settings. national priorities and seeds, and crosscutting issues

\section{The CCA Process and Partners}

The CCA/UNDAF process was launched at a meeting of the United Nations Country Team (UNCT) in Afghanistan in May 2004. A Steering Committee, chaired by the Resident Coordinator and comprised of the heads of UNDP, UNFPA, UNICEF, WFP, UN-Habitat, WHO and the World Bank, set up Thematic Groups on the four priority areas outlined above. Nearly all resident United Nations Agencies appointed focal points and/or participants.

The Government was invited to join the process in June 2004, as were other stakeholders. A total of 19 Ministries and Government departments participated, as well as the National Security Council, the Afghan Independent Human Rights Commission, the Afghan Investment Support Agency, the Microfinance Investment and Support Facility for Afghanistan, the Supreme Court, the Law Faculty of Kabul University, the Chamber of Commerce and 14 non-Government organisations (NGOs) and civil society organizations. Twenty non-resident Agencies also were invited to participate and asked to share an overview of their current engagement in Afghanistan. ${ }^{7}$ The four Thematic Groups held frequent meetings, where members identified additional issues for review and corresponding indicators and carried out their analytical work. Drafting of inputs to the CCA document began in August/September 2004. ${ }^{8}$

\section{Follow-Up}

The United Nations Country Team and the Government of Afghanistan will refer to the CCA to consolidate the process of human rights and MDG monitoring at the country level and to follow up on implementation of United Nations Conventions and Agreements. It also will be used to ensure that data gaps and research needs will be systematically addressed through programme- and project-specific components by all organisations. Through the Poverty Redúction Strategy (PRSP) process, it will assist the United Nations System and the donor community in aligning, coordinating and monitoring assistance strategies and budgets for poverty reduction at the national level. Ultimately, the analysis of the CCA rests on the concept that it will complement the Government's vision behind national policies - that is, the achievement of a climate conducive to poverty reduction, human rights and human security. 


\section{Who Are the Poor in Afghanistan?}

Poverty in Afghanistan is complex, involving low assets (physical, financial and human), years of insecurity and drought, cultural traditions, and poor infrastructure and public services. Most of Afghanistan's estimated 24.5 million people - particularly women and girls - remain severely challenged in terms of human development. More than 1 in 5 Afghans cannot afford a food consumption level of 2,070 calories per day, which in many circumstances defines the poverty line. The highest maternal mortality rate in the world is found in the northeast of the country, and despite significant recent advances in girls' enrolment, 2 out of $3 \mathrm{girls}$ are still not in school. Only 4 in 10 Afghans have access to safe drinking water. Around 1 million people have disabilities, 25 percent as a result of war. Finally, large parts of the country are still under the control of commanders and warlords and out of reach of assistance, despite urgent needs. The following table shows the magnitude of the gaps between today's social indicators and the global MDG targets for 2015 :

\section{Progress Towards the MDGs for Afghanistan}

Current Level MDG Target 2015

\begin{tabular}{|c|c|c|}
\hline Caloric deficiency rate -- poverty line & $20.4 \%$ & \\
\hline Hunger $"=$ caloric deficiency rate plus at-risk population & $37.4 \% *$ & $18.6 \%$ \\
\hline Adult literacy (age 15 and older) & $29 \%$ & $56 \%$ \\
\hline Female literacy (ages 15 and older) & $14.1 \%$ & \\
\hline Primary school enrolment ratio, net & $54 \%$ & $100 \%$ \\
\hline Girls in primary school (age 7-12) & $40 \%$ & $100 \%$ \\
\hline Life expectancy at birth & 44.5 yea & \\
\hline Infant mortality per 1,000 births & 115 & 40 \\
\hline Under -5 mortality per 1.000 births & 172 & 60 \\
\hline Matemal mortality (per 100,000 live births) & 1,600 & 400 \\
\hline Measles (cases per annum.) & 903 & 0 \\
\hline Malaria prevalence & $4.2 \%$ & $1.1 \%$ \\
\hline Tuberculosis (per 100,000 population) & 321 & 48 \\
\hline Access to safe drinking water & $40 \%$ & $80 \%$ \\
\hline
\end{tabular}

Souces: Central Statistics Office of Afghanistan; UNDP, Human Development Indicators, 2003. UNICEF. The State of the World's Children, 2003, Multiple Indicator Chuster Survey, 2003; World Bank, World Development indicators, 2003; Word Health Organisation, 2003. 
Governance and Institutional Development 

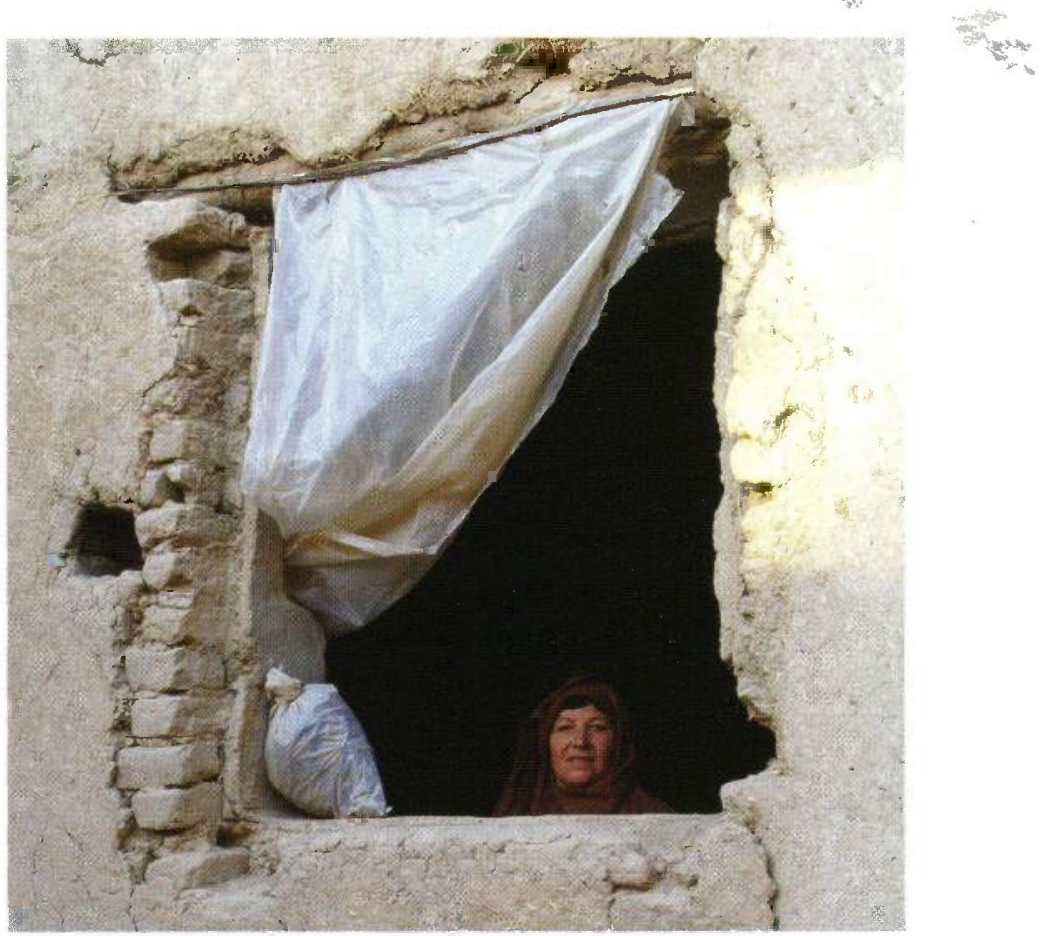

is

${ }^{9}$ The Joint Electoral Management Body (JEMB) finalised a list of 18 candidates for the presidential election and registered more than 10.5 million Afghans as prospective voters $(58.2$ percent men, 41.8 percent women). At the time of writing, this figure is still preliminary and subject to change, given that the electronic counting of registrations by the data center had not been completed.

10 Human Security and Livelihoods of Rural Afghans, 2002-2003, Feinstein International Famine Centre, Tufts University, June 2004, p. 8.

\section{The Situation in Afghanistan}

Specific characteristics of a country's political institutions, especially those that prevent the efficiency of legislative activity, appropriate administration of justice, and participation of the poor in defining policies, may be related to factors that have caused poverty to persist. The Millennium Declaration recognises this and represents the strongest, most explicit and unanimous statement of United Nations Member States in support of democratic and participatory governance. It articulates that the interlinked goals of poverty reduction, the MDGs and the protection of rights to survival, livelihood, protection and participation must be achieved through good governance, encompassing power that is effective, honest, equitable, transparent and accountable. This will ensure not only the full enjoyment of political rights, but also meaningful economic development and improvements in standards of living in both rural and urban areas.

In Afghanistan, issues of governance and conflict also are intricately related. Support to governance factors such as participatory decision-making, strengthening of civil society and public administration reform thus will have implications for reducing the outbreak of violent conflict, strengthening efforts at poverty reduction. Progress has been made toward establishing a central Government through the 2001 Bonn Conference and two loya jirgas (grand councils), a traditional governance institution. These set out the formation of the transitional Government after the fall of the Taliban; agreed upon a schedule for permanent elections; and adopted the new Constitution, which recognises women as equal citizens. Now, accountability of the public sector and political authorisation by the people is emerging through the budding democratic elections process, reflected in the high voter turnout - including the wide participation of women - in the October 2004 presidential election ${ }^{9}$.

Even so, civil society as a vehicle for participation is severely underdeveloped. More than 50 percent of rural Afghans in selected provinces have no knowledge of the new Constitution. ${ }^{10}$ Overall, NGOs are relatively recent in the Afghan context. A large number deliver short-term emergency and reconstruction assistance and thus act more as private contractors than as genuine civil society fora fostering popular participation and social 


\section{National Policies and Priorities}

National policies and priorities in governance are laid out in the National Development Framework (NDF), which articulates a clear vision of the role of Government as limited to providing only essential services. Under the NDF, the Government has developed a number of relevant programmes:

\section{National Solidarity Programme (NSP)}

- Participatory governance policies can well be illustrated by the NSP, which was developed to reduce poverty by building the ability of communities to identify, plan, manage and monitor their own development projects.

- The NSP promotes a new development paradigm whereby communities are empowered to make decisions and control resources during all stages of the project cycle. In accordance with Government policy, the programme is expected to make local governance more representative (e.g. for women, ethnic minorities, returnees/IDPs) and to provide assistance for community reconstruction and development.

- The NSP aims to establish a framework for highly inclusive, village-level consultative decision making through community meetings and development councils. This process will serve as a basis for interaction within and between communities, as well as among communities, the central Government and aid agencies.

\section{Afghanistan Stabilisation Programme (ASP)}

- The ASP offers an integrated strategy for addressing security, governance and reconstruction challenges at provincial and district levels, and is designed to make urgent changes to the way provinces and districts are governed. It intends to re-establish basic security and good governance at district and provincial level through sequenced, coordinated projects.

- Through one of the ASP sub-programmes, the Provincial Stabilisation Fund, decision-making is decentralised, and governors are provided with capacity to address priorities in their provinces and to plan and implement projects. Initially, it intends to cover 158 districts by the end of the current Afghan fiscal year (21 March 2005). The second phase, in the course of 2005 , aims at addressing the rest of the country's districts.

\section{Public Administration Reform (PAR)}

- The PAR strategy provides a framework for programmes and projects that will build a sound legal, administrative and physical environment for efficient, effective public service, in which civil servants can be held accountable for their performance.

- The PAR covers these major components: civil service legal framework, personnel management, institutional and functional streamlining and development, financial management and machinery of Government, administrative efficiency, and improvement of Government physical infrastructure.

- The document Securing Afghanistan's Future, presented to donors in March 2004, describes a decade long plan to build a civil service that is better equipped, skilled, and managed, while more representative of Afghan society. Ambitious targets include a merit-based and transparent system of civil service appointments that will cover 90 percent of the system by March 2015. Another goal is to increase the percentage of civil service staff based outside Kabul (currently 63 percent) in order to decentralise and provide services to the provinces and districts. For its strategic vision of economic management, public administration and technical assistance, the Government is requesting US\$201 million this year and US\$1.1 billion over a seven-year period.

- Within the PAR strategy, the Government in 2003 launched the Priority Reform and Restructuring Programme (PRR), which rationalises the responsibilities of employees and labour market pay scales. More than 41 departments in Ministries had their priority restructuring and reforming plans approved by September 2004.

\section{National Urban Programme (NUP)}

- Through good urban governance and management, this programme aims to establish a network of dynamic, safe, liveable urban centres that are hubs of growth, and arenas of cultural and social inclusion. 


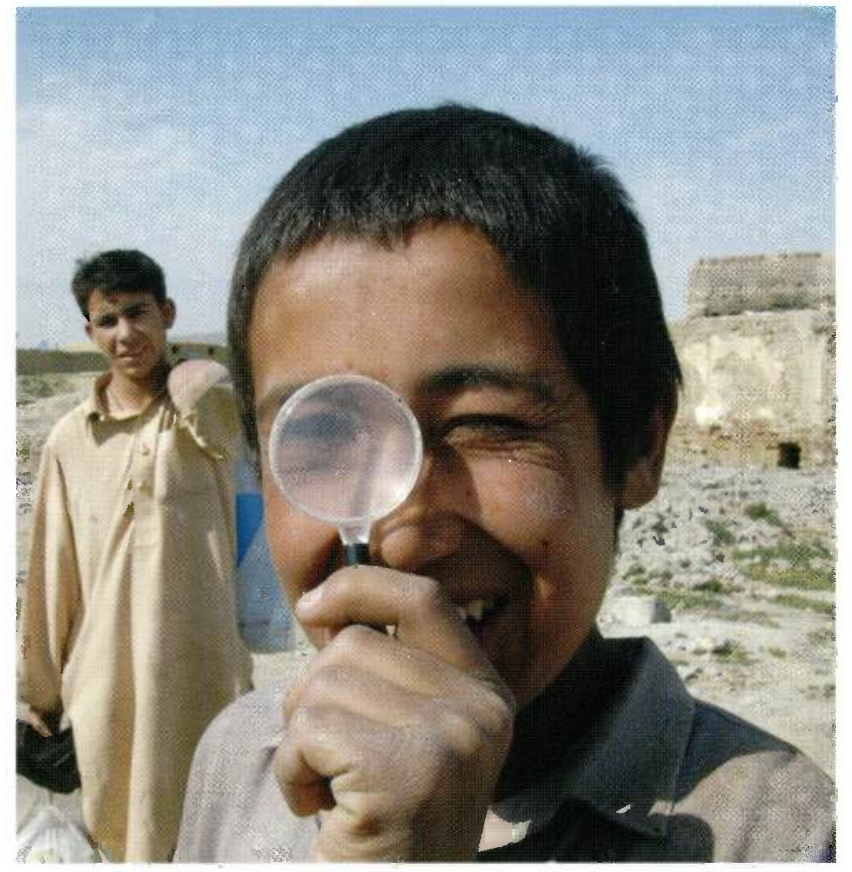

organisation. In particular, serious limitations remain on participation of women in political and civil affairs, representing a direct obstacle to their rights and human security, as well as to nation-building and poverty reduction. ${ }^{11}$ Regional military factions, conservative religious leaders and insurgent forces are limiting women's participation in society through death threats, harassment and physical attacks. ${ }^{12}$

Meanwhile, Afghanistan's civil administration has little reach beyond Kabul, given that local commanders retain control of vast regions. Administrative arrangements remain highly centralised, politically, fiscally and administratively. The central Government suffers from overlapping functions, a serious lack of skilled professionals, severe gender imbalance, low pay and lack of merit-based recruitment ${ }^{13}$. ${ }^{14}$ Many policies are not yet well-defined or pro-poor, and capacity for oversight and enforcement by Government institutions is lacking at all levels. Often, the central Government makes policy decisions for provincialand district-level administrations. ${ }^{15}$ At the same time, good governance also is critical for ensuring that cities function well and are engines of growth, with decentralisation leading to devolution of power serving as a key component for poverty reduction. A number of reform initiatives are under way, largely within the framework of the Public Administration Reform (PAR) programme. In its landmark investment programme Securing Afghanistan's Future, the Government describes a decade-long plan to build a civil service that is better equipped, skilled and managed, while more representative of Afghan society.

Concerted efforts must be supported to provide an enabling environment for all of Afghanistan's ethnic minorities with regard to participatory governance, given that ethnic politics has long held sway in the country. Another important area in which the Government must take full ownership is the reintegration of the millions of refugees and IDPs who have returned to their places of origin since 2002; Afghans represent the second-largest number of refugees and IDPs in the world. A long-term mainstreaming policy for returnees/IDPs is critical, despite considerable developmental and economic absorption challenges. This should include integration into democratic participation, given that return and reintegration are not solely humanitarian issues.

\section{Analysis of Key Issues and Underlying and Root Causes}

The CCA analysis is synchronised with national priorities [see National Policies and Prioritjes box], and the United Nations System is supportive of Government efforts toward governance and institutional development, particularly the National Solidarity Programme, the Afghanistan Stabilisation Programme, the Public Administration Reform Programme and the National Urban Programme. Analysis has identified the following key issues, all of which relate to good governance:

- Democratic accountability and the rights of the citizen

- Participation in political process and social inclusion, including gender equality and civil society partnerships

- Corruption 


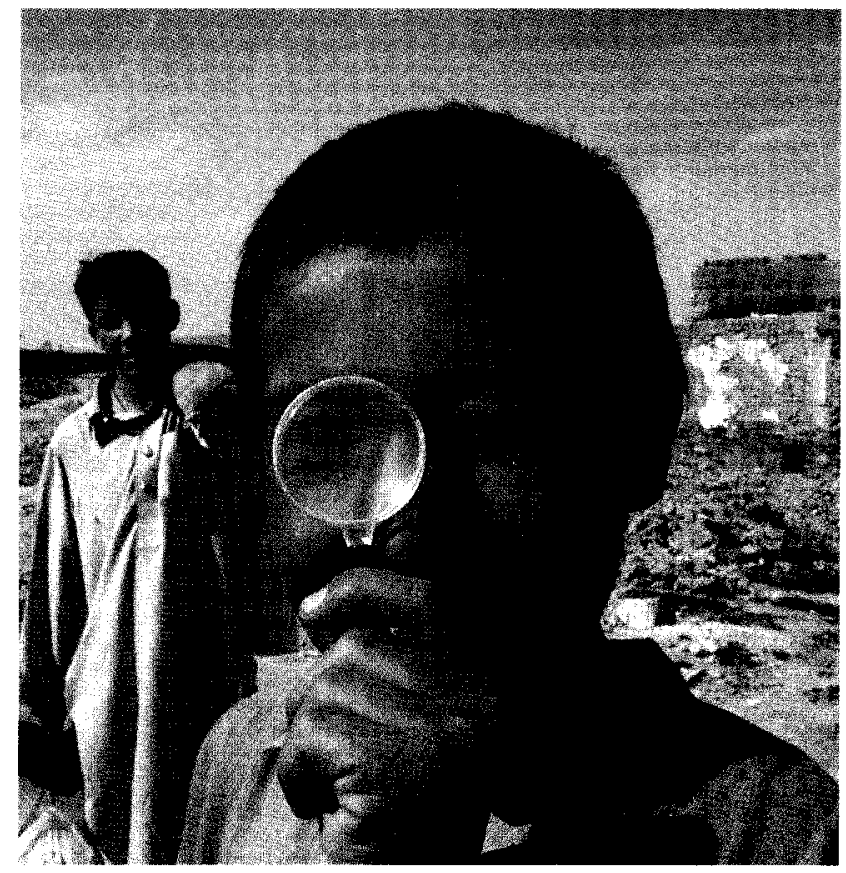

organisation. In particular, serious limitations remain on participation of women in political and civil affairs, representing a direct obstacle to their rights and human security, as well as to nation-building and poverty reduction. ${ }^{11}$ Regional military factions, conservative religious leaders and insurgent forces are limiting women's participation in society through death threats, harassment and physical attacks. ${ }^{12}$

Meanwhile, Afghanistan's civil administration has little reach beyond Kabul, given that local commanders retain control of vast regions. Administrative arrangements remain highly centralised, politically, fiscally and administratively. The central Government suffers from overlapping functions, a serious lack of skilled professionals, severe gender imbalance low pay and lack of merit-based recruitment ${ }^{13}$. ${ }^{14}$ Many policies are not yet well-defined or pro-poor, and capacity for oversight and enforcement by Government institutions is lacking at all levels. Often, the central Government makes policy decisions for provincialand district-level administrations. ${ }^{15}$ At the same time, good governance also is critical for ensuring that cities function well and are engines of growth, with decentralisation leading to devolution of power serving as a key component for poverty reduction. A number of reform initiatives are under way, largely within the framework of the Public Administration Reform (PAR) programme. In its landmark investment programme Securing Afghanistan's Future, the Government describes a decade-long plan to build a civil service that is better equipped, skilled and managed, while more representative of Afghan society.

Concerted efforts must be supported to provide an enabling environment for all of Afghanistan's ethnic minorities with regard to participatory governance, given that ethnic politics has long held sway in the country. Another important area in which the Government must take full ownership is the reintegration of the millions of refugees and IDPs who have returned to their places of origin since 2002; Afghans represent the second-largest number of refugees and IDPs in the world. A long-term mainstreaming policy for returnees/IDPs is critical, despite considerable developmental and economic absorption challenges. This should include integration into democratic participation, given that return and reintegration are not solely humanitarian issues.

\section{Analysis of Key Issues and Underlying and Root Causes}

The CCA analysis is synchronised with national priorities [see National Policies and Priorities box], and the United Nations System is supportive of Government efforts toward governance and institutional development, particularly the National Solidarity Programme, the Afghanistan Stabilisation Programme, the Public Administration Reform Programme and the National Urban Programme. Analysis has identified the following key issues, all of which relate to good governance:

- Democratic accountability and the rights of the citizen

- Participation in political process and social inclusion, including gender equality and civil society partnerships

- Corruption 
20 Zakhilwal and Niazi, "The Warlords Win in Kabul," The New York Thes, 21 June 2002. 27 "The increased politicisation of bot the judiciary and the constitutiona process has complicated and in a number of areas, undermined the? development of an indevendent fustice system capable of serving the pople of Afohanistan. According to several judges in Kabul city, the decisions of urges ara open to the influence of the political and miltary feadership independently or via the Supreme Cout. Such activities dangerously blur the ine beween the exeoutive and the judciary branches of the Afohan Govemment in Kabu and throughout the country." Human. Securty and Livelhoods of Rural Afohans 2002 2003, op cit. p. 210.

22 Civit society in Atghanistan includes a number of interest groups, religious networks and voluntary associations; interest groups encompass non-Govemment orgarisations ¿NGOs) professional, women's and youth groups, student associations and political partios some observers, the course of this loya jirga demonstrated that powerful forces inside and outside the country are still categorically opposed to democratic accountability. ${ }^{20}$ In addition, vetting processes with regard to prosecution for human rights violations need to be in place for election candidates (presidential and parliamentary), members of the Cabinet and civil servants, which will further increase public accountability.

\section{Challenges to separation of powers}

Currently no elected legislative body exists, so the executive branch both proposes and implements laws. Reports exist of repeated violations of the independence of the judiciary by members of the executive branch. ${ }^{21}$

\section{Lack of capacity within civil society to monitor Government}

In the absence of an elected legislative body, a strong civil society would function as the people's primary monitor of Government. Constraints on the capacity of civil society are fully reviewed below.

\section{2b. Participation in Political Processes and Social Inclusion}

Civil society in Afghanistan is weak. Traditionally, Afghan society centred on family, tribe and community, and political and social authority were embedded in the institution of jirga or shura, which included only adult men. Now, a need exists to stimulate participation in governance through civil society activities and organisations, in order to generate legitimate demands, articulate social needs, and enhance state accountability in realising basic rights. ${ }^{22}$ Among the most promising platforms for promoting good local governance in Afghanistan is the institution of Community Development Councils (CDCs), established in 34 provinces under the National Solidarity Programme (NSP) as community self-management structures with regard to prioritising developmental needs. Thuis far, CDCs appear more representative and proactive than traditional jirgas/shuras, and they have greatly increased the opportunities available for women's participation in village life.

\section{Women's Participation in NSP Community \\ Development Councils (CDCs) Source: GTZ, September 2004}

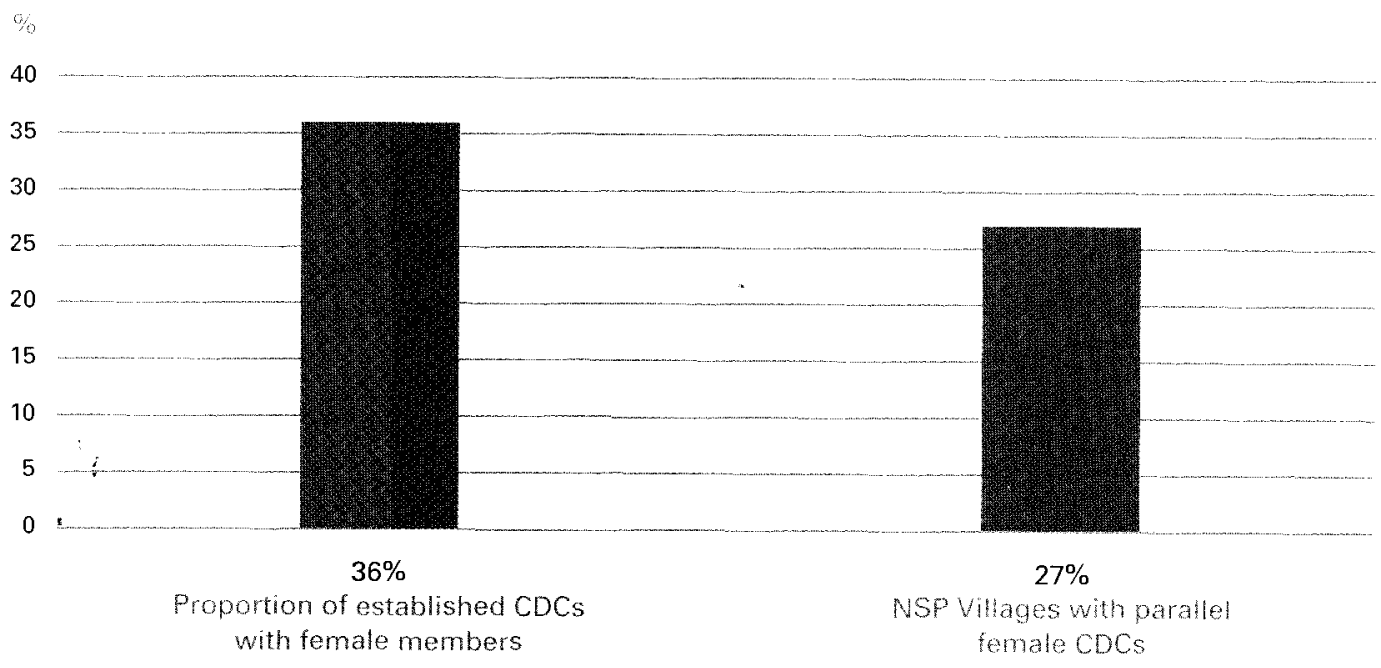


23 Between Hope and Fear: Intimidation and Attacks Against Women in Public Life in Afghanistan, op.cit., p. 3. In addition, a recent survey conducted by Asia Foundation found that 87 percent of Afghans said that women would need to obtain permission from their husband or head of the family to vote. [Between Hope and Fear, p. 27] Eighteen percent of the men surveyed said they would not let their wives vote at all, and in the south, almost 1 in 4 men surveyed felt that way. However, Community Development Council elections data from five provinces (Bamyan, Farah, Herat, Kandahar and Parwan) indicate that 76 percent of voting-age women cast ballots in those contests and that, of the total delegates elected, 38 percent were women. IKhalilzad, "Democracy Bubbles Up." The Wall Street Journal, 25 March 2004.l The participation of men in decision-making in $\mathrm{CDCs}$ has been found generally higher than that of women [finding of a lessons learnt workshop that the NSP Oversight Consultant held in September 2004l. Even so, disbursement of funding for priority projects in communities is conditional upon full compliance with NSP regulations.

24 Between Hope and Fear: Intimidation and Attacks Against Women in Public Life in Afghanistan, op.cit., p. 3.

25 The verification of political rights is, upon request of the Government, jointly exercised by the Afghan Independent Human Rights Commission (AIHRC) and the United Nations Assistance Mission in Afghanistan (UNAMA)

${ }^{26}$ AIHRC-UNAMA Joint Verification of Political Rights, Second Report, p. 1. Civil society actors, including women, who have recently organised protests or criticised local rulers have faced threats and/or violence.

27 According to the Constitution, civil society should be "free of oppression, atrocity, discrimination and violence, and based on the rule of law, social justice, protection of human rights and dignity, and ensuring the fundamental rights and freedoms of the people." [Preamble of the

Constitution, para. 8.]

${ }^{28}$ Human Security and Livelihoods of Rural Afghans 2002-2003, op.cit., p. 89

29 Between Hope and Fear: Intimidation and Attacks Against Women in Public Life in Afghanistan, op.cit., p. 20
Although much has been achieved since the fall of the Taliban, a major challenge remains in the enactment of new constitutional provisions. The NSP and the scheduled elections are two new mechanisms that constitute channels for participation in democratic governance, particularly for rural women. With regard to voter registration, the percentage of female registration has been higher than expected, although in some traditionally conservative southern provinces such as Kandahar, women comprised less than 10 percent of registered voters. $^{23}$ Upcoming parliamentary elections may represent a significant test of Afghan women's ability to exercise their political rights; many women say they expect to face threats from commanders and their supporters if they run for parliament. ${ }^{24}$

Based on analysis, three key challenges have been identified as underlying causes that prevent the full enjoyment of rights of participation in political processes. These include:

- Consequences of the lack of a human rights culture

- Lack of a policy framework, as well as lack of capacity

- Consequences of gender inequality

\section{Consequences of the lack of a human rights culture}

Democratic habits must be institutionalised to make representative government work. This includes majority rule, working toward compromise solutions, respect for the civil and political rights of other individuals, and respect for minority rights. The political rights verification process ${ }^{25}$ found a nationwide pattern of self-censorship among political formations, which often are not willing to take advantage of freedoms under the Constitution for fear that they will suffer reprisals. ${ }^{26}$ This tendency is reinforced by the dominant role of commanders or misguided approaches to political activities, which has resulted in an inability to build on political momentum.

\section{Lack of a policy framework and capacity}

To date, policies and legislation have not been formally adopted to enact the Constitution with respect to empowering civil society. ${ }^{27}$ In general, NGOs suffer from lack of a regulatory framework and coordination mechanisms; a marked fragmentation and a lack of capacity contribute to NGOs' lack of influence when it comes to decision-making.

\section{Consequences of gender inequality}

Those who have the ability to participate in democratic governance are few and mostly limited to urban areas. Rural women especially lack awareness of governance issues. Many still do not have a full understanding of their rights, knowledge of how to participate in complex economic and political processes, or how to hold their leaders accountable. ${ }^{28}$ In numerous cases, freedom of expression - in terms of speaking freely about women's rights issues or dressing according to one's preference - remains elusive, given the extent of intimidation by armed factions and political or religious leaders. ${ }^{29}$ Lastly, traditional stereotypes prevent the public - including women themselves - from recognising women's leadership capabilities; women therefore are rarely appointed or elected to high positions.

\section{2c. Corruption}

Corruption undermines social confidence in the willingness and capacity of public institutions to fulfil their obligations to the people. Likewise, it reinforces existing power relationships that are themselves typically part of development problems. Corruption also promotes poverty because it deprives disadvantaged sectors of much-needed programmes and environmental stewardship due to financial losses of the state.

Afghanistan has particular reasons to guard against corruption, given that it will depend 


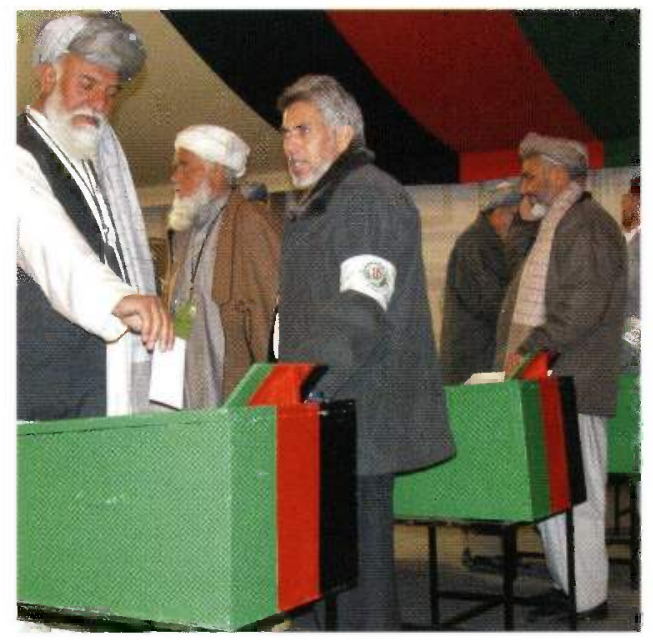

for many years on international assistance to rebuild. Such aid may not be forthcoming if donors fear it will be lost to corruption, nor will the nation benefit as it should if aid is wasted in this manner. ${ }^{30}$

The presence and perception of corruption permeate many areas of governance in Afghanistan. Of notable concern are the suspected close links between corruption and the drug economy as well as other criminal activities. ${ }^{31}$ While there is no systematic data on corruption, a recent "typology" 32 estimates corruption within both formal and illegal private sector activities as high; this includes payoffs to officials to avoid taxes and licensing/planning regulations, as well as bribes by those involved in narcotics-related activities, and arms and human trafficking. The typology estimates corruption associated with the public sector is also high, in connection with procurement, "ghost employment" and patronage positions. Corruption is believed to be high as well in "captured" areas of the public sector, under warlords or commanders who maintain parallel governance structures. In March 2004, the Government established an anti-corruption department.

Based on analysis, two key challenges have been identified as underlying causes of corruption, which denies the rights of the poor by discriminating against them in access to services, among other negative aspects. These include:

- Absence of legal and regulatory systems and efficient enforcement, as well as absence of institutional structures that encourage accountability, transparency and information sharing

- Low level of salaries in the public sector and delays in payment

${ }^{30}$ Rubin, Summary of Papers on Anti-Corruption Measures in the Constitution of Afghanistan, Centre on International

Cooperation, New York University, 2003, p. 1.

31 The World Bank, Afghanistan: State Building, Sustaining Growth and Reducing Poverty - A Country Economic Report, June 2004, p. 43. The Special Rapporteur on adequate housing as a component of the right to an adequate standard of living recommended in all matters of housing and land, including in cases of land distribution and prevention of illegal and occupation and forced . evictions, that a moratorium be made until a national housing and land policy has been adopted and an effective judicial system is in place. [E/CN.4/2004/48/Add.2, cited in Country Profile of Afghanistan and the international human rights system, Office of the High Commissioner for Human Rights, July 2004, p. 8.]

32 Ibid., pp. 43-44.

\section{Absence of legal and regulatory framework and efficient enforcement, as well as absence of institutional structures that encourage accountability, transparency and information sharing}

In general, regulatory systems and enforcement are very limited in both the private and public sectors. This, as well as the extent to which the public administration, police and judiciary appear affected, makes enforcement practically impossible. Moreover, the overarching structures that allow for efficient regulation are lacking. A few exceptions are noteworthy, such as in late 2002, when President Hamid Karzai sent delegations to investigate corruption in different parts of the country and sacked a small group of officials in line with the delegations' findings.

\section{Low level of salaries in the public sector and delays in payment}

Recent reports show that civil servants, as well as law enforcement and judicial personnel, experience delays of several months or more in receiving their salaries. Lack of timely payment does not necessarily lead to corruption, but low, intermittent pay is an important contributory factor. The tendency toward corruption is reinforced by large amounts of money that can be made through smuggling, extortion and trafficking. 


\section{2d. Public Administration Reform}

Overlapping of functions between Ministries, and between central and local Government, hinders successful implementation of policies, diminishes Government efficiency and increases the cost of doing business. Eventually, this negatively affects the accessibility of basic services and thus increases the social and economic dimensions of poverty. In addition, the magnitude of the task to which Afghanistan must respond with its weak institutional capacity is enormous, compared to what administrations in other countries deal with. ${ }^{33}$

The Afghan civil service remains large and cumbersome, including the problem of "ghost employees" listed on the payrolls of Ministries without actually working. A serious lack of experienced professionals with modern management skills exists, particularly women. Perhaps most importantly, the payment of civil servants in the provinces and districts occurs only after a complex chain of events and is often delayed [see also Corruption sub-section above]. Some basic reforms are under way; legislation has been established to allow individual Ministries to restructure. Another key challenge lies in ensuring that revenues are transferred to the central Government from the periphery, ${ }^{34}$ to ensure that the state has a sufficient domestic resource base.

Based on analysis, one key challenge has been identified as the underlying cause for the lack of institutional capacity. This is:

- Politicisation of the public administration institutions and absence of a merit-based system

33 For example, aid coordination is daunting, with a very high level of aid flows delivered through various channels and relying on widely varied allocation mechanisms. [The World Bank, op.cit., p. 41.] More than 150 percent of GDP was pledged for the next three years at the Berlin donor conference of March/April 2004.

34 This is particularly challenging in the case of provinces that are "captured" by regional power brokers. A key element in the effort to raise revenues is the 2003 customs reform and new tax policy reforms enacted in 2004

35 Ghai, Unitary or Federal - A False Choice? Decentralisation of state powers in Afghanistan, Centre on International

Cooperation, New York University, 2003, p. 1 (http://www.cic.nyu. edu/pdf/E5DencentralizationofPow erGhai.pdf)

${ }^{36}$ Malikyar and Rubin, CentrePeriphery Relations in the Afghan State: Current Practices, Future Prospects; Centre on International Cooperation, New York University: December 2002, p. 2 (http://www. cic.nyu.edu/pdf/CPReport0107031. pdf)

37 Ghai, op.cit., p.1.
1. Politicisation of public administration institutions and absence of a merit-based system In Afghanistan's public administration, employment patterns privilege alignment to certain political factions and loyalty to local power brokers. Nepotism and favouritism can outweigh merit and provide for service delivery by people without the necessary background and skills. Public service thus may be used as a form of improvised political and social safety net, which also negatively affects the quality of service delivery.

\section{2e. Decentralisation and Devolution}

Throughout its history Afghanistan has been a nominally centralised state, although it has had limited control and ability to deliver services to the periphery due to the geographical layout and climatic conditions. Especially since 1978, local power brokers have been in control over different parts of the country, and armed conflict over territory has been almost continuous. ${ }^{35}$ The fragmentation that has resulted, reinvigorated through the war on terrorism, ${ }^{36}$ differs significantly from the global trends that see decentralisation as conducive to democracy and grassroots development.

By and large, the Afghan population is demanding a centralised state because of the current political-military ground realities of fragmented power. Consequently, the Constitution provides for centralisation, but many features counter it - taxation, revenue raising, dispersal of armed forces, dissident activity, and extensive regional control by power brokers. ${ }^{37}$ A decentralised system, however, does not necessarily ensure higher participation - although improved responsiveness of the central Government to public demands can reduce poverty while improving efficiency and quality of public services.

In Afghanistan, at the district level is where the real challenge of decentralisation lies and where an effective solution is an urgent priority. In its policies, such as the 
NSP, the Government is attempting to strike a balance between rigid centralism and moderate decentralisation, and to attempt to encourage provincial- and district-level administrations to improve their management systems as they are given more autonomy in financial matters ${ }^{38}$ and policy decision-making. However, resource allocation by local administrations is not conducted transparently, and local officials possess little financial accountability. In reality, this may be compounded by a bold refusal to transfer resources to the centre.

A challenge for the international community is to support strengthening of the central Government while working simultaneously only with regional forces that collaborate with the central Government. No legal framework has yet been established to regulate centreperiphery relations and address the challenges outlined above, which could provide for such a balanced approach. Through the eventual devolution of powers - which broadens decentralisation from a focus on administrative and financial issues to embrace principles such as participation, empowerment, democracy and equity - service delivery benchmarks can help to assess the performance of local governments and their impact on the poor. If Afghanistan eventually can achieve devolution, subsequent major effects are likely on poverty reduction, corruption, planning and accountability.

Based on this analysis, one underlying cause has been identified as central to realising good governance through decentralisation and devolution:

- Absence of an integrated local governance framework

\section{Absence of an integrated local governance framework}

It is imperative to support the integration of elected assemblies at sub-national level into the national planning and budgeting framework. Such integration has yet to be undertaken.

\section{2f. The Role of the Media}

As with democracy and civil society participation, no tradition of a strong, independent media exists in Afghanistan. ${ }^{39}$ Indeed, the media remain far from being able to fulfil their role as independent guarantors of human rights, monitors of public policy and channels for the expressions of citizens' views. This is, however, changing slowly.

Radio is the main source of news information for most Afghans because of the low literacy rate, the high costs linked to television and the poor electricity infrastructure of the country; it has been shown to be highly effective in educating rural populations. Available data indicate that only 25 percent of households in urban areas and 36.5 percent in rural areas, on average, do not have a radio. ${ }^{40}$

38 provinces have, for instance, no inputs into the budget process, and there is no transparency for the geographic distribution of expenditures.

39 Internews, Afghan Media Directory. 1st Edition, March 2004, p. 7 .

40 Afghanistan Progress of Provinces: Multiple Indicator Cluster Survey 2003, Afghan Central Statistics office and UNICEF, P.86

4 intemews, op cit; interview with Dr. Abdul Samay Hamed. Agghan journalist and winner of the 2003 Committee to Protect Joumalists award.
Based on analysis, three key challenges have been identified as limitations on the freedom of expression that the media must enjoy to fulfil their role. These include:

- Financial dependence of the media

- Climate of fear among journalists

- Cónsequences of gender inequality :

\section{Financial dependence of the media}

The costs linked to media management are high, and the majority of media are financially dependent on Government agencies, international organisations or political parties. A potential exists for content to be controlled. ${ }^{41}$ 


\section{Climate of fear among journalists}

The lack of a tradition of investigative journalism still affects today's Afghan journalists and their standards in relating to authorities. Limited understanding of freedom of expression is exacerbated by a climate of intimidation resulting from the dominance of strong political and armed factions as well as the absence of the rule of law. This leads journalists, especially women, to self-censor on sensitive issues and to present their work as moderate and mainstream. ${ }^{42}$ In particular, conservative forces have tried to exercise media control by threatening and physically attacking journalists.

\section{Consequences of gender inequality}

Women journalists are encountering particular problems, mainly intimidation and discrimination, since they resumed work after the fall of the Taliban. This is a result of the traditional socio-cultural environment. Many women journalists and women's rights activists who have been outspoken on issues such as human trafficking or violence against women have reported death threats, visits to their homes by gunmen, and dismissals from their jobs. ${ }^{43}$

\section{What Does Success Depend On?}

Given the strategic analysis of issues related to governance and institutional development, it appears there is a long way to go for Afghanistan to create an environment conducive to achieving good governance and the commitments in the Millennium Declaration, leading to the realisation of basic rights. Even so, in barely three years the Government has accomplished much in terms of formulating policies and prioritising needs [see National Policies and Priorities box]. The momentum must be maintained and appropriate policy sustainability ensured through full support, including:

- Support for strengthening Government implementing capacity, including the ability to formulate pro-poor policies

- Support for strengthening civil society, encompassing establishment of a regulatory framework for NGOs, assistance in NGO coordination/knowledge sharing, and support to Government actors to understand that a strong civil society is beneficial for a strong Government

- Support for transparent and credible political processes, including through vetting of serious human rights violators

- Support for rights education, especially for women, vulnerable groups and children; outreach must particularly be increased to women outside of urban centres

42 Between Hope and Fear: Intimidation and Attacks Against Women in Public Life in Afghanistan, op.cit., p. 22.

43 Ibid., p. 2. One journalist and women's rights activist in Mazari-Sharif was forced into hiding in 2003 after she published an article on women's rights in Islam that enraged a military faction and local religious leaders. The Council of Religious Elders called for her trial, while others accused her of attacking Islam and called for her death. Although the case was thrown out of court, the woman and her family say they still encounter harassment in their workplaces, educational institutions and daily lives from officials affiliated with the dominant political faction.
- Support for monitoring of human rights, women's rights and political affairs, with special emphasis on strengthening independent monitoring bodies to observe the 2005 parliamentary and local elections

- Support to freedom of expression and to the right to information, including full use of the media and Information and Communications Technologies (ICTs) to disseminate rights information and contribute to civic education in a democratic society

- Support to data collection on human rights violations and cases, NGOs/ civil society organisations, violations of the freedom of expression, and census data [see also Significant Data Gaps box]

- Support to an integrated local governance framework that fully involves elected assemblies at sub-national level in national planning and budgeting

Ultimately, success in all these areas will also depend upon vastly improved security and genuine respect for the rule of law. 


\section{International Context and Commitments}

\section{International Context and Commitments}

- International Covenant on Civil and Political Rights

- International Covenant on Economic, Social and Cultural Rights

- Convention on the Elimination of All Forms of Discrimination Against Women

- International Convention on the Elimination of All Forms of Racial Discrimination

- Convention Against Torture and Other Cruel, Inhuman or Degrading Treatment or Punishment

- Convention on the Rights of the Child

Likewise, international political commitments such as the Millennium Declaration and the Copenhagen Declaration on Social Development incorporate basic issues of governance, freedom of the media, citizens' rights, empowerment and improved equality. Afghanistan also has just recently signed the United Nations Convention Against Corruption.

The Constitution stipulates that "the Afghan state shall observe (...) international treaties which Afghanistan has joined and the Universal Declaration of Human Rights" (Article 7). The state and its institutions are therefore bound by constitutional law to uphold the rights identified as relevant to governance. The Constitution likewise provides explicitly for enjoyment of such rights and freedoms as the freedom of expression and the right to political participation, and it enshrines strong safeguards against corruption of state officials.

\section{Significant Data Gaps}

- Data must be collected and rendered easily accessible on human rights violations, reported and unreported cases, resolved cases and sentences delivered. This also should include a comprehensive human rights needs assessment to ensure that reconstruction programmes are based on priorities expressed by Afghans themselves. Such an assessment can serve as a tool for enabling community participation and providing a check against corruption and waste. The lack of accessible data in this area hinders awareness raising of individual citizen rights and fosters continued unpunished violations.

- No overview exists on how many NGOs or civil society organisations - shuras, religious networks, and voluntary associations and interests - are in the country, or of their objectives and actual capacity to influence political decision making. In addition, little systematic research has been conducted to understand the capacity of vulnerable groups, such as women, ethnic minorities, or returnees/IDPs, to persuade decision makers.

- Likewise, a need for deeper research exists with regard to intimidation of journalists and other violations of the freedom of expression, along with systematic recording and analysis of cases.

- The absence of accurate census data severely affects the reliability of all statements on popular participation and involvement in governance issues. The upcoming census will provide detailed information on the composition and location of the Afghan population.

- Reliable data on the number of public and private sector employees is needed. 


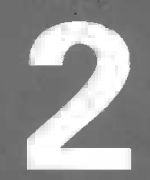

Peace, Security

and Justice 
44 The Secretary-General's report on transitional justice 2004 states that "Our experience in the past decade has demonstrated clearly that the consolidation of peace in the immediate post-conflict period and the maintenance of peace in the long term, cannot be achieved unless the population is confident that redress for grievances can be obtained through legitimate structures for the peaceful settlement of disputes and the fair administration of justice."

[Secretary General report on Rule of law and transitional justice in conflict and post-conflict societies, 3 August 2004, at 3 UN S/2004/ 616$.

45 The frameworks for action on this priority, within the United Nations System include the following statement by the Secretary-General to the United Nations Security Council, June. 2001 , on the prevention of armed conflict: "The role of the United Nations is principally to assist national Governments and their local counterparts in finding solutions to their problems by offering support for the development of national and regional capacities for early warning, conflict prevention and long-term peace-building." Likewise, the statement of the

President of the Security Council on the adoption of Resolution 1325 of the Security Council, 31 October 2001, is relevant to the critical role of women in peace and security issues: "The Security Council reaffirms its commitment to the implementation of its

Resolution $1325(2000)$ of 31

October 2000 and welcomes the efforts by the United Nations System, Member States, civil society organisations and other relevant actors in promoting the equal participation and full involvement of women in the maintenance and promotion of peace and security and in implementing the provisions of Resolution 1325 (2000)."

${ }^{46}$ The vast majority of

humanitarian and reconstruction activities cannot be carried out in large parts of the south, southeast and east. Overail, incidents involving deliberate targeting or threats against humanitarian workers and agencies have been " increasing. Since 27 March 2003, the date of the first deliberate killing of a foreign aid worker post-Taliban, 44 civilian foreigners have been killed. [Associated Press, 29 July 2004]

${ }^{47}$ Human Security and Livelihoods of Rural Afghans, op.cit. pp. 6-7.

48 ibid., p. 7

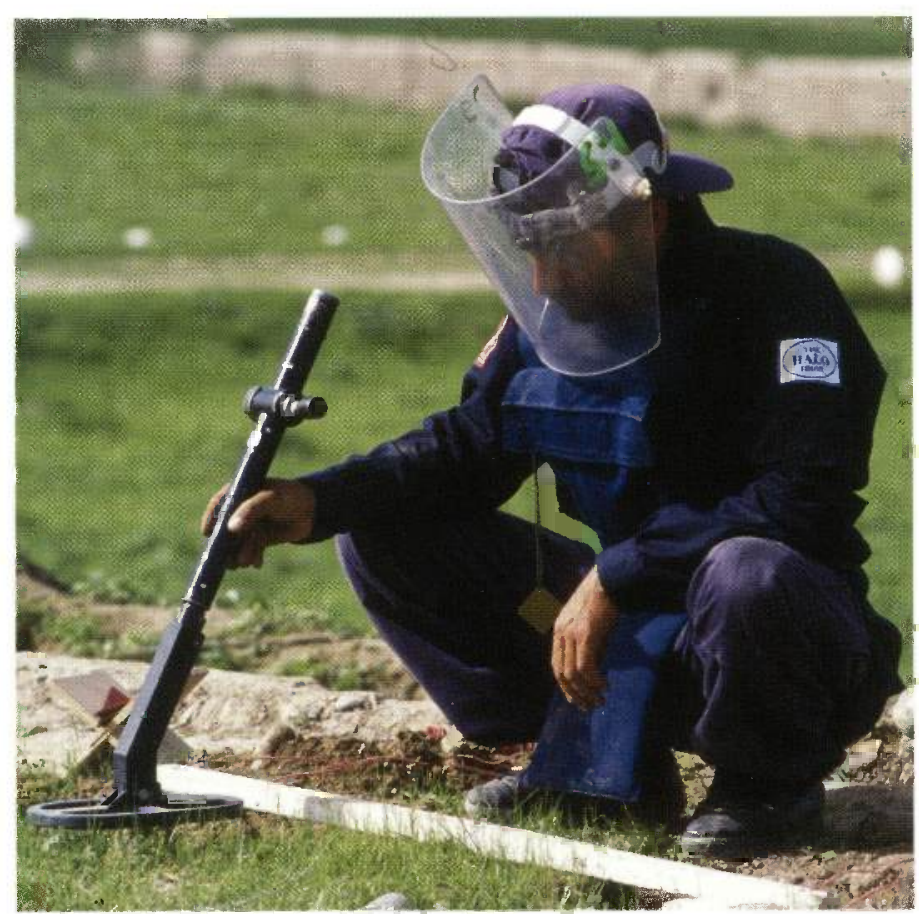

\section{The Situation in Afghanistan}

Perhaps in no way do the poor suffer more than during a conflict situation, where their vulnerability to human rights violations, lack of opportunities and formal powerlessness come to the forefront. What this means, ultimately, is that every step taken toward reducing poverty and achieving broad-based economic growth can be a step toward conflict prevention and realising human rights. However, peace, security and justice for all in Afghanistan are still far from being achieved. While large" parts of the country have been pacified, the security situation in some areas has deteriorated despite the presence of international troops and ongoing security sector reform. The importance of achieving a peaceful, secure society is given prominence in the Millennium Declaration and is intrinsic to the realisation of rights to survival, livelihood, protection and participation. Nonetheless, countries such as Afghanistan have fewer economic and political resources with which to contain or resolve conflicts.

Especially in the aftermath of the first presidential elections in Afghanistan, understanding dimensions of reconciliation will be critical. Development efforts must be used strategically not just to prevent and settle conflict, but also to consolidate peace when settlement has been reached. ${ }^{44}$ In so doing, strategies addressing such issues as those at the base of all peace-building - poverty, governance, justice, environment - also must be developed through a "lens" of peace-building, recognising that dialogue can triumph over discord and that diversity is a universal virtue. ${ }^{45}$ The dominant perception of security and insecurity in Afghanistan is based largely on the ability of international and national relief and development staff to safely implement programmes in certain areas. ${ }^{46}$ Views of Afghans, however, are often different - Afghans living in many areas considered "low risk" by and for the United Nations report high levels of insecurity and conflict, primarily in the north, west and centre. ${ }^{47}$ Women's and children's rights are particularly affected, with their right to protection compromised. However, Afghans' own definition of security goes beyond the mere absence of fighting or armed attacks and includes access to education, health care and economic opportunities. ${ }^{48}$ Significantly more research and data collection are required on all aspects of peace, security and justice. 


\section{National Policies and Priorities}

\section{Security Sector Reform}

- The Afghan National Army (ANA) is to achieve its full strength of 70,000 trained soldiers in 2009. Measures taken to improve the quality of recruits and reduce attrition rates continue to be implemented; as a result, the attrition rate dropped from 15 percent per month in November 2003 to 1.3 percent per month in July 2004.

- Slow progress has been made on the commitment to DDR of at least 40 percent of the stated strength of factional forces $(100,000$ Afghan Militia Forces, AMF), as well as the cantonment of all heavy weapons, by June 2004. Participation of various army corps in the exercise has been very uneven. AMF units in the southeast have been practically demobilised while, in the south, DDR was discontinued. Still of concern is the fact that very few commanders are among those demobilised. In addition, by August 2004, about 3,300 minors associated with fighting forces - out of an estimated 8,000 underage soldiers - were demobilised in the northeast, east, central highlands and part of the central region. Recently, the DDR process has gained new momentum, and the Government has made presidential candidacy and political party registration conditional upon signature of an agreement to cooperate with the DDR programme.

- By August 2004, about 20,000 Afghan National Police (ANP) had received training, including basic training and training for illiterate police. The target strength of the force provides for a core of 47,500 national police, 12,500 border police and 2,500 highway police, to be attained by the end of 2005 . Recruitment of women in the police force needs to be actively encouraged.

\section{National Justice and Rule of Law Programme}

- This National Priority Programme (NPP) is one of the six new NPPs launched at the Berlin donor conference in March/ April 2004. It aims at achieving "a society that respects the law, seeks resolution of disputes and cases through an orderly process, provides justice in the best way while protecting human rights, and also enhances the legal knowledge of citizens of the country." Activities have been grouped into areas on law reform, justice survey, justice infrastructure, legal training, legal awareness, capacity building, and procurement of equipment and vehicles. Together, these sub programmes are designed to achieve an immediate impact on justice reform while ensuring progress in reviewing and simplifying existing legislation, enhancing the understanding of the rights and obligations of individuals, and establishing defence lawyers.

- Major challenges for justice reform include the need for mechanisms to ensure independence of judges and manage perceived excessive concentrations of judicial power; level and reliability of internal security forces; perceptions of corruption and nepotism; lack of qualified criminal justice professionals; and low level of adequate correctional facilities and related resources.

\section{Afghanistan Stabilisation Programme (ASP)}

- This two-year Government initiative intends to re-establish basic security and good governance at district and provincial levels through sequenced, coordinated projects. Through one of the ASP sub-programmes, the Provincial Stabilisation Fund, decision-making is decentralized, and governors are provided with autonomy to plan and implement priority projects in their provinces. 


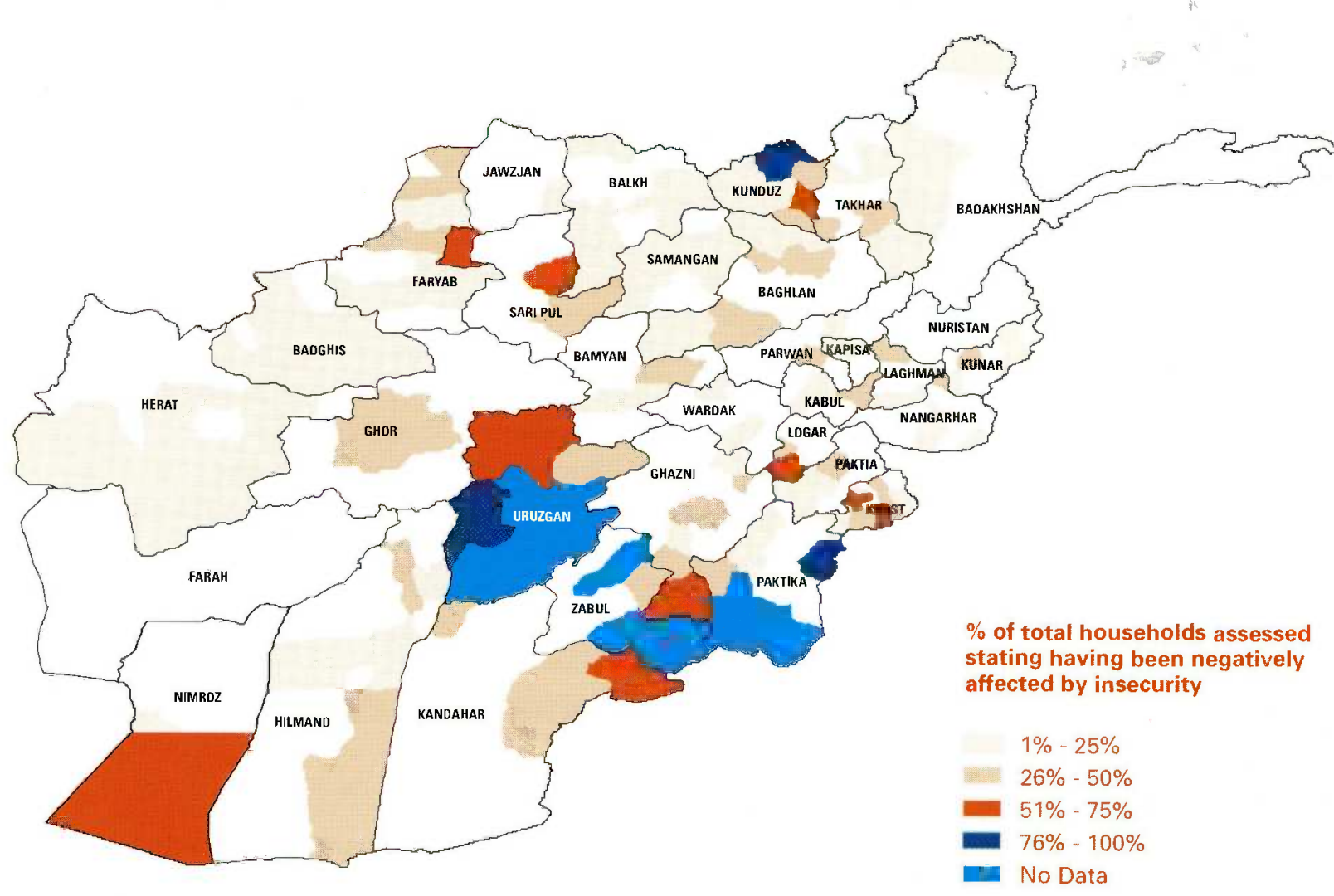

Afghanistan provides an estimated three-fourths of the world's heroin and produced 19 times more opium poppy in 2003 than in the last year of Taliban rule. In some areas, up to 50 percent of arable land may be used to cultivate poppy. The country has begun refining poppy in-country, making a large portion of the production apparatus domestic. In 2002, revenues from the drug trade were estimated to be worth US\$1.2 billion, equivalent to total international assistance that year.

\footnotetext{
49 It is estimated that it will take several more years to train the targeted numbers of Afghan National Army, Afghan National Police, judges, prosecutors and defence lawyers.

50 The Road Ahead - Issues for Consideration at the Berlin Donor Conference for Afghanistan, op.cit., p. 22.
}

Relevant challenges in Afghanistan stem from at least three sources: a resurgence of Taliban and al-Qaeda activity along the south-eastern border; the huge increase in poppy production and trade; and constraints to reconstruction, particularly with regard to Disarmament, Demobilisation and Reintegration of armed factions as well as development of capacity in the security/law enforcement and judicial sectors. ${ }^{49}$ The continued existence and perceived legitimacy of commanders throughout Afghanistan compounds all three issues, ${ }^{50}$ as does the continuing proliferation of small arms. Incidents of armed violence that affect civilians occur in the contexts of coalition military activities, terrorist activities, factional fighting and violence, and commander violence (forced recruitment, forced labour, extortion of money, physical assaults). Increased narcotics production, by maintaining allegiance systems and the economic dependence of considerable portions of the population on regional power brokers, particularly contributes to the worsening security situation and must be tackled through reduction of supply, demand and harm.

\section{Analysis of Key Issues and Underlying and Root Causes}

The CCA analysis is synchronised with national priorities [see National Policies and Priorities box], and the United Nations System is supportive of Government efforts toward peace, security and justice, particularly security sector reform, the National Justice and Rule of Law Programme and the Afghanistan Stabilisation Programme. Key issues identified as relevant to peace, security and justice, all of which point to an ongoing lack of realisation of human rights in Afghanistan, include:

- Explosive remnants of war

- Continued power and influence of non-statutory armed forces under commanders and warlords, along with the persistence of incidents of armed violence 
51 Afghanistan has more than 872 square kilometres of suspected mined land and an additional 450 square kilometres thought to be contaminated by UXO, making it one of the most UXO- and mineaffected nations in the world. Up to five people a day are killed or injured by mines and UXO. Out of the total recorded new casualties of landmines in 2002, children younger than 18 accounted for more than half and require strengthened protection. Elderly people also are disproportionately affected, especially those not fully familiar with the situation in their homeland, such as returning refugees and IDPs. It is estimated that 12,000 new victims will suffer from mine/UXO incidents over the next decade if no clearance activities occur and no mine risk education is conducted.

52 Fully one-third of respondents in mined areas in Afghanistan said that someone in their household had gone into areas they knew were mined. Asked why they took the risks involved, most gave reasons related to livelihood, including to collect firewood (37 percent); to take a shortcut (18 percent); to tend livestock (17 percent); and agriculture (10 percent). (Andersson et al., Mine smartness and the community voice in mine risk education: lessons from Afghanistan and Angola, in: Third World Quarterly, Vol. 24 (2003), No.5, pp. 873-887.)

53 Afghanistan has never been a landmine producer; however, some individuals and groups have been known to assemble improvised mine-like devices. Several incidents occurred in 2002 and 2003 in which resistance elements were suspected of having used or attempted to use landmines. (International Campaign to Ban Landmines, Landmine Monitor Report 2003:

Toward a Mine-Free World, September 2003, p. 49.)
- Contested allocation of resources, particularly land and water

- Cultivation of poppy

- Dysfunctional formal justice system and preference for traditional justice mechanisms

- Social violence and lack of social protection

Duty bearers that hold an obligation to fulfil these entitlements are primarily State actors and institutions at various levels of the governance structure, as well as non-State actors - including armed factions, local commanders and civil society itself - that can influence the rights of others. The root causes of the above challenges, which are interlinked, arise from:

- An underdeveloped human rights culture, along with lack of traditions of democracy, state-building and civil society participation

- Young governance structures still in the process of establishment and/or early stages of development, and unable to curb political insecurity

- Shortage of human resources that can propel democratic reforms

- Wide variations in socio-economic indicators, by gender, region and rural-urban divide

- Weakened social infrastructure

- Socio-cultural traditions that result in widespread marginalisation based on gender, social status or ethnicity

\section{2a. Explosive Remnants of War: Landmines, Unexploded Ordnance}

Landmines and Unexploded Ordnance (UXO) constitute a structural impediment to the development of Afghanistan, the result of more than two decades of mine use by many armies and factions. ${ }^{51}$ Besides the old mine/UXO caseload, an unknown number of landmines remain in the possession of commanders and militias in various regions, as well as with the Government. According to its obligations under the Mine Ban Treaty, Afghanistan must destroy all stockpiled anti-personnel mines by March 2007 and must clear all mines by March 2012.

Based on analysis, two key challenges have been identified as inhibiting reconstruction and economic development that lead to the realisation of rights to free movement, to access land and resources, to safe return - and, most importantly, to life. These include:

- Lack of awareness of risk related to landmines and UXO

- Lack of a legal and regulatory framework

\section{Lack of awareness of risk related to landmines and $U X O$}

Mine risk education often does not reach the populations most vulnerable to mine-related injuries or death, because of geographic or climatic obstacles. Often, too, the dire economic situation drives Afghans to enter contaminated areas, even if they are aware of danger, to collect mines/UXO in order to earn a small amount of money by selling metal scrap. ${ }^{52}$

\section{Lack of legal and regulatory framework}

National legislation has yet to be passed in order to penalise the use, stockpiling, transfer and production of anti-personnel mines. ${ }^{53}$ This provides legal loopholes for offenders in Afghanistan. 
Combined Landmine Victims from 2001 to March 2004 Source UNMACA

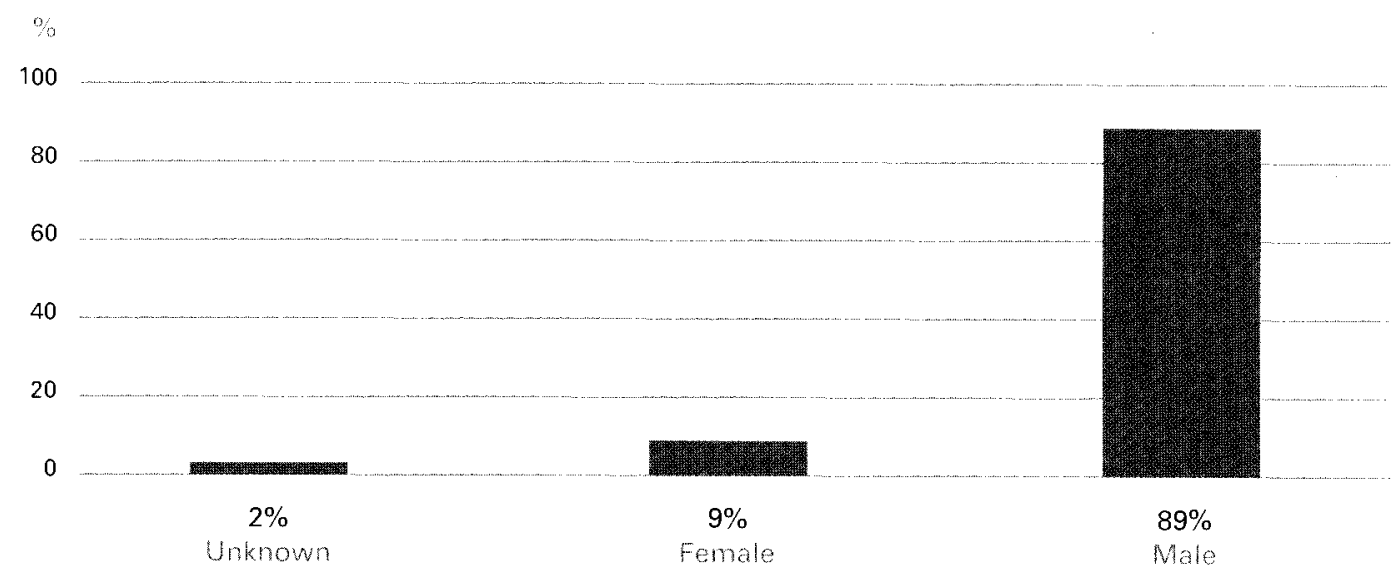

\section{2b. Continued Influence of Non-Statutory Armed Forces and Persistence of Incidents of Armed Violence}

A general climate of impunity and limited power of sanction by the central state are at the core of the issue of peace, security and justice in Afghanistan. The most significant threat to security for Afghans is the recurrent challenge to the monopoly of coercive force by the state - in other words, the widespread nature of violence, or the threat thereof, by nonstatutory armed forces under the leadership of local commanders, armed political groups or militias. Generally this is achieved through land occupation, illegal taxation and extortion, along with forcible recruitment and forced labour. ${ }^{54}$ It is also important to note that many "ordinary" incidents of armed violence against civilians, especially women and children, are left unreported. ${ }^{55}$

The continued presence of these forces undermines efforts to extend the legitimate authority of the central Government; inhibits the establishment of effective, democratic and accountable local Government; and threatens national unity. More specifically, nonstatutory armed forces present direct and indirect threats to the staging of elections and chal tenge efforts to establish the rule of law. Economically, they distort and impede efforts to establish a system of central Government revenue collection. In the context of organised crime, they become a key obstacle to combating narco-trafficking. Non-statutory armed forces often have manipulated ethnic sensitivities to mobilise support and loyalty from local communities. ${ }^{56}$

54 UNHCR, Retumee Monitomitg Report, $2002-2003$

55 These include extortion. beatings, illegal detention, unlawful execution and sexuat violence. Human Rights Watch, Killing You is an Easy Thing for Us - Human Rights Abuses in Southeast of Afghanistan, 29 Julv 2003: Human Rights Watch, All Our Hopes Are Crushed . Violence and Repression in Westem Afghanistan, 5 November 2002. 56 Access for humantarian and development actors, particularly the United Nations, has sharply declined in some provinces. mainly in the south, southeast, east and west. This is a result of the persistence of incidents of violence, especially by armed groups, as well as because of open military operations.
Based on analysis, four key challenges have been identified as underlying causes for these continued issues. They affect the rights to life; freedom of association, expression, assembly and movement; freedom from torture and cruel, inhuman and degrading treatment or punishment; liberty and security of the person/freedom from arbitrary arrest and detention; freedom from discrimination; and property/freedom from arbitrary interférence with privacy, family, home and correspondence. These include:

- 'Slow progress on implementation of Disarmament, Demobilisation and Reintegration (DDR)

- Traditional widely dispersed authority

- Insufficient and inadequate law enforcement capacity

- Weakened conflict resolution mechanisms 


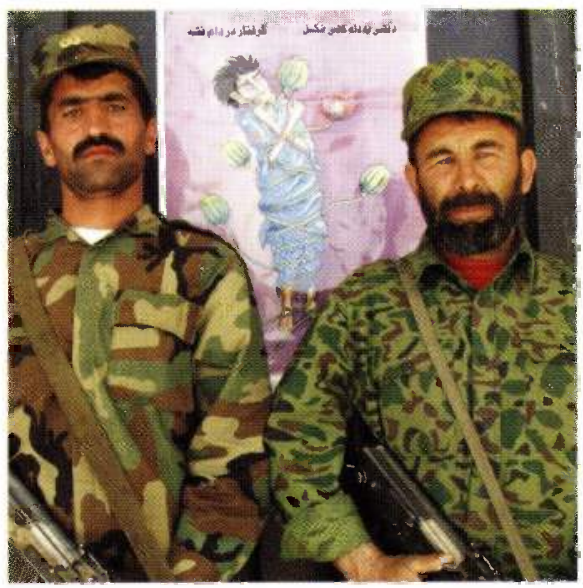

\section{Slow progress on implementation of DDR}

Although 20,000 ex-combatants have been demobilised, lack of overall progress with DDR creates a condition in which non statutory armed forces can continue to operate, leading to an increasing risk of factional fighting. DDR is not being seriously implemented by many commanders; ${ }^{57}$ at the same time, few military actors have been removed from power, despite well-documented evidence of illegal activities and human rights violations. ${ }^{58}$ Lack of sufficient incentives or coercion to lead warlords to subordinate to state authorities and disarm also has played an important role in limiting the success of DDR. The unregulated provision of arms through regional and international networks, and dissemination and availability of heavy weapons in spite of ongoing disarmament efforts, has likewise been an aggravating factor.

\section{Traditional widely dispersed authority}

Strong central Government is not a traditional concept in Afghanistan despite de jure centralisation. In practice, people generally gave their allegiance to tribes, factions and local military strongmen, along ethnic lines.

\section{Insufficient and inadequate law enforcement capacity}

Fledgling institutions such as the Afghan National Police and Afghan National Army still do not have the strength and support to enforce law and order or counter attacks by anti-Government armed forces. They are affected by a severe lack of resources and infrastructure, limited remuneration and lack of professional recognition. In spite of recent improvements in the salary rates and distribution systems supported by the international community, cases of police receiving their small salaries late, or not at all, are still regularly reported. The police force is chronically under-funded, compromising the capacity of the police to guarantee the safety and security of those living within the state's boundaries. This gives rise to the widespread privatisation of security and undermines public confidence in the police. In addition to reports of corruption and extortion by police forces, the police also are allegedly involved in arbitrary arrest, rape, sexual assault, home invasions, kidnappings, torture and ransoms for the release of prisoners. In Afghanistan, the distinction between military and civilian police forces, typical of democratic societies, is blurred, while the police are often recruited from local commanders. Capacity and authority of the police at local level is heavily dependent on their alignment with armed political forces controlling an area $^{59}$ Lack of ethnic diversity and representation of women also is a source of concern.

\section{Weakened conflict resolution mechanisms}

Besides the struggle for political power, economic interests are an important cause for ongoing violence, especially in relation to conflicts over resource control - land, water and poppy harvests [see also Economic Development and Growth, Social Well-Being]. While in other environments such conflicts may be solved peacefully, there is often recourse to arms in Afghanistan because of the absence of a culture of peace during the past 25 years. New challenges to peace and sustainable development require creative thinking and response, 


\section{2c. Contested Allocation of Resources}

Illegal or contested allocation of resources, particularly land and water, plays a central role in increasing insecurity and conflict at both individual and community levels across Afghanistan [see also Economic Development and Growth]. Numbers of disputes recorded over property ownership have increased significantly since 2002; a consistent pattern of forced evictions and land grabs has been found. Arable land comprises only 12 percent of the country's total area, and resources are made even scarcer by Afghanistan's frequent natural disasters.

Data supported by qualitative analysis also points to the high incidence of involvement of commanders, Government officials and other powerful persons in these disputes, operating in a climate of impunity for responsibility. The de facto control by commanders and warlords over areas of forest and mineral resources also has been documented as a serious issue. De facto inequality for women in land ownership and tenure contributes significantly to inequities in allocation of land and property.

The Special Rapporteur on adequate housing as a component of the right to an adequate standard of living ${ }^{60}$ has recommended development of national legislation on housing and land rights. It was recommended that customary, civil, religious and state laws be incorporated and codified into one comprehensive source, prioritising the right to inheritance of housing and land by women, IDPs, nomadic peoples, ethnic minorities and other vulnerable groups. The Special Rapporteur drew attention to the fact that the Constitution, while recognising the need for compliance with international human rights instruments in this respect, does not explicitly guarantee the respect of the right to adequate housing and related rights.

Five key challenges have been identified as underlying causes that inhibit the rights to life; property; non-interference with privacy, family and home; security of the person; freedom from discrimination; and peaceful enjoyment of possessions. These include:

- Lack of central Government control over natural resources, including weak rule of law

- High and increasing indebtedness, leading to increased vulnerability

- Shifts in traditional decision-making mechanisms

- Lack of coherent resource policies

- Consequences of socio-cultural traditions

1. Lack of central Government control over natural resources, including weak rule of law For the past 25 years, the security situation has limited the ability of the Government in Kabul to establish national sovereignty over natural resources, including land, water and minerals. Traditional or statutory controls relating to boundaries between arable and pastoral lands have broken down, resulting in rampant encroachment, contestation and environmental degradation. As noted above, local or community control in many cases has been supplanted by the influence of local commanders, militias or wealthy landowners, many of whom exert influence in the formal and informal justice systems. Formal land record's are considered unreliable, with transactions since 1990 most often disputed. Weak to non-existent rule of law render application or enforcement of law unlikely at this point.

\section{High and increasing indebtedness, leading to increased vulnerability}

Food and economic insecurity of semi-nomadic and farming populations has been 


\section{Shifts in traditional decision-making mechanisms}

Years of war have led to shifts in traditional decision-making mechanisms, including, in some areas, the erosion or corruption of the system of local water management at the village level.

\section{Lack of coherent resource policies}

Coherent policies or strategies for management of natural resources are in many cases nonexistent. With regard to water management, for example, responsibility for water is fragmented between six Ministries; jurisdiction among the Ministries overlaps, and no central coordination mechanism exists.

\section{Consequences of socio-cultural traditions}

In general, because women enjoy lesser inheritance rights, land access is a special problem for widows and women-headed households [see also Economic Development and Growth].

\section{2d. Cultivation of Poppy}

Overall, rural populations are increasingly turning to opium production as a livelihood strategy [see also Economic Development and Growth]. Poppy cultivation has influenced power dynamics and brought shifts to local politics by providing substantial revenue to a large number of mid-level commanders in parts of Afghanistan. ${ }^{61}$ Farmers do not always grow poppy voluntarily - evidence exists that returnees and economically vulnerable families are most likely to be forced by commanders into cultivation.

\section{Afghanistan Opium Poppy Cultivation by province 2002 - 2003}

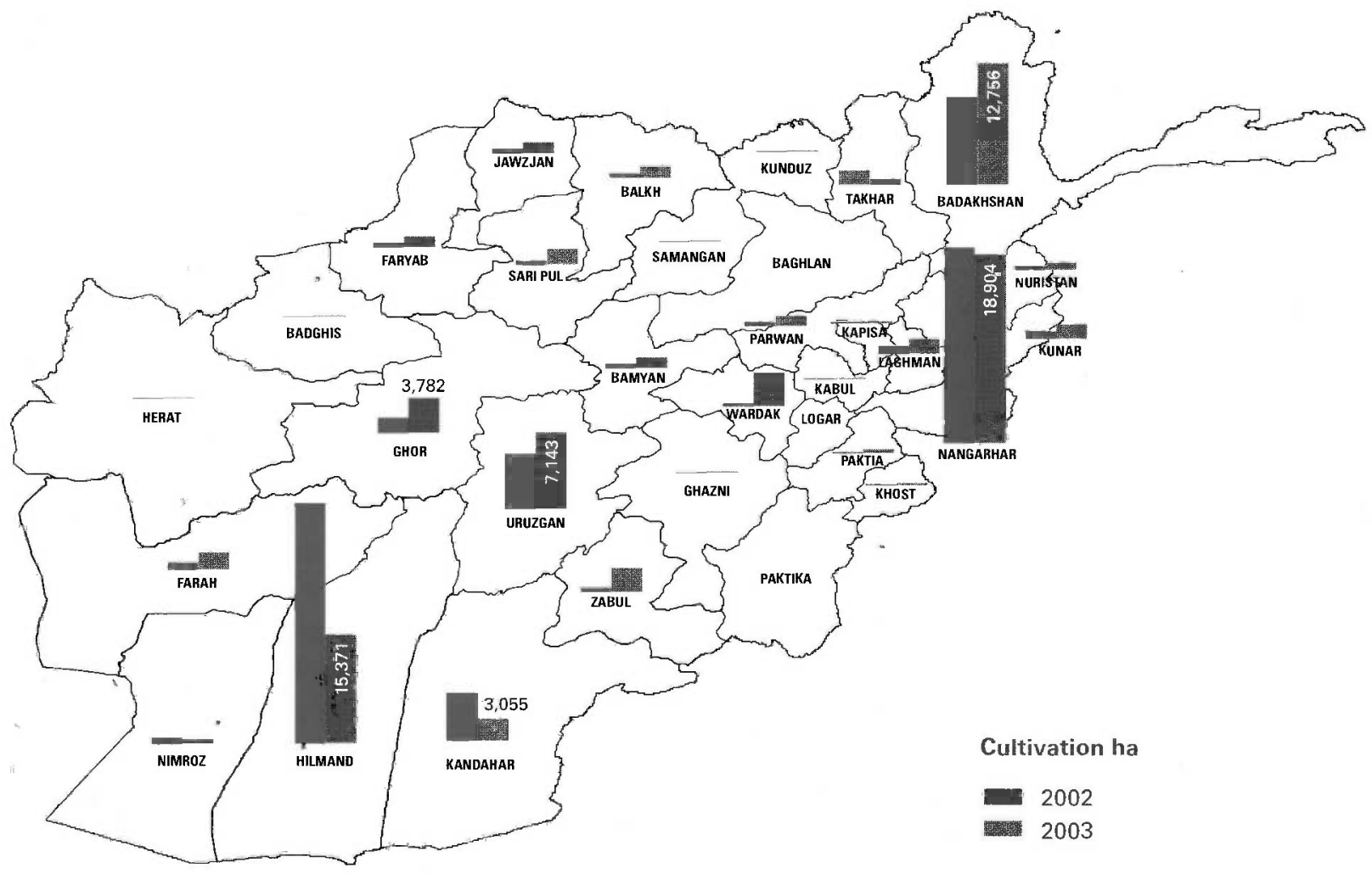


Three key challenges have been identified as underlying causes stimulating opium. production in Afghanistan and further constraining the rights of the Afghan people. These include:

- Lack of institutional capacity for drug control

- Limited law enforcement capacity

- Need for credit

- Lack of adequate engagement of poppy farmers in eradication plans

\section{Lack of institutional capacity for drug control}

The Government has set up a Counter-Narcotics Directorate and developed sound policies, which foresee total eradication of poppy by 2013 and achievement of a 70 percent reduction in five years. This will combine the provision of alternative livelihoods for poppy-growing farmers; extension of drug law enforcement; implementation of drug control legislation; establishment of effective institutions; and introduction of prevention and treatment programmes for addicts. However, the de facto focus of policy implementation thus far has been almost exclusively on eradication/law enforcement.

\section{Limited law enforcement capacity of Government}

The effectiveness of law enforcement is hampered by alleged widespread involvement of Government officials in the narcotics trade and related activities, and by patron-client relationships of military actors with rural police and judicial authorities.

\section{Need for credit}

The opium industry provides an important source of credit for rural Afghans, and engaging in opium cultivation can enhance household liquidity and increase food security. However, the greater availability of credit and the often-unfavourable borrowing terms for opium production also can lead to increased indebtedness. ${ }^{62}$

\section{Lack of adequate engagement of poppy farmers in eradication plans}

Until now, emphasis has been directed mostly to narcotics enforcement and high- or medium-level commanders involved in the narcotics trade, with little effort toward farmers themselves. Direct awareness raising and alternative development initiatives must be strengthened.

\section{2e. Dysfunctional Formal Justice System and Preference for Traditional Justice Mechanisms}

A functioning system of governance cannot exist without a judicial system able to enforce existing law and resolve disputes equitably and consistently. Due to the history of the Afghan legal tradition, formal legal mechanisms are much less consolidated than usually presumed, and not easily understandable by the people. ${ }^{63}$ Women's and children's rights are particularly affected by the lack of functioning formal justice mechanisms at every stage, including knowledge of rights, access to justice, and trial and detention. Other vulnerable groups, particularly nomadic tribes and the poorest sector of society, face similaŕ disadvantages.

(

Overall, the plurality of legal systems across the country creates serious issues of access to justice. The Afghan legal system draws from different influences: Sharia (Islamic law); traditional/customary law, by which justice is administered through jirgas/shuras; secular law, in the form of the Constitution and all other legislation enacted; and international obligations stemming from human rights and other treaties. Without eventual integration 
${ }^{64}$ See Atmar and Goodhand, Afghanistan: The Challenge of "Winning the Peace," in: Searching for Peace in Central and South Asia, 2002. See also Wardak, Building a post-war justice system in Afghanistan, Crime Law and Social Change, Vol. 41 (2004), No. 4, 319-341:326 328.

${ }^{65}$ This includes enforcement of a method of compensation known as badal, which involves resolution of a dispute between two families through exchange of young girls for marriage. Vulnerable groups and those not directly part of the community may be excluded or denied a just hearing because of the monopoly of power by elders who comprise the shura/firga. In addition, the Constitution introduced the respect of basic rights at the same time as it conditioned the legal output to non-contradiction with Islam. Hence, the concept of compatibility between human rights and Islam is indispensable for both advocacy and effective realisation of such rights.

${ }^{66}$ While the right to defence and legal assistance for the indigent has been recognised in the Constitution (Art. 31), the Afghan judicial system does not have a tradition of professional lawyers assisting clients in court cases, nor does it have a bar association or systems of provision of legal aid. Up to now, the international community has focused on addressing the lack of Government capacity to provide justice, leaving it to human rights bodies like the AlHRC and a few NGOs to support the capacity to seek justice, through legal awareness and education programmes as well as legal aid schemes. Slowly, more attention seems to be devolved on starting training programmes for defence attorneys and the need for an institutional solution to this issue. ${ }^{67}$ Human Security and Livelihoods of Rural Afghans, op.cit., pp. 11 and 200. of these sub-systems into a consolidated system, administration of the justice sector will remain difficult; a legal strategy still remains to be developed to address this task. In this diverse framework, limited data available on the use of traditional justice mechanisms indicates that as many as 80 percent of people use shura and jirga mechanisms as the main avenue of redress for a range of disputes; they thus provide established access to a conflict resolution mechanism. ${ }^{64}$ At the same time, these shuras/jirgas are male-dominated and therefore a very limited venue for women to address their issues. Their rulings, based on customary law, can directly contradict Sharia law, state legislation and international human rights standards. ${ }^{65}$

The formal justice system in Afghanistan faces numerous additional obstacles, including: a severe lack of human capacity, infrastructure and material resources; ineffective coordination and communication, as well as ideological disagreement among the Ministry of Justice, the Office of the Attorney General, and the Supreme Court; an apparent high susceptibility to military and political influences, with some appointments made and cases tried on the basis of personal, tribal or ideological ties; a low number of women lawyers and judges; and the non-existence of defence attorneys ${ }^{66} .{ }^{67}$ A significant gap exists between urban and rural areas, with urban courts mostly operational and overwhelmed by a high caseload, and rural courts, where present, extremely under-resourced and subject to the will of local military actors. At the same time, the prison system in Afghanistan is devastated after 25 years of being used as a political tool for the repression of opponents. With the exception of a few provincial capitals, in the majority of provinces children are detained with adults, often without going through due process. All this effectively compromises the efficiency and integrity of justice administration and decreases people's trust in the formal justice system.

Five key challenges have been identified as underlying causes for the lack of fulfilment of rights to an effective remedy/equal protection before the law; freedom from torture and cruel, inhuman and degrading treatment or punishment; liberty and security of person/ freedom from arbitrary arrest and detention; and freedom from discrimination. These include:

- Lack of awareness of basic rights and the legal system, impeding access to justice

- Low level of capacity/resources of the formal justice system

- The shortcomings of traditional justice mechanisms in safeguarding human rights in a situation of monopoly of traditional justice mechanisms for many years

- Lack of clarity of the transitional legal framework

- Insufficient capacity of the correctional system

\section{Lack of awareness of basic rights and the legal system, impeding access to justice}

The Afghan population has very limited knowledge of their rights and entitlements and the mechanisms to protect them; of the normative framework of Afghanistan; and of the international legal framework. This is a result of a low level of education, high illiteracy and the restrained access of women to information. Several studies have indicated that many citizens who are aware of the court system are not confident about its integrity and have little confidence in legal professionals. Inadequacy of dissemination of information about basic rights and the legal system, combined with lack of an institutionalised legal defence, impairs overall access to justice. 


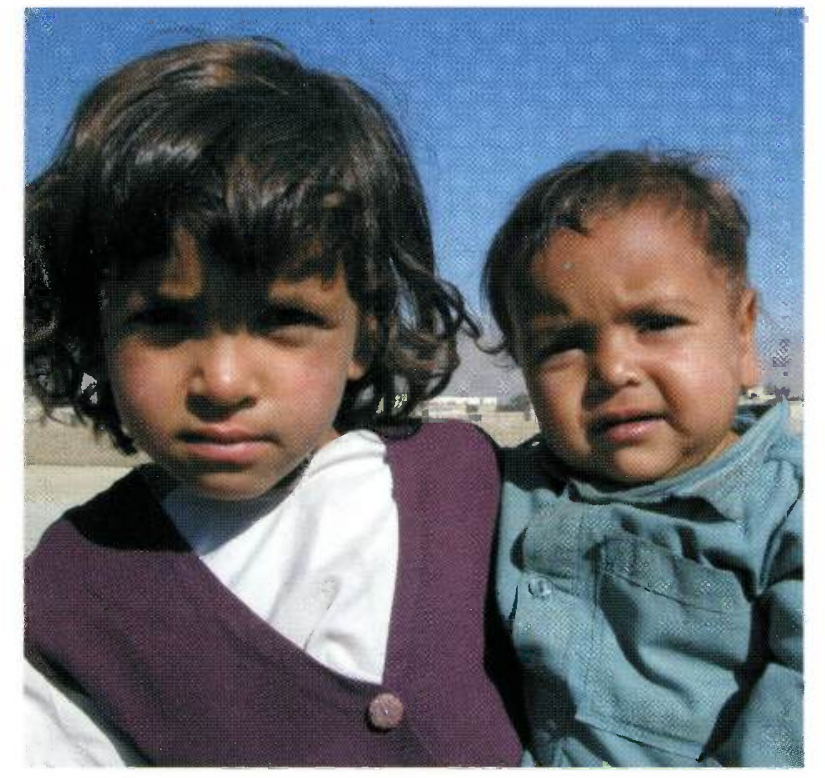

2. Low level of capacity/resources of the formal justice system

Lack of national coverage of the natignal justice institutions, combined with lack of infrastructure, are but the first of a series of issues that make the formal justice system inefficient and inadequate to deal with the administration of justice nationwide, effectively impeding the fulfilment of access to justice and basic human rights. This is exacerbated by lack of security for staff involved in the administration of justice, inadequate salaries, and lack of an adequate law enforcement mechanism. In addition, serious concerns exist about the education level of personnel for the administration of justice.

3. The shortcomings of the traditional justice system in safeguarding human rights in a situation of monopoly of traditional justice mechanisms for many years

The lack of control of the central Government over the majority of the country during the years of internal conflict meant that traditional justice fora were the only conflict resolution mechanisms. Unlike state courts, traditional mechanisms settle disputes without long delays and without financial costs. Because they do not involve written communications, access for illiterate people is easier. However, traditional justice mechanisms have a controversial human rights record, both in terms of procedures used and mechanisms of enforcement, especially with regard to the rights of women.

\section{Lack of clarity of the transitional legal framework}

The legal framework operating in Afghanistan is in a transitional phase. While the Constitution provides an overall framework, the work of indexing and digesting existing laws to underpin future law reform has yet to be carried out. Given that the Constitution provides that currently enacted legislation contrary to constitutional provisions is automatically invalid, the review will have to ensure consistency and lack of gaps in the legal framework.

\section{Insufficient capacity of the correctional system}

The correctional sector, including the courts and the penal system, is severely underresourced and, because of a shift of responsibility between Ministries, many staff are unfamiliar with new standards. The penal system has been an area where it is extremely difficult to get donor support. 


\section{2f. Social Violence and Lack of Social Protection}

Although lack of documented information on many forms of social violence is a constraint to analysis, indications are strong that social violence ${ }^{68}$ is increasing as a result of a lack of social protection ${ }^{69}$ for vulnerable groups [see also Social Well-Being]. While the main form of social protection has come from the family, longstanding conflict, civil unrest and dislocation have severely eroded the capacity of many families to provide such protection to their members. Even within intact families, severe abuses of members occur. Women and girls are disproportionately affected, exacerbated by their absence from decisionmaking fora at all levels. ${ }^{70}$ Police, militia, armed political groups and commanders allegedly continue to use rape and sexual violence as a weapon against women and girls, their families and communities. Afghan boys also are targets of sexual abuse. ${ }^{71}$

68 Social violence encompasses comestic violence, trafficking in persons, abduction, early or forced marriage, self-immolation. suicide and child labour.

69 Social protection is defined. according to the Asian Development Bank, as a set of policies and programmes designed to reduce poverty and vulnerability by promoting efficient labour markets. diminishing people's exposure to risks and enhancing their capacity to protect themselves against hazards and intemuption loss of income. The policies and procedures included in social protection involve five major kinds of activities: labour market policies and programmes, social insurance programmes, social assistance. micro and area-based schemes. and child protection.

70 The United Nations

Commission on Human Rights has stated that the "precarious legal social and economic siuations of women and gints are factors which increase their vulnerability to traffickng and other forms of explotation."ECN/Sub.2/2001/26)

7 Human Securty and

Wvelhoods of Rural Afghans,

opecit, p. 113 .

Effectiveresponses to protect chilren from abuses also is constrained by lack of incomegenerating opportunities for famies; sociocultural practices and religious beliefs; inadequate fegat and policy frameworks; poor or inadequate law enforcement including corruption; and absence of sevvices and progranmes for protection.

73 The Special Rapporteur on Volonce Against Women has urced the Govemment to take steps to tacke impunity for perpetrators of violence against women, while at the same time establishing the rule of law. CN,4200466, cited in Country Profile of Afghanistan and the international human rights system opcit, p. 8 .
Physical punishment of children at home and at school is common, and a sharp increase in child trafficking, kidnapping and exploitation has been reported, in large part because of extreme poverty. Comprehensive research into child abuse is yet to be undertaken [see also Social Well-Being]. ${ }^{72}$ Based on analysis, four key challenges have been identified as inhibiting the realisation of rights to freedom from discrimination for victims of social violence; to life; and to freedom from torture and cruel, inhuman and degrading treatment or punishment. Rights under the Convention on the Elimination of All Forms of Discrimination Against Women and the Convention on the Rights of the Child also are relevant. The challenges are:

- Lack of rights awareness

- Lack of redress for violations in the absence of a formal legal system

- Consequences of diminished livelihoods

- Consequences of socio-cultural traditions

\section{Lack of rights awareness}

The widespread lack of awareness of rights particularly affects women, because of their limited access to information, low educational status and illiteracy, and thus has significant implications for social violence issues. It likewise has a significant effect on children, who are left extremely vulnerable to abuse and exploitation.

\section{Lack of.redress for violations in the absence of a formal legal system}

Legal and political factors that allow social violence to continue include disputed legal definitions of rape, domestic abuse and marriage age. This is exacerbated by the de jure or de facto lesser legal status of women and some ethnic minorities, which has made redress for violations against these groups difficult in many instances. ${ }^{7}$

\section{Consequences of diminished livelihoods}

Economic constraints, in many instances, lead families to send their children to work so as to contribute to the household income, and to marry off daughters at an earlier age than normal.

\section{Consequiences of socio-cultural traditions}

The perceived status of powerlessness of women and their inability to defend themselves against violations of their well-being - through forced marriages, for example - leads an increasing number of girls and women into suicide, in many cases through self-immolation. 


\section{What Does Success Depend On?}

Given this strategic analysis, it appears difficult to create the necessary environment to achieve progress toward the MDGs, Millennium Declaration targets and rights of survival, livelihood, protection and participation, specifically with regard to disarming militias, expanding access to justice, and establishing mechanisms to control corruption [see also Governance and Institutional Development]. This requires ambitious institutional reforms and sustained domestic and international support. The existence of considerable disparities in human development across regions and among different social groups must be recognised, and development policies must address these inequities.

Full support must be given to appropriate national policies and priorities on peace, security and justice, including:

- Support to the overall elimination of the culture of impunity and tackling the issue of crimes of the past

- Support to revitalise and accelerate the DDR process, as well as to ensure that security and law enforcement institutions are comprised of individuals who are not suspected of having carried out serious human rights violations. An effective screening methodology and a reliable database are required ${ }^{74}$

- Support to human rights/rule of law education for all citizens, including children, to create an enabling environment for peace and sustainable development. This can be particularly achieved through the education system [see also Social Well-Being]

- Expanded support to an effective reform of the Afghan National Police as a democratic law enforcement actor, both from an administrative and a command/control perspective, including the provision of adequate training and equipment and the recruiting of women

- Support to strengthening of capacity to implement relevant policies, especially at subnational level

- Support to development of information bases for appropriate early warning systems for conflict prevention

- Support to the rebuilt judicial system, including the juvenile justice system, to operate in a manner promoting full respect for international human rights standards; ${ }^{75}$ enactment of non-discriminatory laws and repeal of all legislation and other measures that discriminate against women or children or impede their full enjoyment of human rights and fundamental freedoms. The plurality and overlapping of judicial systems must be addressed through support to integration of these different sub-systems

- Support to curbing of poppy cultivation, opium processing facilities and drug trafficking. Assistance must be given to establish benchmarks and achievements indicators [see also Economic Development and Growth]. It is recommended to support the mainstreaming of the counter-narcotics strategy within overall strategies in support of national policies. A need exists, however, for clearer articulation with regard to the

4 See also the 21 Augus 2004 statement and news comference of the United Nations Independent Expert on thman Rights in Afghanistan, Prof. Cheris. Bassiouni.

\%s Spectal Papportem on mopendence of Jurges and Lawyers. ECN.4/200365/Add.1 paras. 39 , cited in Country Profle on Alghanistan and the international human rights system op.cit. p. 5 .

76 Opening Doos to Opportunty Afghanistan's Millennum fact that poppy eradication implies a substantial reduction in rural incomes, which will be acutely felt among the poor 76

- Support to development of broad-based social protection legislation, policies, programmes and services [see also Social Well-Being] 


\section{International Context and Commitments}

- International Covenant on Civil and Political Rights

- Convention on the Elimination of All Forms of Discrimination Against Women

- International Convention on the Elimination of All Forms of Racial Discrimination

- Convention Against Torture and Other Cruel, Inhuman or Degrading Treatment or Punishment

- Convention on the Rights of the Child and its Optional Protocol on the Sale of Children, Child Prostitution and Child Pornography, and on the Involvement of Children in Armed Conflict; international instruments governing juvenile justice, including United Nations standard minimum rules for the administration of juvenile justice (Beijing Rules), United Nations guidelines for the prevention of juvenile delinquency (Riyadh Guidelines) and United Nations rules for the protection of juveniles deprived of their liberty

- Rome Statute of the International Criminal Court

- Convention on the Prohibition of the Use, Stockpiling, Production and Transfer of Anti-Personnel Mines and on Their Destruction

- Comprehensive Nuclear Test Ban Treaty

- Chemical Weapons Convention

- Protocol (to the Convention Against Transnational Organised Crime) to Prevent, Suppress and Punish Trafficking in Persons

The Constitution stipulates that "the Afghan state shall observe [...] international treaties which Afghanistan has joined and the Universal Declaration of Human Rights" (Article 7). The state and its institutions are therefore also bound by constitutional law to uphold rights identified as relevant to issues affecting peace, security and justice.

Lastly, peace, security and justice are relevant to the overarching MDG goal of halving extreme poverty and hunger by 2015 , to which Afghanistan has subscribed.

\section{Significant Data Gaps}

- Data on access of population to formal justice system

- Extent of domestic violence in Afghanistan; magnitude of suicide among both women and men, as well as reasons for it; number and nature of cases of human trafficking, kidnapping/abduction, and sexual exploitation

- Ways that conflict over resources are resolved by both formal and traditional mechanisms, and how disputes over resources affect women, particularly women-headed households and widows

- Availability of free legal assistance for criminal defence of the poor and disadvantaged

- Need for comprehensive legal awareness survey and comprehensive study of the interface between formal and informal justice

- Studies of how formal institutions, such as the Special Court on Land, are operating in terms of processing cases and taking decisions. Further attention is necessary to enforcement of those decisions, particularly when the ruling is not in favour of a commander or powerful individual

- Proportion of disputes received or arrests made by non-state institutions that are subsequently referred to state institutions 


\section{3}

Economic Development and Growth 

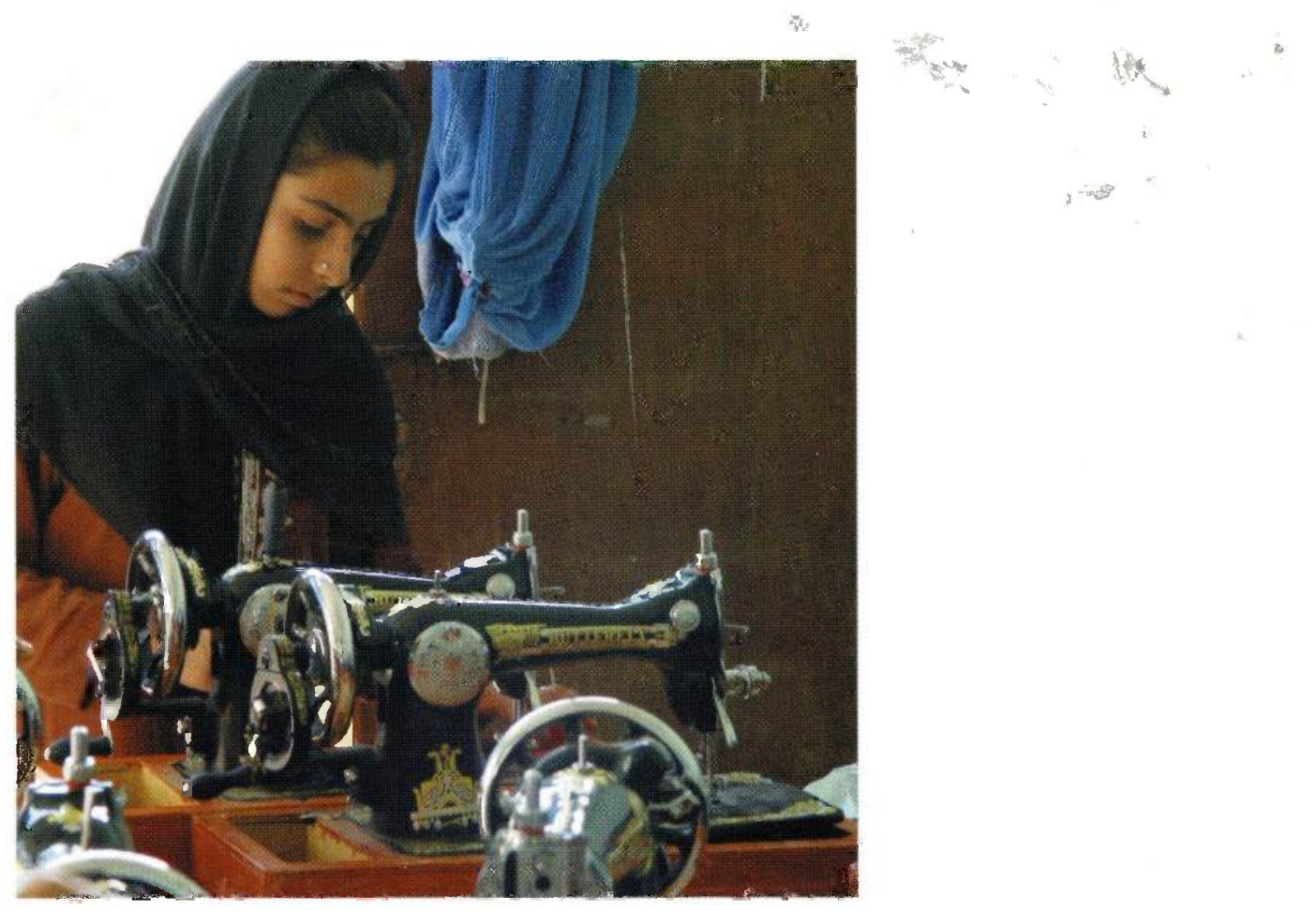

\section{The Situation in Afghanistan}

Economic growth is vital to the rights to survival, livelihood, protection and participation. Likewise, the first MDG, eliminating extreme poverty and hunger, is closely tied to the issue of quality of growth. In 2002, following the end of major conflict, Afghanistan had a percapita Gross Domestic Product (GDP) of less than US\$200 - one of the lowest in the world. Significantly more than half of the population lived in extreme poverty, and the total GDP stood at only US\$4 billion.

But in the last two years, Afghanistan's formal economy has performed strongly, albeit starting from a very low base. Non-drug GDP has increased more than 50 percentage points, primarily reflecting a revival of economic activity, the initiation of reconstruction, and the partial recovery of agriculture in some areas from severe drought. Recent positive growth performance has been supported by the Government's sound macroeconomic policies - a highly successful currency reform, a prudent "no-overdraft" policy prohibiting domestic financing of the budget deficit, a conservative monetary policy that brought inflation down to 10 percent annually, and good management of the exchange rate. Progress also has been made in mobilising domestic revenue and in trade and financial sector reforms.

At the same time, the key to long-term economic development will be a strong local private sector based on considerable skills development. The informal economy in Afghanistan continues to be dominant, accounting for 80 to 90 percent of the total economy; women work primarily in this sector. The legal portion of the sector is centred on agriculture, commerce, manufacturing, handicrafts and transport. Agriculture, not including poppy, generates about half of GDP and employs about 70 percent of the labour force, estimated at 8 million; as such, it is considered the main source of livelihoods. However, illicit activities include the extensive opium production that blights Afghan society, along with widespread unauthorised timber harvesting and mineral extraction. Also on the negative side are the severe deprivations suffered by livestock owners, both settled and nomadic, with regard to animals lost to the drought that continues in many parts of the country. Their recovery, alon with that of reduced agricultural production in general, is expected to take several years. 


\section{National Policies and Priorities}

Poverty reduction through broad-based economic growth lies appropriately at the heart of the National Development Framework (NDF). The Government's vision for investment and social capital is "to create the conditions necessary for the people of Afghanistan to secure sustainable livelihoods in the legal economy and to lay the foundations for the formation of long-term human development."

\section{Public Investment Programme}

- At the International Conference on Afghanistan, held in Berlin with international partners in March/April 2004, the Government proposed a Public Investment Programme (PIP) that aims to enable Afghans to generate the type of economic growth and institutional changes that would sustain the politics of hope and inclusion. Alleviation and elimination of poverty is the critical end result, directly responding to the central issue of the MDGs. Under the PIP for Livelihoods and Social Protection, the focus is on productive aspects as key to poverty reduction - through the NSP, the National Emergency Employment Programme (NEEP), microfinance (MISFA, the Micro-Finance Support Facility in Afghanistan, is to reach 100,000 families by the end of fiscal 1383 [2004-2005]), and community water supply. Direct social transfers are limited to extreme vulnerability and emergencies (see National Vulnerability Programme below).

\section{Overall Vulnerability}

- The new National Vulnerability Programme aims at reducing poverty and addressing vulnerability to risk for the most vulnerable groups (nomadic peoples, vulnerable women, IDPs, persons with disabilities, street children, orphans, child soldiers).

\section{Environment}

- The Government recognises that failure to address environmental degradation will negatively affect the population's health and increase poverty and hunger, slowing progress toward the MDGs, and it is undertaking a National Environmental Action Plan in this regard. Efforts also are being undertaken to counter degradation through usage of integrated water resource management systems, major tree planting programmes, preparation of an Environmental Protection Act, and training and provision of equipment for monitoring air pollution. 
As an alarming example of the informal economy's considerable growth, poppy 'cultivation for opium production has rebounded to near-record levels [see also Peace, Security and Justice]. In 2003, opium comprised about one-third of total GDP, including drugs. Narcotics in Afghanistan thus remain pervasive and increasingly entrenched, with a clear nexus among poppy cultivation, violence and criminality. The scope for expanding poppy production and deepening the skills base represents a major economic concern.

Another important element in the informal sector arises from remittances in the form of payments from labour resulting from economic migration. Such remittances are critical to many households and should be seen as short- or medium-term economic stimuli.

Analysis suggests that countries similar to Afghanistan, and with sound policies and institutions, experience economic growth of around 7 percent annually. In post-conflict economies, growth could be even higher, reflecting a catch-up period. A 9 percent annual growth rate in the Afghan non-drug GDP, driven substantially by external financing, is estimated as necessary to "replace" the opium economy over time while enabling the nation to reduce poverty. ${ }^{77}$

\section{Analysis of Key Issues and Underlying and Root Causes}

The CCA analysis is synchronised with national priorities [see National Policies and Priorities box], and the United Nations System is supportive of Government efforts toward economic development and growth, particularly the National Development Framework, the Public Investment Programme and a National Environmental Action Plan. Analysis has divided key issues of economic growth and development into the following:

- Employment, as it relates to the right to decent work

- Distributive justice, as it relates to rights to human dignity and gender equality

- Environment and natural disaster management, as it relates to the right to sustainable development

Duty bearers that hold an obligation to fulfil these entitlements are primarily State actors and institutions at various levels of the governance structure, as well as non-State actors - including civil society itself - that can influence the rights of others. The root causes for the above challenges in Afghanistan, which are interlinked, can be traced to:

- An underdeveloped human rights culture, along with lack of traditions of democracy, state-building and civil society participation

- Young governance structures still in the process of establishment and/or early stages of development, and unable to curb political insecurity

- Culture of unsustainable resource use that must be reversed

- Shortage of human resources that can propel economic reforms

- Wide variations in socio-economic indicators, by gender, region and rural-urban divide

- Weakened social infrastructure

- Socio-cultural traditions that result in widespread marginalisation based on gender, social status or ethnicity

- 'Obsolete industrial and agricultural technology and practices that harm the environment 
Economic Projections

Estimates

Projectons

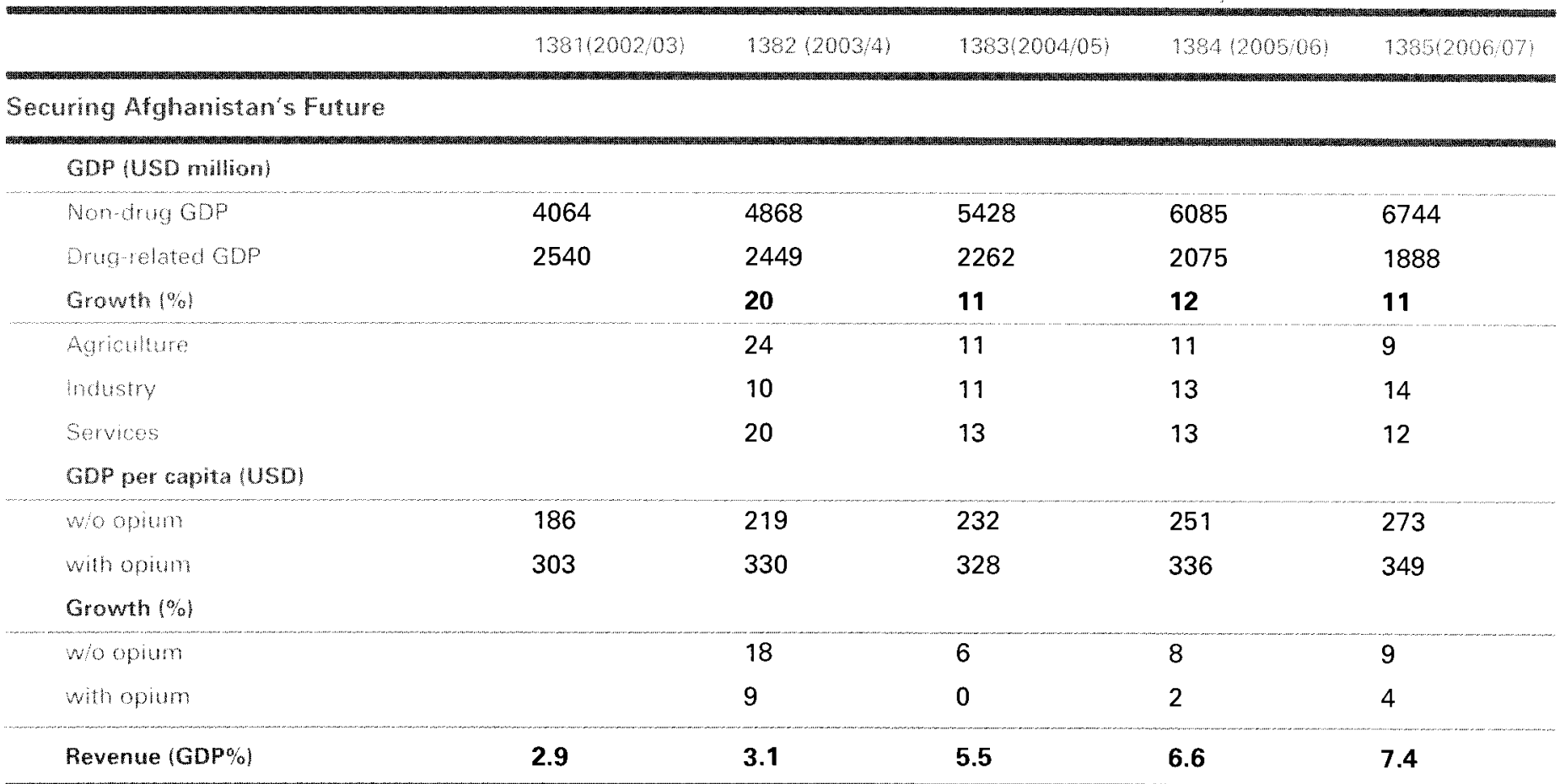

Putting Afghanistan's Future at Risk

\begin{tabular}{|c|c|c|c|c|c|}
\hline Drug related GDP & 2540 & 2449 & 2449 & 2449 & 2449 \\
\hline Growth $(\%)$ & & 20 & 8 & 8 & 8 \\
\hline Agriculture & & 24 & 6 & 7 & 6 \\
\hline indistry & & 10 & 10 & 9 & 9 \\
\hline \multicolumn{6}{|c|}{ GDP per capita IUSOI } \\
\hline wo opium & 186 & 219 & 224 & 235 & 249 \\
\hline with opium & 303 & 330 & 329 & 336 & 348 \\
\hline \multicolumn{6}{|l|}{ Growth $(\%)$} \\
\hline
\end{tabular}




\section{2a. Employment: The Right to Decent Work}

The right to decent work encompasses productive work of acceptable quality, in which rights are protected and which generates an adequate income with adequate social protection. It is not confined to wage employment, but extends to self-employment, home work and other income-generating activities. It also carries with it the responsibility to promote the personal capabilities of people to find productive employment and earn a decent livelihood.

In Afghanistan, although no specific survey on employment has been conducted, the overall jobless rate is 32 percent. $^{78}$ Unemployment among youth, while extremely significant, is lower than the average rate, although in case of increased education not adapted to concrete market needs and opportunities, the potential exists for further worrisome growth. In addition, evidence exists of exploitative employment conditions, particularly in the agriculture sector, leading to increased indebtedness for thousands of families. ${ }^{79}$

Based on analysis, four key challenges have been identified as inhibiting employment and economic growth. These include:

- Lack of an enabling environment

- Lack of support services, including key infrastructure, and market access

- Lack of access to capital and financial services;

78 IRC Labour Market Intormation Survey 2003

79 See also Alden Wily, Rural Land Conflict and Peace in Afghanistan, AREU, 2004. Payments to terants. sharecroppers and fam workers. usually in the form of crops, have more or less been fixed tor 70 vears and are argubbly not a far retum for labour. Even in a good agricutural year, a sharecropper's family may receive enough grain for only 4 to 7 months and become indebted for the rest of the year.

80 Byits nature, work in the informat sector is difficutt to reguab; many wokers are without basic protections and are open to rights viotations and abuse in unsafe or hazardous emumoments

Q7 For poppr production, the Averoge family income suars to US\$4,000 a year, compared with onv USS500 tor logal crops. Though to tmes more tabout intensive than corcat crops. poppy can be grown with cheap. unskited toboul.

82 A typical busmess 153 percent is owned by the family, with 69 pereent of businesses employing only one or two people tha standard make economy the range of actwities in the SME sector would be numerous. In Afghanistan, however tho core of the sector is in only wo areas, constructon and agricutumat processing.

83 Word Bank, op at pp 5 and 331.

- Lack of advanced entrepreneurial skills, knowledge and technology

\section{Lack of an enabling environment}

The weak state of national institutions constitutes a major constraint for economic development and poverty reduction, compounded by the need to strengthen policy and regulatory and legal frameworks. This represents the most important constraint for the small and medium enterprise (SME), industrial and mining sectors, and a significant constraint for the agriculture/livestock sector, making it a key challenge for intervention and reform. Moreover, while only private sector development will be able to take Afghanistan to the next level of economic development, the overwhelming dominance of the informal economy represents a serious issue. ${ }^{80}$ In particular, the opium economy - concentrated in six districts with high rates of insecurity and risk - provides strong incentives that help Afghans cope with hardship but that undermine the rule of law and legal economic alternatives. $^{81}$ In the long term, it contributes to vulnerability, especially for poor farmers. In the legal economy, an enabling environment for the right to work and private sector development is constrained by the static nature of small and medium enterprises. The SME sector contributes less than 10 percent of GDP and is weak particularly because of underdeveloped market linkages that are key to stimulating economic activity beyond subsistence and micro-business. 82

Finally, the slow rehabilitation of the industrial sector must be noted. This sector constituted 22 percent of GDP in 2003, with production deriving mostly from agriculture-related activities. ${ }^{3}$ Private investment toward industrial development continues to be insufficient, with most focused on post-war reconstruction; a long-term industrial development strategy is required.

\section{Lack of support services, including key infrastructure, and market access} Afghanistan's rugged geography and extreme climate seriously constrain access and communication, exacerbated by a scattered population. Support services, including key infrasţructure (electricity, roads, water, irrigated land) and business linkages (warehousing, 
The following points summarise available data on employment:

- Unemployment is highest, 42 percent, in the central region

- The age group 25-60 has the highest rate of joblessness, also 42 percent: among youth (aged 16-25), 26 percent across all regions are unemployed

- The informal sector, including the opium economy, and agriculture/livestock sectors are the two largest employers - A significant group of farmers are casual labourers without land of homes. Their dependency on landlords makes them vuinerable to exploitation

- A total of 62 percent of businesses require additional employees

- State Owned Enterprises, previously the backbone of industry, have largely collapsed following a budget reduction

- About 60,000 children are employed on Kabul's streets. A large number of young girls also are employed. mostly in domestic service

- Unemployment among people with disabilities is 84 percent marketing) are either severely depleted or have never been developed. Any private formal or informal economic activity requires all of these, to a greater or lesser degree. Moreover, many Afghans - including the majority of women - appear to be prevented from accessing markets because of cultural constraints or insecurity arising from militia activity. ${ }^{84}$

As an example of the obstacles faced by Afghanistan's poor, the time currently required for transporting products to market often leads to a loss of quality and profit, compounding low productivity, the neglected development of modern farming techniques, and high production costs. Often, market access is limited by illegal taxation or extortion on roads by armed groups, military factions and local commanders. ${ }^{85}$ Farmers encounter a similar constraint in the absence of market-related information, which makes it difficult for them to even assess the market.

\section{Lack of access to capital and financial services}

Large capital depletion through the loss of land, real estate and machinery during the lengthy conflict forms a major constraint to renewed economic activity. The lack of financial services likewise is a serious concern. Underdeveloped areas include an inadequate banking system as well as lack of financial services, particularly credit, for the informal economy.

A challenge is to deepen and widen such services through the increase in coverage of credit unions, commercial and village banks and microfinance; this must be combined with outreach to vulnerable groups, especially women and ethnic minorities, many of whom have virtually no access to credit. Saving for capital accumulation and capital investment will be equally important. Currently, few livelihood strategies other than poppy cultivation provide ready access to credit, and informal credit systems have become limited only to close family members because of war, drought and other hardship. ${ }^{36}$

\section{Lack of advanced entrepreneurial skills, knowledge and technology}

While the entrepreneurial and commercial skills of the Afghan people are remarkable, many structural gaps in the existing skills sets need to be bridged for the economy to thrive.

Professional, managerial and administrative expertise are sharply lacking, as are technical and craftsman skills. Women in particular do not have advanced skills and experience, given their extended absence from education and economic activity. Most technology is highly outdated; training, research and development to adopt existing technologies also are poor.

All this results in an inability to expand businesses, improving productivity and efficiency. The economy has further suffered from a "brain drain" that has resulted in a loss difficult to replace, although this is partly compensated for in the short term through the inflow of remittances.

\footnotetext{
84 Human Security and 


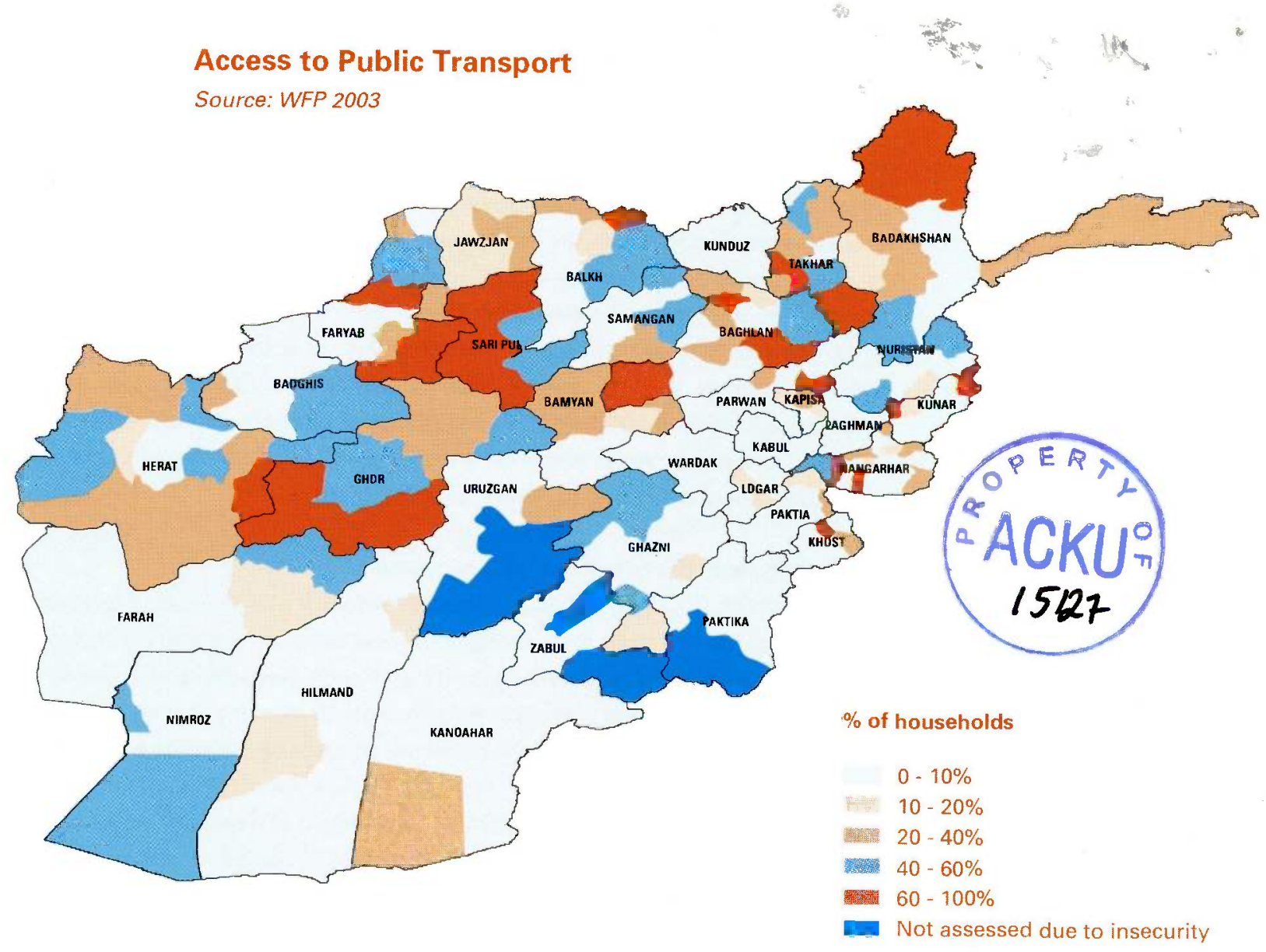

2b. Distributive Justice:

The Right to Human Dignity and Gender Equality

Like employment, equitable access to resources and their benefits represents a key factor for economic development and growth. Discrimination and unequal opportunities represent a major constraint on the right to work as well as overall rights and poverty reduction. This is particularly relevant for marginalized groups, which in the context of Afghanistan include the poor, the landless, ethnic minorities, returnees and IDPs, children, people with disabilities - and, overwhelmingly, women. Overall, the distribution and contested allocation of resources, together with obstacles of access, must be taken into account for a development strategy to lead to more equitable wealth; realisation of social and economic rights, particularly the right to human dignity and-the right to gender equality; and achievement of the MDGs.

The following points include major concerns with regard to distributive justice:

- Because of socio-cultural reasons and lack of opportunities (illiteracy, little or no „capital), women cannot participate in many types of economic activities and may be exploited in terms of the division of labour

- Employment is not equally distributed and often reflect biases based on social status, gender or ethnic group

- Ambiguity and high insecurity in land ownership and land tenure rights also marginalize numerous sections of the population, again based on social status, gender and ethnicity 
In the majority of familles, the wite or wives and daughters do not wherit any property as long as there is a male heit. Women's lack of formal tite to land poses a particular problem for returnee widows trying lo access former homes and plots. It should be noted that under Sharia law, women have the right to own land and to inherit some property and wealth from male relatives. This is rarely upheld in Afghanistan.

\footnotetext{
87 bid. o 158

98 ibid, p. 356 . In pars of Afghanistan, women who can find work outside the home also are subied to severe restrictions on their speech, dress and behaviour. Because women and girls have so few economic opportunties, threats to their jobs carry even greater weight.

39 op.cit, p. 134

90 ibid, p. 134

91 Localregional minorities face inequites from locallegional maiturites, with the two largest ethme groups - Pashtun and Tajk - finding themselves in minority positions outside their main areas of residence.
}

This analysis further examines the critical challenges and underlying causes for the above constraints on the right to work for key marginalized groups.

\section{Women and constrained economic opportunities}

Despite the commitment of the Government to gender equality, significant discrimination against women persists in the workplace, primarily because of cultural constraints. 87 Afghan women could be well-positioned to play a part in the informal economy, which requires flexibility; at the same time, it requires mobility, which many women do not have. The majority of rural Afghan women who work for income do so within their homes; however, women who engage in wage labour earn substantially less than men, and sometimes less than children. ${ }^{38}$ Inequalities for women also are extensive with regard to inheritance laws, which provide for a lesser share for a female inheritor compared to a male or, in the case of a widow, to her in-laws or children.

\section{Landlessness: the insecurity of land ownership}

Land is distributed unequally and is combined with a high level of landlessness, both of which constrain the right to property and freedom from arbitrary interference with privacy, family, home and correspondence [see also Peace, Security and Justice]. An estimated 40 percent of arable land is owned by less than 10 percent of the rural population. ${ }^{89}$ Landlessness stands at around 24.7 percent of rural households but may soar to threequarters of some communities. ${ }^{90}$ In addition, near-landlessness (land insufficient for meeting subsistence requirements) is equally high, at nearly 60 percent of those who own land. Vulnerable groups such as women-headed households, the landless and nomadic peoples are at a distinct disadvantage in terms of access to resources, ownership and maintaining ownership or tenure.

Studies of historical land relations point to an underlying system of discrimination based on socio-economic status. Economic gaps between landlords, small farmers and the landless are large, and landlessness correlates strongly with local perceptions of poverty. Powerful cultural barriers also exist between those with and without land. Landless farmers often perceive acquisition of land as not only financially impossible but as "getting above our station."

At the same time, customary, religious and state laws offer a plural legal basis for land rights, with inconsistency and uncertainty as to norms in each body of law. Customary law, used in a majority of land disputes, tends not to favour women. Most importantly, judicial bodies often are faced with multiple claims to a single piece of property. While conflict over water rights is integral to many land disputes, pastureland is thought to be the most widely contested class of land and represents a rapidly emerging focal point for inter-ethnic conflict.

\section{Ethnic minorities: longstanding discrimination}

Ethnic discrimination against various groups ${ }^{91}$ has effectively prevented access to, and equal distribution of, resources and their benefits, thus constraining the right to work for many Afghans. Discriminatory practices long have provided preferential access to land as a reward for certain ethnic groups and power bases and have levied heavy taxes against groups in political or social disfavour. Such ethnic discrimination has been particularly critical with regard to rights to grazing lands. As a result, violent repercussions have taken place against numerous ethnic groups and are heightened by the return and resettlement of large numbers of refugees and IDPs. 


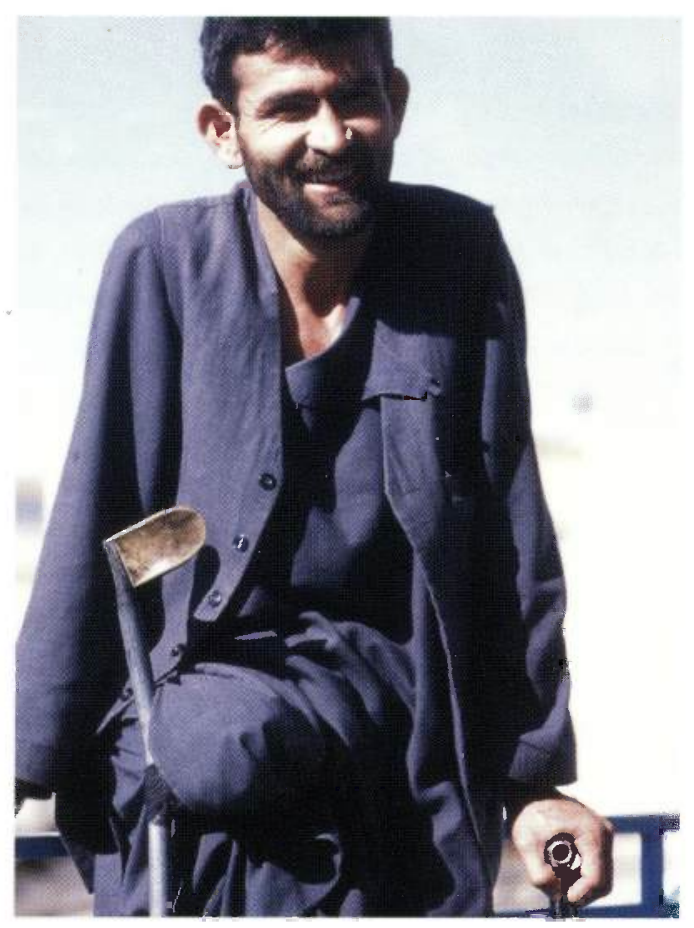

4. Distributive justice for other vulnerable groups Returnees and Internally Displaced Persons Economic growth and the creation of employment opportunities are crucial for the sustainability of the return of refugees and IDPs. A key concern in this regard includes a lack of employment opportunities, discouraging return to places of origin or forcing movements to concentrated areas where absorption capacity of the labour market may be insufficient. This has exacerbated the increasing trend of rural-urban migration. Other concerns include the risk of "back-flow" movements abroad; the scarcity or lack of productivity of landholdings, reducing livelihood opportunities; and the presence of extreme vulnerable groups among returnees, whose poverty levels may force them into illegal activities to survive. In addition, some returnees are professionals, civil servants and other skilled labour who cannot find employment compatible with their status.

\section{Widows}

Widows have been described as Afghanistan's most vulnerable group. The years of war and civil unrest, together with the traditional practice of older men marrying younger women or child brides, have resulted in an estimated 500,000 widows. Many widows are deprived of their inheritance, leaving them dependent upon their late husband's brothers for support. Restricted employment opportunities prevent them from establishing independent households, and large numbers of widows beg for money to support their children.

\section{People with disabilities}

People with disabilities are currently estimated to comprise from nearly 3 to 5 percent of the Afghan population, although the actual figures are likely to be much higher. Because more than 8 in 10 people with disabilities are unemployed, ${ }^{92}$ most rely on the beneficence of their families; few opportunities exist for training or retraining for employment. Children with disabilities are subject to severe inequities and have limited access to educational opportunities.

\section{Street and working children}

Estimates vary on the number of street and working children in Afghanistan, but it appears that most work to support their families, who tend to be poor or single-headed households with little or no extended family support. Many of these children walk great distances to reach their workplaces; they face abuses and hazards including dust and pollution, lack of clean drinking water and toilets, and arbitrary arrest and detention.

\section{Children without parental care}

Parents' descent into poverty has resulted in rising numbers of children without parental care and in families placing such children in institutions, in the hope of a better life for them. Of the current 8,000 children in orphanages, about one-third are there because of poverty, and more than 80 percent have a living parent. ${ }^{93}$ Few children leaving an institution are well prepared for work, having few social or vocational skills. Overall, Afghanistan has the highest child population of orphans in Asia, at 12 percent, as well as the highest of any country in the world without a generalised HIV/AIDS epidemic.

92 IRC Labour Market Information Survey 2003

93 UNICEF, Report on a national assessment of the situation of children of children deprived of parental care in institutions in Afghanistan, 2003. 
Child soldiers and war-affected children

About 8,000 child soldiers and many war-affected children have few work or employable skills, and are caught in a vicious cycle of poverty and exploitation, unless provided with appropriate means of livelihood. Without any opportunities of a better life, this group is the potential source of recruitment into militias if there are rumours of another war, raising serious potential threats to peace and security.

\section{2c. Using Natural Resources Sustainably and Managing Disaster Risks Effectively}

In a country where more than 80 percent of the population relies on the natural resource base to meet daily needs, widespread environmental degradation poses an immense threat to livelihoods and poverty reduction. Particularly affected are the poor, women-headed households, and households of the landless or near-landless, many of whose rights are thus unfulfilled.

On the part of communities, there is a lack of awareness of sound environmental practices, which needs to be addressed at the same time with improving their livelihoods and economic conditions. Communities must become owners of their natural resource base and feel that they actively participate in national economic growth. Otherwise, poverty and environmental damage can be caught in a downward spiral - i.e., past resource degradation deepens today's poverty, while today's poverty makes it very hard to care for or restore the vitality and the carrying capacity of ecosystems. When this self-reinforcing downward spiral reaches it limit, poor people are forced to move in increasing numbers to other ecologically fragile lands of the country.

At the same time, Afghanistan is prone to natural disasters, including drought, earthquake, sandstorms and extremely harsh winters, all of which have a devastating effect particularly on the poor. Between 1970 and 1998 alone, Afghanistan experienced 57 large-scale natural disasters, with the total number of persons killed as a result estimated at 19,630 and the number of persons affected estimated at 3,361,178. ${ }^{94}$ Natural disaster management and emergency preparedness must be strengthened to respond to the onset of these crises.

Based on analysis, four key challenges have been identified as underlying causes that prevent fulfilment of the right to a clean and healthy environment. These include:

- Competing land usage (agriculture, human settlements, forests/rangeland, wetlands)

- Lack of enabling policy, legislative and regulatory frameworks, along with ambiguous legal status of ownership and access to natural resources

- Limited capacity of the Government to prepare for and mitigate natural disasters

- Negative impact from war, drought, increasing population, human settlements, overexploitation and landmines

\section{Competing land usage}

Affecting water resources and land alike is a historic failure to acknowledge common property, as well as the destruction of such property [see also Peace, Security and

94 Citation of UNDP (2001) Disaster Profiles of the Least Developed Countries, in Securing Afghanistan's Future op.cis. Livelhoods and Social Protection, Technical Annex, p. 97.

95 Human Security and Livelhoods of Rural Afghans 2002-2003, op.cit., p. 141
Justice]. Water resources are additionally threatened by contamination from waste dumps, chemicals and open sewers. Many wetlands have dried up and no longer support wildlife or agriculture. Meanwhile, unsustainable grazing and livestock practices, combined with drought, have left the country lacking adequate pastureland or vegetation to sustain large livestock herds. ${ }^{95}$ In urban centres, poor waste management practices and lack of proper sanitation are the main environmental factors affecting human health. Dust from frequent and worsening storms, along with vehicle emissions, represent the primary causes of air 


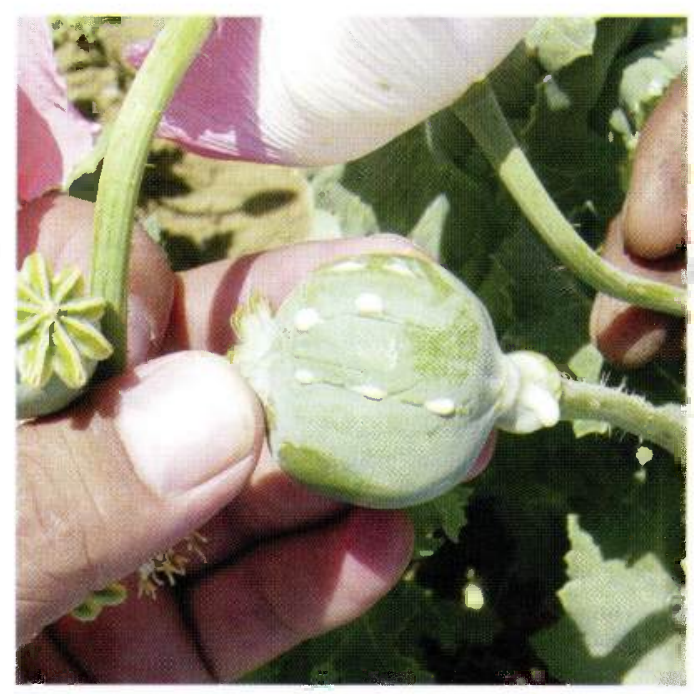

pollution. This is compounded in the cold sêson by usage of stoves and open fires and by toxic fumes from the burning of plastic and tires due to shorages of firewood and electricity.

\section{Lack of enabling policy, legislative and regulatory frameworks/ambiguous legal status}

The absence of strong environmental regulations and a clear natural resource management policy means that no clear guidelines exist for how other sector should take account of the environment as they develop; this can lead to potential serious impacts in the future. Afghanistan has a unique opportunity to make the principles of sustainability the base for its economic development. At the same time, while the Constitution declares that the state owns all resources in their natural state, it is unclear whether a private party may legally explore and exploit such non-renewable resources. ${ }^{96}$ Overall, a particular challenge also exists in the need to develop sound information programmes and monitoring systems that would allow the Government to establish a link between the quality of health and environmental conditions.

\section{Limited capacity of the Government to prepare for and mitigate natural disasters}

Natural disasters such as drought constrain people's livelihoods, including their ability to be food-sufficient and to access safe drinking water, which has a large effect on their health status. While natural disasters affect the population at large, they have more devastating effects on the poorest categories, mostly those in rural areas. Women, children and the landless tend to be most affected in Afghanistan.

\section{Negative impact from war, drought, increasing population, human settlements, over- exploitation and landmines}

Water is key to the health and well-being of the people and essential to maintain agricultural productivity. However, both surface and groundwater resources have been severely affected by drought as well as uncoordinated, unmanaged extraction; worsening water quality is among the most pressing issues facing rural Afghans. In addition, many rural dwellers have reported decreased water levels since 2002 despite an end to the drought in some areas. Restoring vegetation cover to the country is key both to preserve and build up water reservoirs and to fight drought and many of its detrimental effects.

\section{What Does Success Depend On?}

The challenge for Afghanistan is to turn the recent economic recovery into sustained growth, poverty reduction and social progress over the medium term. The past two years of economic successes thus should not lead to an underestimation of the challenges ahead. Given this strategic analysis, it appears difficult to create the necessary environment to achieve progress toward the MDGs, Millennium Declaration targets and rights of survival, livelihood, protection and participation.

96 Taking the mining sector as an example, many small-scale, nonregistered mines exist and trade in illegally exploited minerals. It also appears that the Government does not collect any taxes or royalties on these resources. Trafficking in emeralds from the Panjshir valley alone brings in an estimated US\$3 million annually.
The United Nations System will fully support appropriate national policies and priorities on economic development and growth, including:

- Support to creation of an enabling environment, including regulatory frameworks for private investments and policies for rebuilding and privatising state-owned enterprises

- Support to improved land tenure security and clarified land tenure norms, which will 
enhance future growth in agricultural development. This will include support to constructing an explicit, comprehensive strategic commitment to recognising and addressing land ownership matters [see also Social Well-Being]. "Bottom-up" resolution of land ownership issues at local and community levels will be promoted

- Support to development and implementation of sound policies that manage and reduce the likelihood of physical, social and economic "shocks" from natural disasters. Integration of preparedness mechanisms that help reduce their negative impact, particularly on the most vulnerable, is required 97

- Support to market access/information, as well as investments and institution strengthening in agricultural extension and technology, irrigation systems and rural finance

- Support to establishment of a credit and financial services sector that will assist medium-size enterprises, so that the economy can meaningfully provide employment

- Support to increasing the level and growth of rural incomes from sources other than poppy cultivation, thereby raising its opportunity costs [see also Peace, Security and Justice]

- Support to regulation of ownership of, and access to, natural resources, as well as support to enactment of a framework for natural resource management. Support to implementation of a National Environmental Action Plan

The ongoing Priority Reform and Restructuring exercise of the Government presents an initial opportunity to improve the administrative efficiency of Ministries and departments, which will have significant implications in allowing the Government to improve its capacity to implement economic development programmes. Similarly, economic development can only occur in an environment in which the rule of law is a cornerstone. Strengthening the capacity of institutions such as the judiciary, as well as enhancing access to such mechanisms and institutions, will invariably encourage economic development. Ensuring transparency in the use of state revenues also will be important. Finally, strengthening reform initiatives will clarify the relationships between the private and public sector necessary to fulfil the rights and improve the lives of Afghans and achieve the MDGs. 


\section{International Context and Commitments}

\section{Right to decent work}

- International Covenant on Economic, Social and Cultural Rights

- Convention on the Elimination of All Forms of Discrimination Against Women and its Optional Protocol

- Convention on the Rights of the Child and its Optional Protocol on the Sale of Children, Child Prostitution and Child Pornography, and the Involvement of Children in Armed Conflict

- Slavery Convention and Protocol Amending the Slavery Convention, and the Supplementary Convention on the Abolition of Slavery, the Slave Trade, and Institutions and Practices Similar to Slavery

- Convention Against Torture and Other Cruel, Inhuman or Degrading Treatment or Punishment

- Convention on the Suppression of Traffic in Persons and of the Exploitation of the Prostitution of Others

- Labour instruments including the Conventions on Abolition of Forced Labour; Discrimination; ILO Convention 182 on Worst Forms of Child Labour and ILO Convention 138, Concerning the Minimum Age for Admission to Employment; Equal Remuneration; Night Work (Women) and Night Work (Women) revised; White Lead (Painting); Weekly Rest (Industry) and Weekly Rest (Commerce and Offices); Underground Work (Women); Protection of Wages; Dock Work; Occupational Cancer; Paid Educational Leave; Rural Workers' Organisations, and Human Resources Development

\section{Land rights}

- International Covenant on Economic, Social and Cultural Rights

- International Covenant on Civil and Political Rights

- Universal Declaration on Human Rights; importantly for the Afghanistan context, the Declaration also recognises the right to security of property in the event of widowhood

- Convention on the Elimination of All Forms of Discrimination Against Women

The Constitution recognises the right of every individual to the peaceful enjoyment of his or her property or possessions.

\section{Environment}

- Convention on Biological Diversity

- Convention on Desertification

- Framework Convention on Climate Change

- Agenda 21

Connecting the MDGs with the right to decent work and the right to a clean and healthy environment implies, by 2015 , halving the proportion of people whose income is less than US\$1 a day (Target 1); eliminating gender disparity in primary and secondary education by 2005 and at all levels of education by 2015 (Target 4), in order to promote gender equality and empower women; halving and beginning to reverse the spread of HIV/AIDS (Target 7); integrating the principles of sustainable development into country policies and programmes and reversing issues of environmental resources (Target 9); halving the proportion of people without sustainable access to safe drinking water (Target 10); and achieving a significant improvement in the lives of slum dwellers (Target 11).

\section{Significant Data Gaps}

- Only one study on employment, the IRC's Labour Market Information Survey

- Little information on the size of the informal economy, including its composition, nature, constraints and the role of women. Much information about the informal work sector is obtained through individual informants, discussions and consultations with members of vulnerable groups, along with ad hoc observations. A clear need for comprehensive, wideranging and well-conceived research exists, in order to adequately plan policy and programme development

- Little understanding of market linkages between the informal economy and formal economy ("value chain"); the diversity of livelihoods, especially in rural areas; and of more vulnerable groups within the informal economy, including returnees/ IDPs, people with disabilities, widows and children

- Lack of reliable statistics on several critical sectors, such as environment and mining

- A critical gap in understanding the level, volatility and flow of remittances into Afghanistan, given that many households are reluctant to report regular cash flows or savings 
4

Social Well-Being 


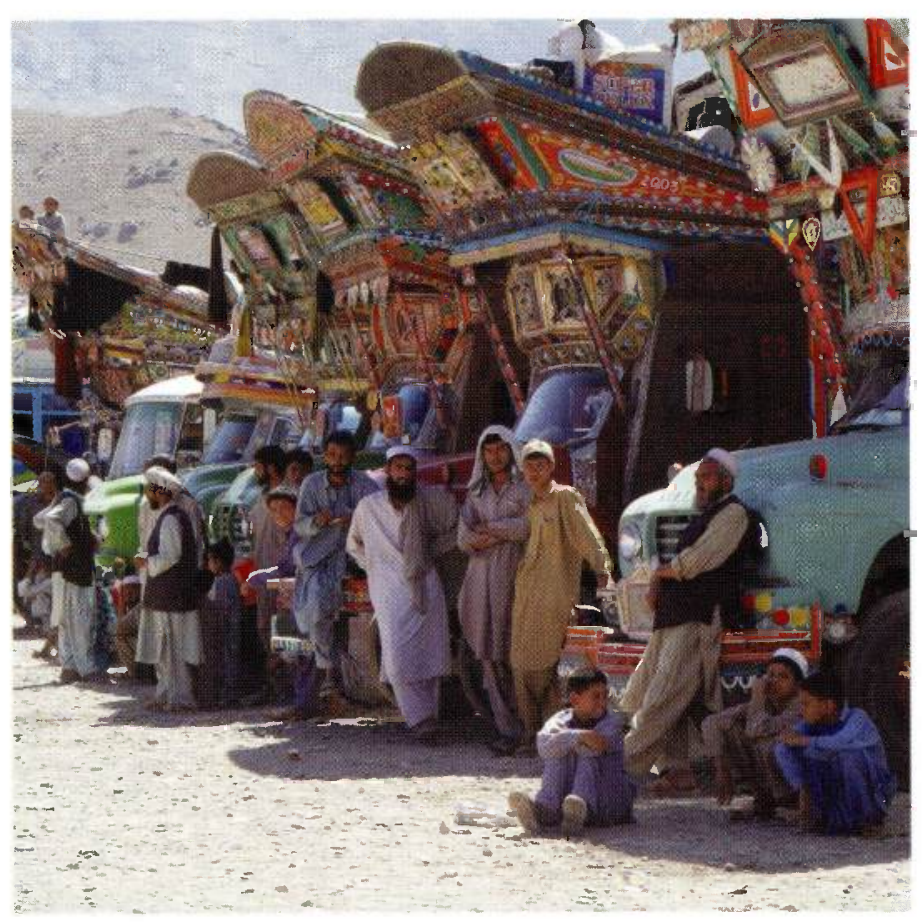

\section{The Situation in Afghanistan}

Afghanistan's social indicators, which were low even before the 1979 Soviet invasion, rank at or near the bottom among developing countries, inhibiting poverty reduction and preventing the fulfilment of rights to health, education, food and shelter. In the almost three years that have passed since the fall of the Taliban, important progress has been made in all sectors, but much remains to be done in order to reach a significantly strengthened social infrastructure, realise the rights to survival, livelihood, protection and participation, and achieve the MDGs [see also Introduction, Who Are the Poor in Afghanistan?]. In addition, the earlier devastation has been compounded by the severe drought that is still ongoing in many areas [see also Economic Development and Growth]. Overall, it should be noted that demand-based approaches are critical to meet social well-being and that local institutions such as Community Development Councils are key to success in this regard.

With an estimated Total Fertility Rate of 6.26 per woman and an average population growth rate of 2.5 percent per year, the population of Afghanistan is increasing very rapidly; 57 percent of Afghans are younger than 18. Average life expectancy, however, stands only at 44.5 years ${ }^{98}$ - as much as 20 years less than the regional average for South Asian countries. The high fertility rate, combined with early marriage ${ }^{99}$ and lack of access to modern family planning measures and health facilities, has taken a devastating toll on the health of both mothers and children.

98 Statistical Yearbook of Afghanistan 2003.

99 A 2004 study by the Ministry of Women's Affairs and women's NGOs estimated that 57 percent of girls marry before age 16. 


\section{National Policies and Priorities}

\section{Education}

- The Government's vision is to ensure that all children complete compulsory education (9 years) and have opportunities to continue to higher levels. To achieve this, the Government will, through the Education Public Investment Programme (PIP), expand access to and raise the quality of primary and secondary education country-wide and will build a higher education system that responds to Afghanistan's reconstruction needs, creates new professional and income opportunities, and meets international standards. The Government also intends to expand citizens' access to vocational and informal education, with specific focus on improving livelihoods opportunities for vulnerable populations such as widows, people with disabilities, returnees/IDPs, demobilised soldiers and unemployed youth. Progress will be underpinned by substantial changes in the governance and management of the education and higher education sectors. Through the PIP, the state also wants to lay the basis for achieving the MDG for primary education.

\section{Health}

- The Basic Package of Health Services (BPHS) aims at reducing morbidity and mortality and contains seven essential elements for the delivery of basic health care services: maternal and newborn health, child health and immunisation, nutrition, communicable diseases, supply of essential drugs, mental health and disability. The BPHS currently covers 40 percent of the population, with 95 percent coverage to be reached by 2015 , also the deadline for achievement of the MDGs.

\section{Food}

- The Livelihoods and Social Protection Public Investment Programme, through its six sub-programmes, envisages enhancing human security and promoting poverty reduction. It aims to empower and support the poorest and most vulnerable, thereby helping individuals, households and communities better manage risks. This strategy, which encompasses both promoting sustainable livelihood strategies and directly providing assistance to those unable to help themselves, is ultimately expected to have a positive effect on food security.

- Basic Package of Health Services [see under Health above].

\section{Water}

- In the Five-Year Development Plan for Rural Water Supply and Sanitation Sector (2004-2008), the Government plans to expand the enabling environment for health and hygiene for more than 15 million people through the provision of 100,000 safe drinking water points and 1 million family latrines. Health and hygiene awareness and promotion messages are intended to reach 2.5 million households. 
Population Distribution by Age Source: MICS 2003 Male

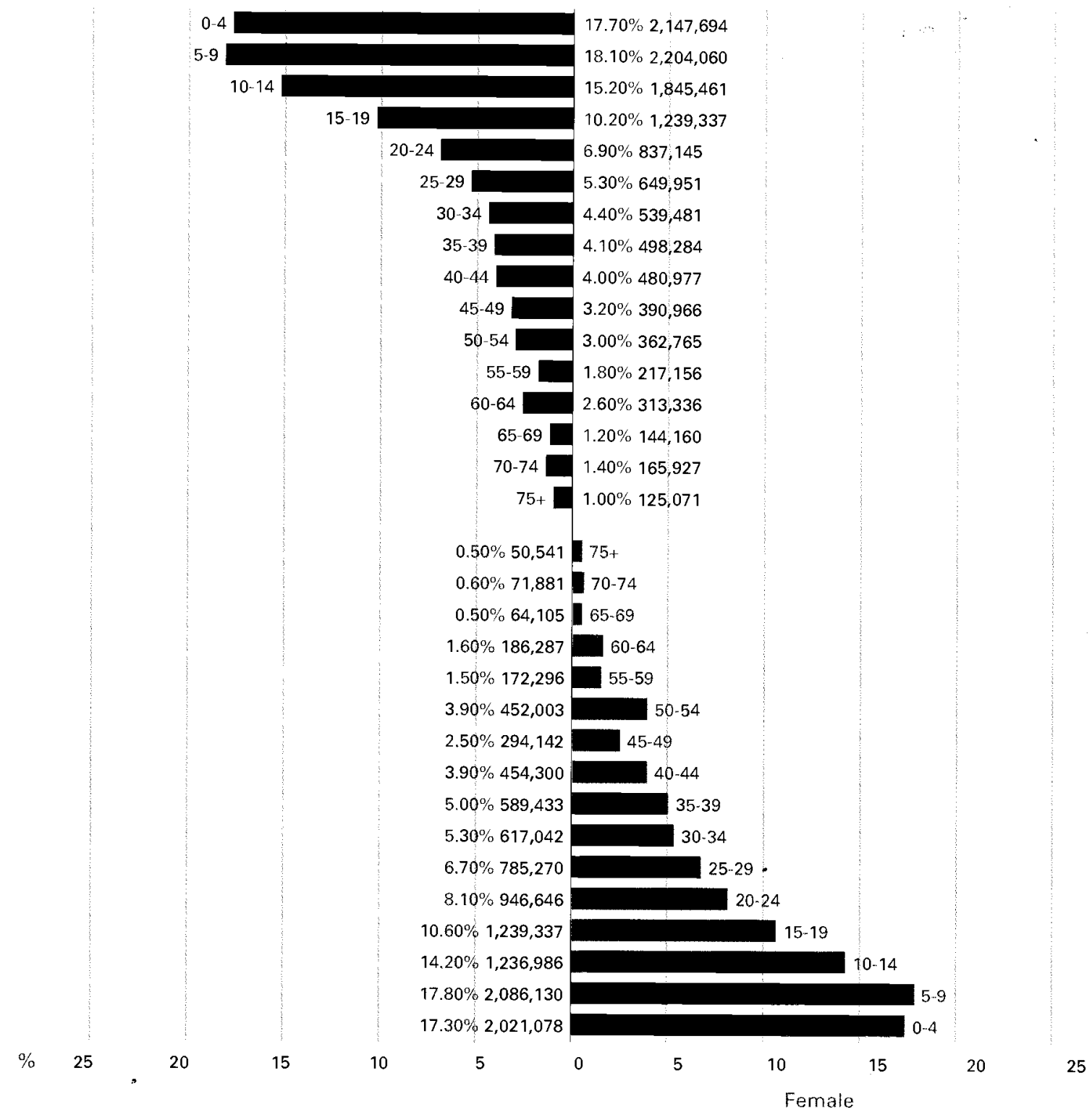

Indeed, health conditions for women in Afghanistan appear among the worst in the world, and women's health has reached a critical stage. Access to health care for Afghan women dropped precipitously under the Taliban and remains extremely limited, in large part because of a lack of female health workers. Nine in 10 rural women deliver babies at home, without skilled birth assistance or proper referral services to save lives through essential and emergency obstetric care. This results in a very high mortality rate of 1,600 maternal deaths per 100,000 live births - including a rate of 6,500 in the province of Badakhshan, the highest ever reported globally. Among Afghan women of childbearing age who die, almost half will succumb from complications of pregnancy; again, the rate in Badakhshan (64 percent) is the highest proportion in the world. ${ }^{100}$ 


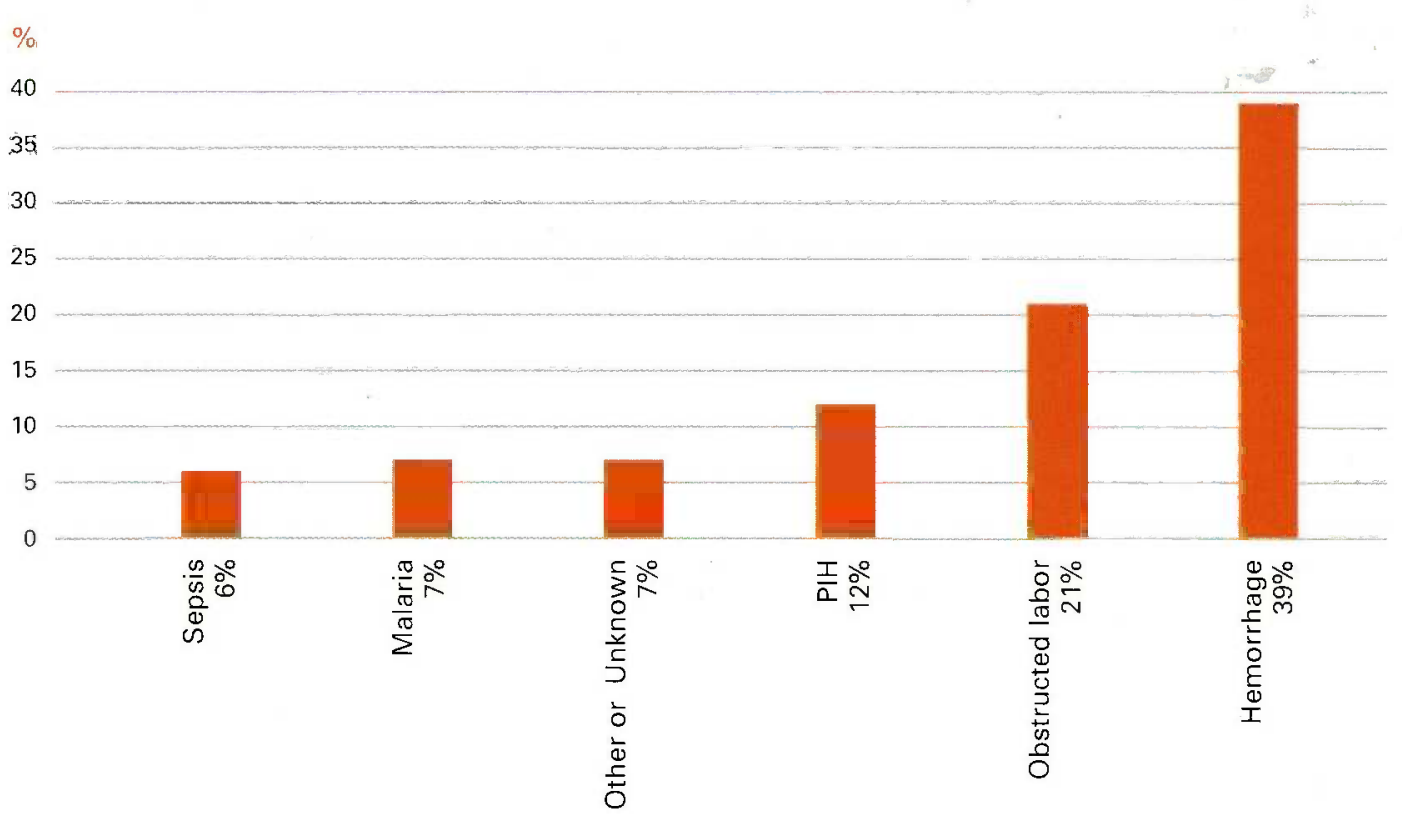

Infant mortality stands at 115 deaths per 1,000 live births, while the under- 5 child mortality rate is 172 per 1,000 live births - both also among the world's highest. ${ }^{101}$ Major causes of morbidity and mortality among children include measles, diarrhoea, acute respiratory infection, malaria, micronutrient deficiencies and intestinal parasites.

\section{Infant and U-5 Mortality Rate: Deaths per 1,000 live births.}

101 Afghanistan - Progress of 、 Provinces: Multiple Indicator Cluster Survey 2003, op.cit., p. 102.

102 Ibid, p. 176.

103 In both urban and rural areas, groundwater is the main water supply source. In some parts of the country, including the north and northeast, groundwater conditions are unfavourable as a result of the deep water table and high levels of salinity and nitrates.

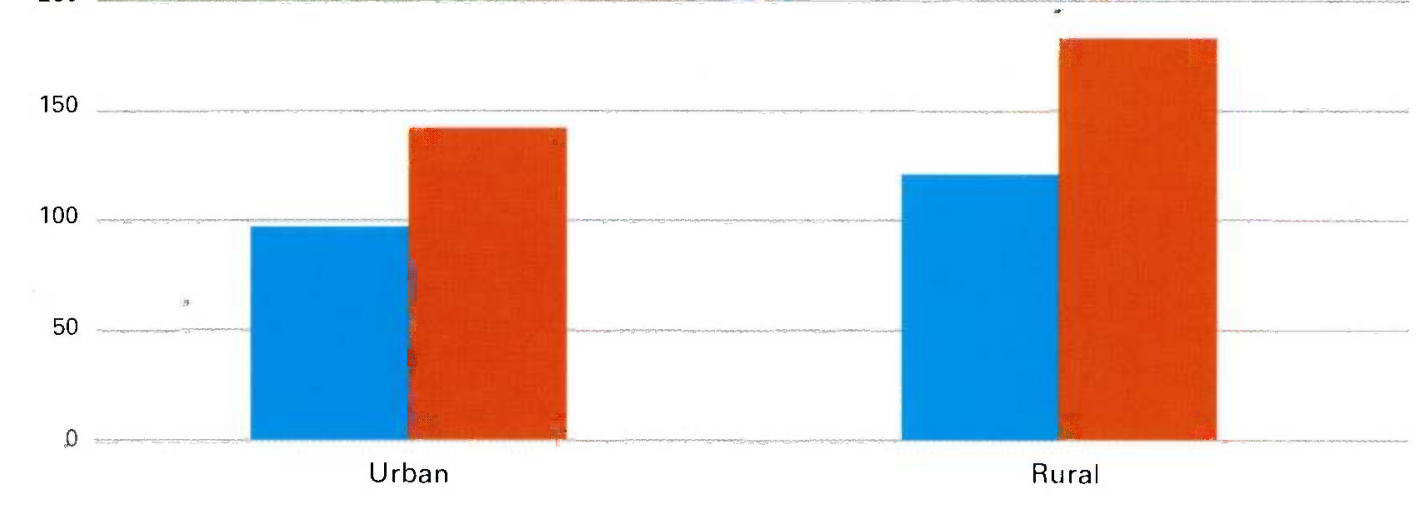

Food insecurity is severe across the country, and chronic malnutrition, resulting from food insecurity, inadequate caring practices and inadequate health and sanitation environments, is disturbingly high. Between 40 and 60 percent of Afghan children are stunted or chronically malnourished. In addition, essential nutrients and minerals from sources of food other than wheat are not part of the average Afghan diet, which has resulted in widespread micronutrient deficiency disorders such as goitre, anaemia and night blindness. About 39 percent of urban households and nearly 69 percent of rural communities do not have access to safe water, with considerable regional disparities. ${ }^{102}$ Sanitary means of excreta disposal likewise are scarce. ${ }^{103}$

Meanwhile, providing quality education is a critical foundation for sustainable poverty alleviation and economic growth in Afghanistan. Since the fall of the Taliban, reconstruction of the educational system has been based on providing emergency needs; as such, 
rebuilding of infrastructure has been a priority. Now, an increasing focus is being given to much-needed institutional development and capacity building, including development of administrative and management systems and financial processes at both national and subnational levels. Despite the considerable success of a 2003 back-to-school calmpaign, girls' non-enrolment in rural area is almost 70 percent, and there continues to be a large gender disparity in net enrolment across the provinces. In nine provinces, the non-enrolment percentage rises to more than 80 percent, and to a stunning 99 percent in the provinces of Badghis and Zabul. ${ }^{104}$ The low educational status not only hampers the degree to which the country can rely on its own human resources for reconstruction and development, but also the degree to which morbidity and mortality can be prevented through awareness.

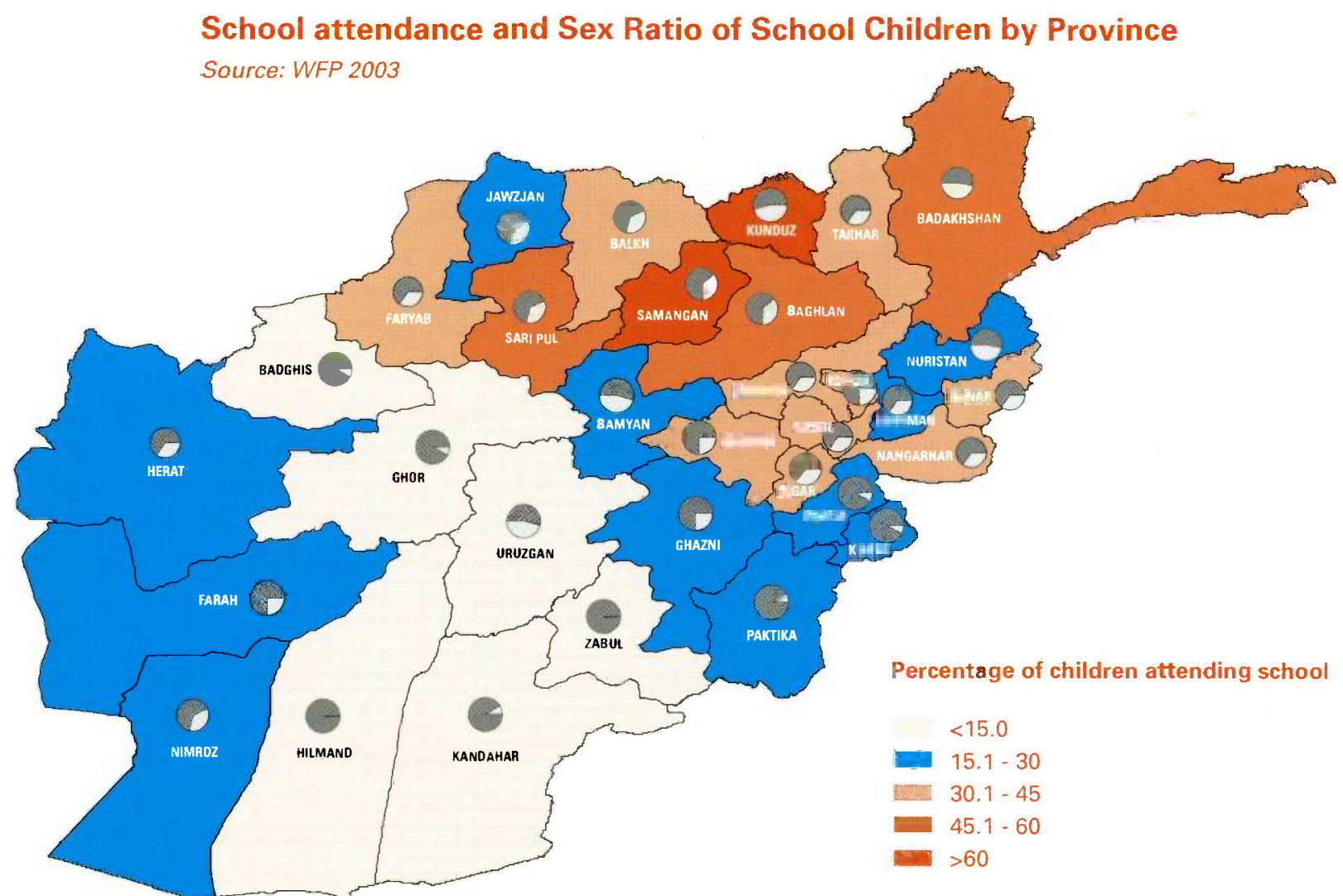

Sex of school children in percent

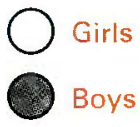

The long years of conflict and chronic under-investment have had a severe impact on the urban housing stock and physical infrastructure, resulting in about 50 percent of total housing units being located in unplanned areas and 26 percent of all units being seriously damaged or destroyed. While a number of rehabilitation and urban governance initiatives are under way, more resources and capacity are required in urban planning, shelter reconstruction, provision of basic social infrastructure, and municipal capacity building and policy advice.

Finally, a serious lack of social protection exists for extremely vulnerable groups [see also Peace, Security and Justice and Economic Development and Growth]. This includes widows, women-headed households, IDPs, children without parental care, people with disabilities, former child soldiers and others. In particular, there exists an imperative to respond to the social and psychosocial needs of children, few of whom have been unscarred by extremes of violence and poverty and many of whom have experienced the

104 Afganistan - Progress of Provinces: Multiple Indicator Cluster Survey 2003, op.cit., p.66. 
105 Compulsory basic education in Afghanistan now comprises the primary (grades 1-6) and middle school levels (grades 7 9) while secondary education covers grades 10-12. The Ministry of Education thus no longer differentiates between primary and middle education. Until now, indicators referring to primary education were calculated for grades 1-6; in the future, the Ministry is likely to calculate secondary enrolment rates, for instance, for grades 10 12. This means that for internationally comparative, sequential and diachronic analysis, there is a need to recalculate "old" statistics for grades 10-12 only, or to incorporate grades $7-9$ in "new" data. Likewise, primary education indicators will need to be recalculated as well trauma of seeing family members killed. State-provided social protection services are very limited, and further strengthening is needed to enable them to be technically adequate, well-managed and well-targeted. Strengthening also is required among service users to ensure adequate utilisation of available services and appropriate service-seeking behaviour.

\section{Analysis of Key Issues and Underlying and Root Causes}

Poor quality and limited access to basic services, especially among rural families, women, returnees/IDPs and other vulnerable groups, are crosscutting areas of analysis in this section. The CCA analysis is synchronised with national priorities [see National Policies and Priorities box], and the United Nations System is supportive of Government efforts toward social well-being, particularly the Basic Package of Health Services, the Education Public Investment Plan, the Livelihood and Social Protection Public Investment Plan, the Priority Reform and Restructuring Programme, and the Rural Water and Sanitation Programme 2004-2008. Key issues related to social well-being include:

- Availability of/access to quality education

- Availability of/access to quality health care

- Availability of/access to food

Many factors - deteriorating quality of education, increased risks of disease and infection, outdated management styles, inadequate dietary intake, lack of potable water and sanitation facilities, and poor family and community knowledge, skills and practices, among others - contribute to the low level of social well-being affecting Afghanistan today. While those listed in the sections below are more related to specific thematic areas, some permeate and affect all aspects of people's daily lives.

Duty bearers that hold an obligation to fulfil these entitlements are primarily State actors and institutions at various levels of the governance structure, as well as non-State actors - including parents, teachers, community leaders and others in civil society - that can influence the rights of others. The root causes for the above challenges in Afghanistan, which are interlinked, can be traced to:

- An underdeveloped human rights culture, along with lack of traditions of democracy, state-building and civil society participation

- Wide variations in socio-economic indicators, by gender, region and rural-urban divide

- Weakened social infrastructure

- Socio-cultural traditions that result in widespread marginalisation based on gender, social status or ethnicity

- Young governance structures still in the process of establishment and/or early stages of development, and unable to curb political insecurity

- Shortage of human resources that can propel social reforms, especially for women and girls

- Culture of unsustainable resource use that must be reversed

\section{2a. The Right to Education}

With its full endorsement of the Millennium Declaration in March 2004, Afghanistan has committed to meet the second and third MDGs, which are to achieve universal primary education ${ }^{105}$ and gender equity at all levels by 2015. The World Fit for Children target of gender parity in education by 2005 also serves as an impetus to realisation of the MDG commitment. However, regional comparisons of primary school completion rates and progress toward the MDG goal showed Afghanistan to be the only country out of 16 ranked 
as "seriously off track," 106 in large part as a consequence of past Taliban edicts that seriously reduced school enrolment for boys and eliminated it for girls. ${ }^{107}$

A large proportion of people aged between 8 and 33, particularly women and girls, thus have been deprived of basic education as a consequence of war, civil unrest and dislocation. Even before the Soviet invasion, many people were not able to undertake basic education. In 2003, male literacy stood at 43.2 percent and female literacy at only 14.1 percent, with barely 8 percent of rural women literate - one of the lowest rates in the world. ${ }^{108}$

\section{Adult Illiteracy Rate Source: MICS 2003}

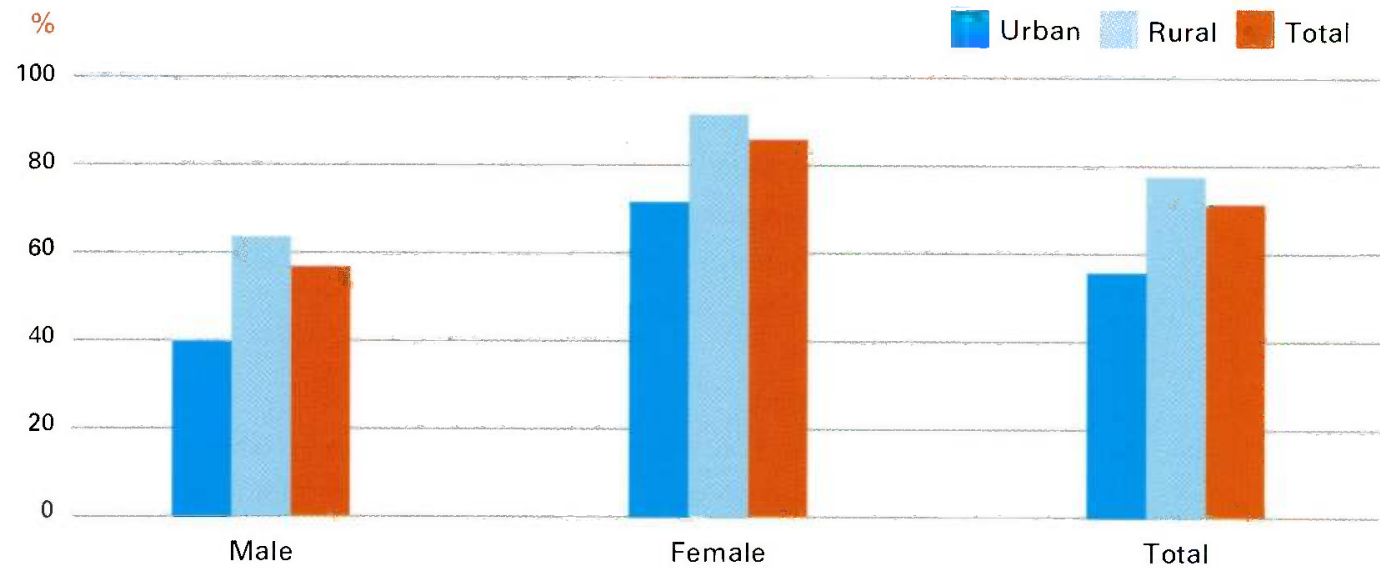

Teacher numbers have increased to more than 100,000, of whom about 1 in 4 are women, although qualifications vary from university degree holders to primary school graduates. In addition to wide gender disparity, ${ }^{109}$ a sharp disparity in school enrolment between urban and rural areas is observed, in large part as a consequence of the historical lag in expanding education to rural areas. While the net enrolment ratio in Kabul Province was 76 percent in 2003, the ratio in Uruzgan was only 19 percent.

106 Bruns et al., Achieving Universal Primary Education by 2015: A Chance for Every Child, Report Published by The World Bank, August 2003.

p. 180 , Table B. 13 .

107 In 1990 the gross primary enrolment ratio for boys was 35 percent and for girls 19 percent. By 1995 , the ratios had risen to 63 percent for boys and 32 percent for girls, but by 1999 , under the Taliban, they again had declined to $40-60$ percent and 3-6 percent respectively (Education For All 2000 Assessment for Afghanistan; UNESCO, UNDP, UNICEF, UNHCR, SC-US and SCA). Following the back-to-school campaign in 2003 , school enrolment increased to more than 4 million students, with net enrolment rèaching 40 percent ' for girls and 67 percent for boys.

108 Afghanistan - Progress of Provinces: Multiple Indicator Cluster Survey 2003, op.cit., p. 64

$109 \mathrm{Girl} /$ boys ratio in primary education in 2003 was $1: 2$ both in rural and urban areas [Afghanistan - Progress of Provinces: Multiple Indicator Cluster Survey 2003, op.cit., p.66].

\section{Percentage of children 7-12 Years Not Enrolled in School in 2003}

\section{Source: MICS 2003}

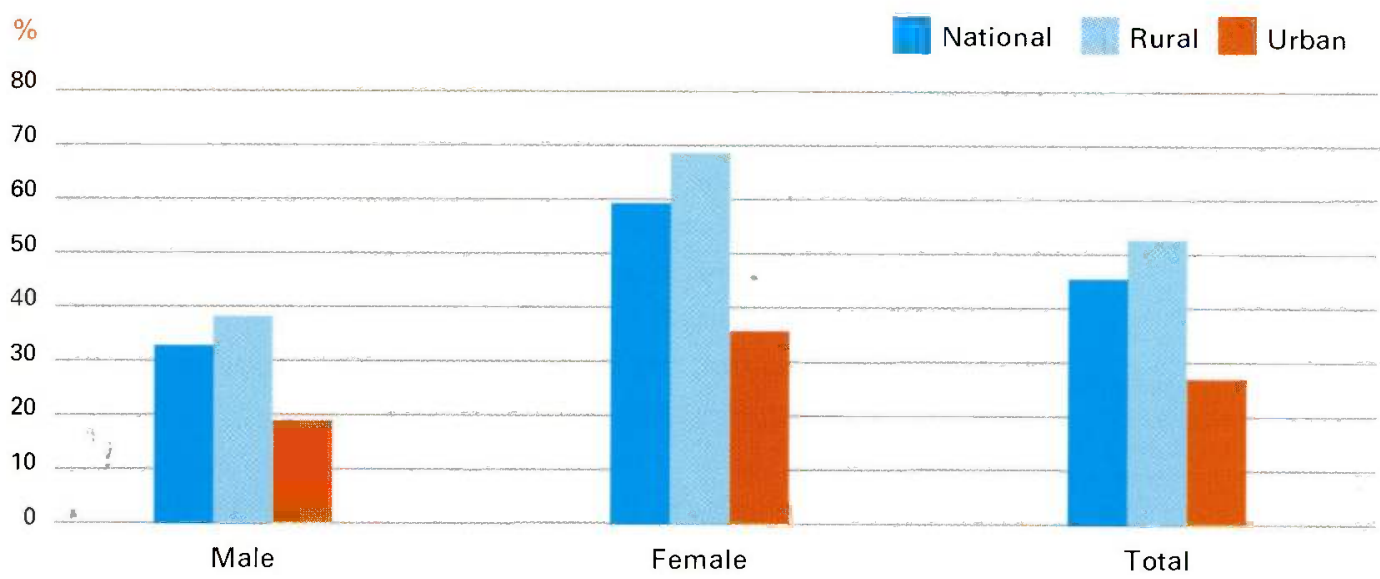


Beginning in 2005, higher proportions of both recurrent and capital public spending may begin to shift the emphasis toward upper basic compulsory education (grades 7-9) and secondary education; the focus will be on curriculum development, teacher training, equipment and infrastructure. Secondary schooling will be an increasing priority in shaping Afghanistan's educated workforce. A large amount of funding, logistical and technical expertise nevertheless is needed for primary education and literacy, which will become more expensive as enrolment increases. ${ }^{110}$

Based on analysis, four key challenges have been identified as underlying causes for availability issues, while three further challenges related to access also constrain the right to education and the achievement of the MDGs. These include:

- Poor institutional capacity to plan and manage education programmes

- Poor quality of education and outdated curriculum

- Shortage of adequate learning spaces and essential teaching-learning materials

- Shortage of qualified teachers, particularly women, and lack of training

- Consequences of diminished livelihoods

- Consequences of socio-cultural traditions

- Limited community involvement

\section{Availability}

\section{Poor institutional capacity to plan and manage education programmes}

Education officials at the national, provincial and district levels have limited management capacity, particularly to cope with the increasing number of externally funded projects and the consequent need for efficient management of contracts and large-scale education development projects. Review of policy issues related to education, along with aid coordination, remain major challenges. An education database with updated figures also is lacking. As a result, project planning and management to promote girls' education in particular is seriously constrained. In addition to the planning and management capacity, the current education system does not have a well-established educational administrative structure with clear, unambiguous rules and regulations. This lack, as well the unfamiliarity of educational administrators at central and provincial levels with rules and regulations, further weakens management capacity. Some rules and regulations also are applied without public consultations, which may lead to an issue of democratic governance in the formal education system.

\section{Poor quality of education and outdated curriculum}

In general, the quality of education is affected not only by teacher qualifications and experience, but also by curriculum, textbook quality and availability, status of infrastructure, the student-teacher ratio and class time. All current academic curricula are heavily outdated. However, revised textbooks for Grades 1 and 4 have been developed and are being field-tested, and the full introduction of a new curriculum is expected to take place in 2005, provided funding for printing is secured. Meanwhile, the student-teacher ratio

110 While higher education students numbered only 4,000 in 2001, they had increased substantially to 31,000 by the end of 2003 [Securing Afghanistan's Future, op.cit., Education. Technical Annex, p.9]. Even so, less than 2 percent of the population is involved in higher education, one of the lowest rates globally.

111 Situational Analysis, Teacher Education and Professional Development in Afghanistan, AREU, not yet published. in Afghanistan has enormous provincial variations, with the worst figures being 185:1 in Kandahar and 120:1 in Kabul city. ${ }^{111}$

At the same time, the curriculum reforms under way have created some tension because of limited transparency and unclear policies on how to address the integration of religious studies. Support must be given to ensure that the madrasa curriculum is fully aligned with the concepts of conflict resolution and coexistence.

Tertiary education is biased toward law and engineering and does not offer the skills needed for reconstruction and economic development. Likewise, vocational, technical and non-formal education must meet reconstruction needs, while educating those who 


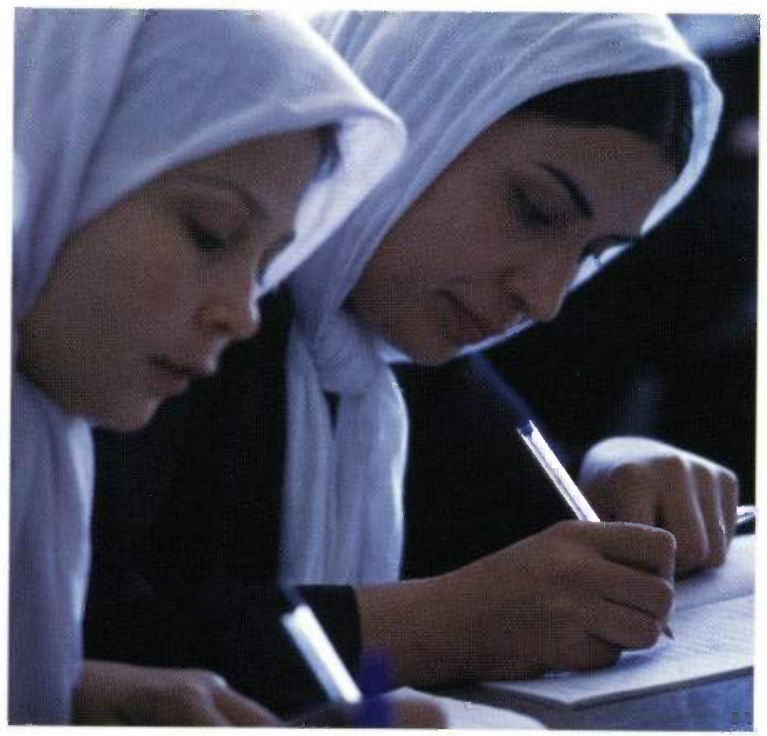

have missed out on formaleducation. Numerous organisations and institutions are providing vocational and skills training, but no uniformity or coordination exists in duration, cost and substance. Market feasibility and phase-out strategies are missing, and immediate participation incentives often substitute for longer-term income-generating objectives of participants. Vocational training for women in particular lacks creativity and focuses on traditional roles such as tailoring, doing little to provide a sustainable means of income.

Lastly, years of war, repeated displacement and drought have constrained the extended family network and community system through which Afghan children have pursued early childhood development and socialisation. Today 238 kindergartens operate, accommodating 25,400 children, according to the Ministry of Labour and Social Affairs. Methods and activities are outdated, however, focusing in most instances on cognitive development of the child. No early childhood activities were funded through the National Development Budget for 1383 [2004-2005].

\section{Shortage of adequate learning spaces and essential teaching-learning materials} In 2003, there were 7,029 schools (4,783 formal schools recognised by the Ministry of Education), of which only 48 percent and 25 percent respectively had water and sanitation facilities. ${ }^{112}$ Many students were simply crowded under tents or in the open air. Since $2002,1,753$ schools have been rehabilitated or constructed, ${ }^{113}$ yet it is estimated that 5,574 schools still need to be built over the next three years. ${ }^{114}$ In many rural areas no learning facilities exist at all and, because of socio-cultural and security reasons, girls are not allowed to walk with boys, or unaccompanied, or to travel long distances to attend schools. Most parents also are not in a position to provide teaching-learning materials for their children; many children, especially girls, drop out of school because of this lack.

The quality of learning facilities is particularly low in tertiary institutions, with ill-equipped laboratories, if any, and extremely limited access to libraries. A total of 17 higher education institutions are functioning, but construction or rehabilitation of universities is critical. Although several private institutions run by NGOs offer access for students with disabilities, few public educational institutions, other than those constructed since 2002, have such access.

\section{Shortage of qualified teachers, particularly women, and lack of training} In most parts of the country, girls still cannot be taught by male teachers, particularly once they reach adolescence. With at most 25 percent of teachers being female, this represents

112 Rapid Assessment of Learning Space, UNICEF 2002.

113 See website of Ministry of Education ("Achievements"), http://www.moe.gov.af/ achievements.asp

${ }^{114}$ Ministry of Education submission to the 1383 National Development Budget

115 Rapid Assessment of Learning Space, op.cit.

116 Survey Results from the Rural Education Support Programme in Baghlan, AKDN 2004. a serious constraint to girls' right to education. In addition, more than 3 in 4 teachers have no formal teacher training, ${ }^{115}$ and some have no formal education at all. ${ }^{116}$ An additional 40,000 ieachers are required to fulfil requirements as of early 2004 ; as enrolment increases, this figure also will increase. Teachers, like other civil servants, are inadequately and irregularly paid, if paid at all [see also Governance and Institutional Development]. This results in their working for supplementary incomes - likely negatively affecting teachers' attendance as well as quality of performance - and in qualified personnel choosing higherpaid careers outside of teaching. 


\section{Access}

\section{Consequences of diminished livelihoods}

Parents cannot send their children to school because they cannot afford to do so, given that the actual and opportunity costs are too high for their meagre incomes. Girls are required at home to perform domestic work, while boys are sent out to earn additional money.

\section{Consequences of socio-cultural traditions}

In large parts of Afghanistan, preference and high value is attached only to boys' education. The link between girls' education and reduced fertility/child mortality, higher economic productivity and increased well-being for the family is not recognised. ${ }^{117}$ Insufficient schools for girls still exist. As girls progress through adolescence, the chances for their continued education are reduced even further because of the prevalence of male teachers. In particular, security plays an important role in ensuring girls' continued access to education - dozens of girls' schools have been attacked or burned since 2002, allegedly by the Taliban or local military factions. ${ }^{118}$ In addition, access to schools for children with disabilities remains an unmet need, not only with regard to physical access but also in terms of having parents accept the child as capable of being educated.

\section{Limited community involvement}

Education is highly valued in general, but its improvement is often seen as the Government's responsibility. After 23 years of conflict, families are first and foremost concerned with rebuilding their own homes and reconstructing their lives. The role of the teacher in the community is poorly understood, and teachers may not feel a responsibility toward children or adolescents not attending their school. ${ }^{119}$ More structured Government approaches to community and parental participation are under way as part of reconstruction.

117 The main reasons for girls' non-enrolment include "education not necessary"; schools too far away; inadequate facilities: no school separate from boys; child needed for work; and teachers gender. (Afghanistan - Progress of Provinces: Multiple Indicator Cluster Survey 2003 , op.cit., pp. 68-69.)

118 Between Hope and Fear: Intimidation and Atacks Against Women in Public Life in Afghanistan, op.cit., p. 7.

119 Situational Analysis: Teacher Education and Professional Development in Afghanistan, op.cit.

120 Matemal Mortality in Afghanistan: Magnitude, Causes, Risk Factors and Preventability, Summary Findings, Centres for Disease Control/UNICEF, 6 November 2002, p. 4.

121 No information exists about any specific adolescent reproductive health programmes in the country, although the Government has identified the needs of this vulnerable group USman: Afghanistan Country Profile: Reproductive Health 2002 , p.61.

122 Sexually transmitted and reproductive tract infections are believed to be relatively high among poor women without access to clinical care UUsmani. op.cit, p.6

\section{2b. The Right to Health}

Current assessments of under- 5 and maternal mortality, the spread of major diseases, and the level of access to safe drinking water show that Afghanistan may fall seriously short of realising the right to health for all and achieving its MDG targets, despite significant Government efforts to reduce the health burden.

In particular, support must be given to address the very serious issue of maternal mortality (MDG 5), already noted as the highest in the world in some regions of Afghanistan. In certain provinces, such as Badakhshan, to be a woman is literally a matter of life and death; overall, maternal mortality remains among the leading causes of death in the country, with up to 25,000 Afghan women dying annually as a result of pregnancy and childbirth. Moreover, when the mother of a newborn dies, the child has only a 1 in 4 chance of surviving until its first birthday. ${ }^{120}$ In all, family planning and reproductive health issues also require much stronger attention to meet acute needs, including HIV/AIDS prevention, adolescent reproductive health information and services, ${ }^{121}$ and treatment for sexually transmitted infections. ${ }^{122}$ Likewise, chronic malnutrition represents a serious health challenge, which can be addressed in part through food fortification. 


\section{Mortality Rate per 1,000 Live Births}

Source: IMR and U5 from MICS 2003, MMR from UNICEF/COC 2002

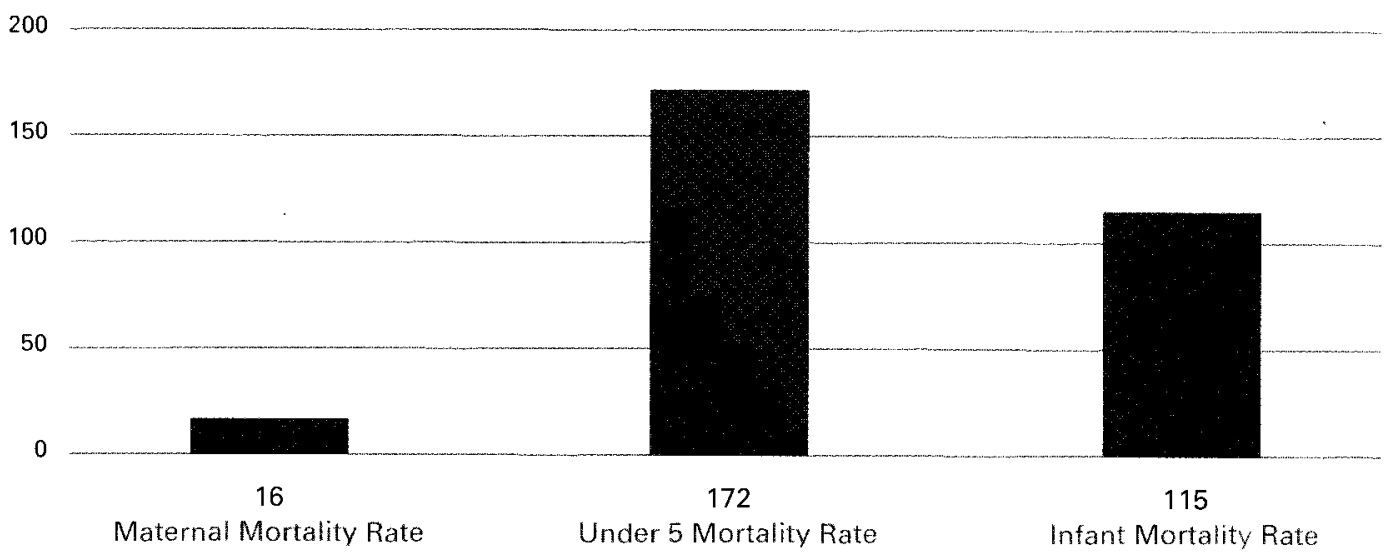

Afghanistan has launched its Basic Package of Health Services (BPHS), ${ }^{123}$ which aims at reducing morbidity and mortality in general and emphasises maternal and child health, as well as safe motherhood. Through the BPHS, a standardised package of basic services forms the core of service delivery in all primary health care facilities, with redistribution of health services promoted by levelling urban-rural disparities. Although overall health policies and strategies are in place, ${ }^{124}$ and while central management capacities have been progressively strengthened, the extent and quality of service delivery remains unsatisfactory. Even where services are available, a serious issue remains in that they are often not fully utilised. Preventive health practices must be improved, in view of the lack of information and to inadequate practices in hygiene, nutrition, water-related health behaviour and simple disease prevention, such as immunisation and supplemental Vitamin A provision.

123 The BPHS, launched in March 2003, comprises five "first-tier" components - maternal and newborn health, child health and immunisation, public

nutrition, communicable diseases (tuberculosis and malaria control) and the supply of essential drugs, with mental heatth and disability as "second-tier" components. The elements comprised in the package have been chosen on the basis of their likelihood for their successful delivery; the burden that tarceted diseases have imposed on the population; and the need for equity in ensuring that critical health services are provided to all, especially the poor.

124 However, no separate population policy yet exists

125 Afghanistan - Progress of Provinces: Multiple Indicator Cluster Survey 2003, op.cit., p. 75.

While routine immunisation reaches no more than 50 percent of the targeted age group, immunisation coverage for children has increased; it is much higher in urban areas than in rural areas. More efforts remain to be made in immunisation against childhood tuberculosis and diphtheria/pertussis/tetanus. The best coverage has been achieved in measles immunisation, following a mass campaign in 2003 - only 16 percent of children in urban areas and 27 percent in rural areas have not yet been reached. With regard to polio eradication, the level of the disease has fallen dramatically to only 3 cases by the end of September 2004. Large differences in coverage exist between provinces, and sometimes even between districts within the same province.

Outside major cities only about 30 percent of households have access to safe drinking water; in some provinces such as Bamyan, Baghlan and Sari Pul, the figure stands at less than 10 percent. This represents a major underlying cause of both morbidity and malnutrition in the country. Among those with access to safe water, only about onequarter had a water source within their compound. While more work is required to make surface water safe, promotion of sanitary latrines and hygiene practices has been the most neglected aspect of water and sanitation work in the country. 125 
Based on analysis, three key challenges have been identified as underlying causes for availability issues; six further challenges related to access also constrain Afghans' right to health and achievement of the MDGs. While lack of awareness has been highlighted in several areas, it should be noted that it must be considered in a broader context of sociocultural and economic determinants and strongly linked to both health-seeking behaviour and health service provision. The key challenges include:

- Shortages of skilled and trained health staff, especially female health workers, in rural areas, along with lack of physical infrastructure, equipment and medical supplies

- Limited accountability and lack of clear relations in Government at the provincial level

- Limited capacity of Government to prepare for and mitigate natural disasters

- Consequences of socio-cultural traditions

- Degraded and limited road infrastructure

- Lack of awareness of hygiene, child care and feeding practices

- Lack of awareness of patterns of transmission, prevention and treatment of communicable and non-communicable diseases

- Lack of awareness of both mental health and the ill effects of drugs in society

- Reports of discrimination against some ethnic groups

\section{Households with Safe Drinking Water From Pump/Protected Spring \\ Source: MICS 2003}

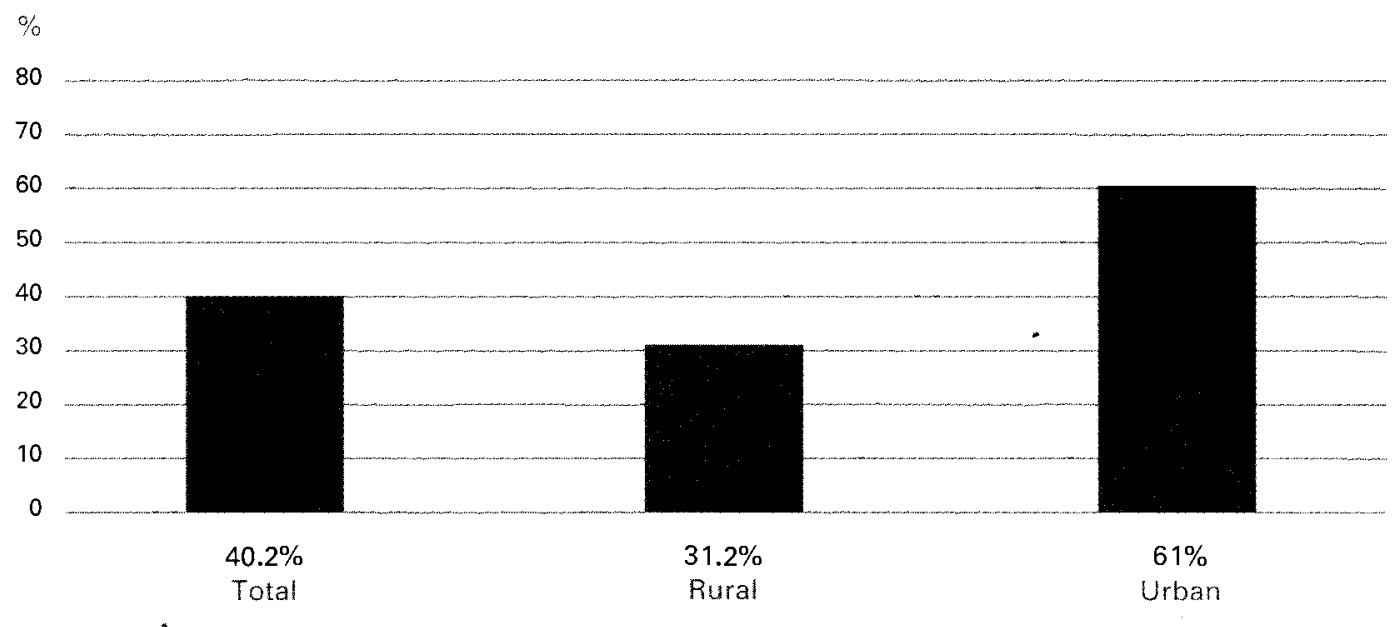

\section{Availability}

1. Shortages of skilled and trained health staff, especially female health workers, in rural areas, along with lack of physical infrastructure, equipment and medical supplies

Prolonged conflict has led to the retirement or emigration of skilled instructors, lack of material and financial resources, and restricted access to equipment and updated technical information. Prohibitions affecting education under the Taliban, along with low literacy, have added to a degradation of skills and further reduced the already-limited number of female health staff, who are absent in 40 percent of all health care facilities. This in turn limits the access of women to health care, although the Government is making a particular effort to build capacity for female health workers. Skilled health staff are more likely to be found in urban areas than in rural areas, making the latter even more underserved. In some provinces, no hospital buildings or ambulances exist, and private houses are used to provide health services. ${ }^{126}$

\section{Limited accountability and lack of clear relations in Government at the provincial level} Although a clear description of provincial health departments has been indicated under the Government's Priority Reform and Restructuring (PRR) programme, the bulk of the process of recruitment to meet the necessary scope of services at the provincial level has not yet 
started. In the vast majority of provinces, there appears to be limited consistency among national health policy and priority programmes, except the BPHS. In addition, the lack of clarity in the relationship between the Ministry of Health and its provincial departments renders the departments reactive rather than proactive in relation to decision-making and preparation, management and control of budgets. Hence, there is a low level of budget execution - typically 25 percent - due to non-availability of cash, which heavily affects the availability and delivery of services. Accountability is low because staff are unaware of expectations, and a system of regular review discourages high performance. Huge gaps in salaries and benefits between provincial Ministry of Health staff and those hired by NGOs implementing the BPHS further discourages Ministry staff.

\section{Access}

\section{Degraded and limited road infrastructure}

Access to transport and ability to travel is the primary reason for unequal access to health care, with travel for women and children more restricted than travel for men, and with travel for women more restricted than travel for children. ${ }^{127}$ Physical access is especially difficult during winter and early spring, as well as after heavy rainfalls, such that Afghans living in remote areas appear to wait until their health problem has become serious before they travel to medical centres. These basic centres, however, are often not equipped to handle the more severe cases and emergencies. ${ }^{128}$

\section{Households' Access to Healthcare Source: World Bank}

\footnotetext{
127 Although distance is a limiting factor for both men and women. it has a greater effect on women. They are unable to travel far from their villages, especially alone or with a sick child.

128 Human Security and Livelihoods of Rural Afghans 2002-2003, op.cit., p. 78.

129 In Afghanistan's initial health, population and nutrition sector needs assessment in December 2001 , only one-third of provinces surveved had any capacity to deliver emergency obstetric care, while only 35 percent of districts offered reproductive health services [World Bank, UNDP, Asian Development Bank, Afghanistan Preliminary Needs Assessment for Recover and Reconstruction, January 2002, in Usmani, op.cit. p.8].

130 UNFPA Fact Sheet on Reproductive Health in Afghanistan/Ministry of Public Health, National Health Policy Statement document, cited in Usmani, op.cit., p. 14.

131 Afghanistan - Progress of Provinces: Multiple Indicator Cluster Survey 2003, op.cit., p. 24. At the same time, a study conducted in 12 intervention areas in 2000 showed that 98 percent of women were interested in obtaining contraceptives. The ideal family size, according to many women, was four children (two boys and two girls).
}

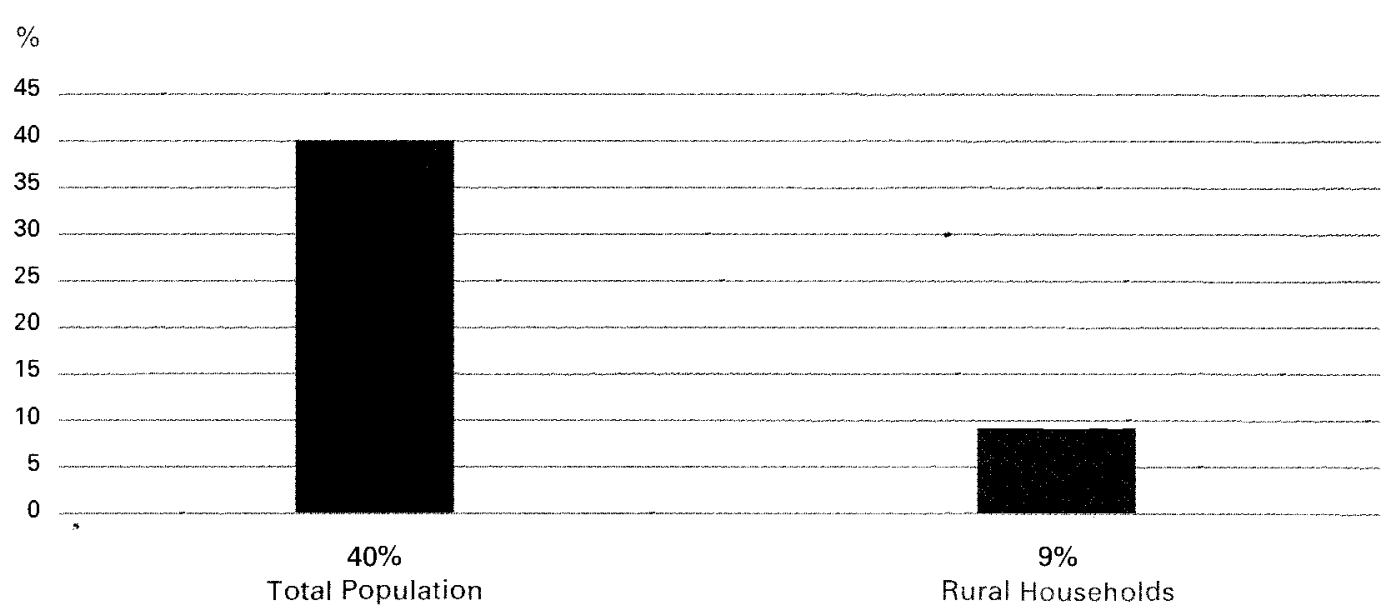

\section{Consequences of socio-cultural traditions}

Maternal mortality is perhaps the most important indicator demonstrating that life is extraordinarily difficult for women in Afghanistan. Nearly 9 in 10 maternal deaths were judged to be preventable, according to a 2002 Ministry of Health/Centres for Disease Control/UNICEF study. ${ }^{129}$ Numerous factors contribute to the high maternal mortality, many of them related to traditional socio-cultural perceptions: high fertility, as a result of poor education and poor access to contraception; poor nutrition, with resulting anaemia and maternal stunting; inadequate or nonexistent antenatal care; and an inability to access urgent obstetric care when needed. National coverage for prenatal care has been estimated at only between 8 and 12 percent. ${ }^{130}$ Again, even where services are available, utilisation of such services traditionally is low.

Knowledge and use of contraceptives, at only 10.3 percent, ${ }^{131}$ is believed to be hampered by low availability as well as socio-cultural factors, leading to one of the highest unmet family planning needs in the world. While family planning is generally approved of for economic and health reasons, it is often determined by having a certain number of sons. Research 
also shows that women are required to seek permission from their husbands to attend" family planning clinics and must give persuasive arguments to justify using reproductive health services. It appears there is very little communication about reproductive health and sexual behaviour at family level. In particular, adolescents face severe access constraints given the lack of youth-friendly services and policies, as well as lack of social choices, such as when and whom to marry, and whether and when to have children.

\section{Lack of awareness of hygiene, child care and feeding practices}

In relation to the large constraints on access to safe drinking water and improved sanitation facilities, only 32.2 percent of mothers of under-5-year-olds in urban areas and 13 percent in rural areas use water or soap/ash to wash their hands after their own or their child's defecation. In addition, 29 percent of households in urban areas and 50 percent in rural areas have no fixed place for disposal of child faeces. Exclusive breastfeeding for an appropriate period is not commonly practiced, and complementary feeding occurs either too late or too early, with foods that are often nutrient-poor. Breastmilk substitutes are being more aggressively marketed without proper regulation, further undermining breastfeeding practices. Mothers' level of awareness increases with their level of education.

\section{Lack of awareness of patterns of transmission, prevention and treatment of communicable and non-communicable diseases}

Minimal or no knowledge of HIV/AIDS exists, and high levels of illiteracy present noticeable barriers to HIVIAIDS awareness and prevention. An important opportunity thus exists to increase attention and focus on the threat of the disease at an early stage in Afghanistan, given that numerous risk factors are present, such as prostitution, Men having Sex with Men, drug use and population movements. The Ministry of Health estimates that 200 to 300 persons in the country are living with HIV/AIDS; it is believed that routes of infection are mainly heterosexual transmission, transmission through blood transfusions and the sharing of contaminated needles during drug use. ${ }^{132}$

At the same time, Afghanistan is heavily afflicted by tuberculosis, with young women comprising 70 percent of all adult cases recorded in public clinics. Again because of lack of awareness, one of the main problems lies in the widespread non-adherence to treatment regimes. An overall 16 percent of the population is considered at risk for malaria, which is prevalent in more than half of the country and endemic below 1,500 meters of altitude. Awareness of preventive practices such as usage of insecticide-treated bed nets must be raised at household level.

\section{Lack of awareness on mental health and on the ill effects of drugs in society}

Recent history has left the population extremely vulnerable to a range of mental health problems, particularly chronic depression, anxiety, insomnia and post-traumatic stress disorder. The World Health Organisation estimates that 20 to 30 percent of Afghans suffer from mental disorders, with another 30 to 40 percent having psychosocial problems. No reliable data are available, although it appears that women, children, returnees/IDPs and people with disabilities have significantly poorer mental health status. ${ }^{133}$ While mental health is listed as a second-tier priority in the BPHS, no clear policy has yet been developed, and an extreme shortage of trained mental health professionals exists.

132 Out of 15 new cases recorded in 2003, 13 were among local residents who had not travelled abroad.

133 Journal of the American Medical Association, Theme Issue on Violence and Human Rights, No. 292, pp. 575-584, 4 August 2004.
In such a context, the availability of cheap opium, heroin and other pharmaceuticals is causing a rapid rise in drug dependency in Afghanistan as well as neighbouring countries. A lack of awareness, openness and information concerning drugs adds to the severe predicament of drug users, as they often underestimate the character and the consequences of the drugs they use. 
Finally, social well-being depends on the ability of enjoying and benefiting from social support networks. Evidence suggests that the Afghan environment has become less conducive to complete social well-being; limited information is available on an increased trend toward self-immolation and suicide, particularly among young women, as well as on child abuse and kidnapping.

\section{Discrimination against ethnic minorities}

Anecdotal reports suggest there may be cases of limited access to health care facilities by ethnic minorities in some areas, where health personnel refuse to treat patients because they belong to a certain ethnic community. ${ }^{134}$

\section{2c. The Right to Food}

Whether a population has adequate food or not largely depends on the availability and diversity of food, its nutritional adequacy, and its accessibility, all heavily affected by availability of adequate roads or transport, purchasing power, and knowledge. While actively involved in the fight to combat hunger, Afghanistan again remains far from achieving the right to food and reaching its MDG targets. Currently, those afflicted by or at risk of hunger stand at a very high 37.4 percent of the population, while the MDG target is 18.6 percent. ${ }^{135}$ No right to food strategy exists, however. An information system also is needed that allows disaggregated analysis of food-insecure groups.

Headcount rate (\% individuals) with energy consumption below age $\&$ sex adjusted basic requirements (NRVA average $=2070$ kcalories per day)

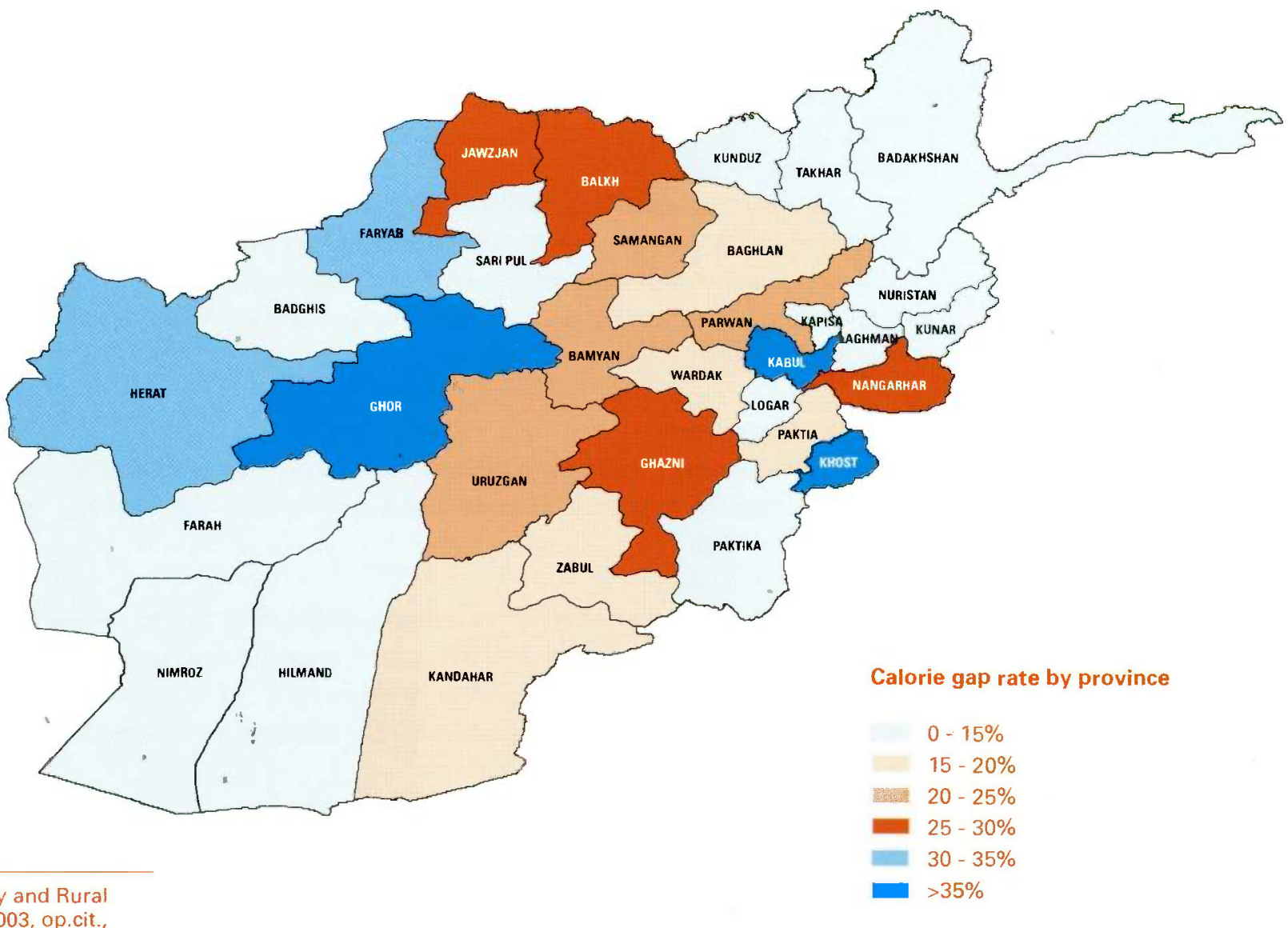


Inequalities within households, which are based primarily on economic and gender factors, are evident in skewed consumption patterns. The richest 20 percent of people consume nearly half the food, leaving the other half to the remaining 80 percent of the population. Again, this is a result of the uneven access to natural resources and assets such as land and water [see also Economic Development and Growth.] In addition, the frequent natural disasters that afflict the country, as well as the conflicts that characterised Afghanistan for so long, have acted as precursors to widespread and persistent food insecurity.

Results from nutrition and health surveys suggest that women, infants aged less than 6 months and infants between 6 and 24 months are at particular risk of malnutrition, which, as noted above, is prevalent in Afghanistan. ${ }^{136}$ Malnutrition is related not only to food deficiency, but also to contaminated water [see also The Right to Health sub-section], poor infant feeding practices, low levels of female education and other issues. Fortification of food thus represents an important intervention for support by the United Nations System. On the policy side, policies must be supported to help strengthen dietary diversity and healthy eating habits and food preparation.

Based on analysis, four key challenges have been identified as underlying causes for availability issues, while three further challenges related to access also constrain the right to food and achievement of the MDGs. These include:

- Lack of rule of law

- Lack of fair land ownership norms and a single body of land tenure laws

- Limited capacity to respond to natural disasters

- Unregulated water rights and decimated irrigation systems

- Consequences of diminished livelihoods

- Lack of awareness of nutrition and the importance of dietary diversity and correct child care practices

- $\quad$ Lack of dietary diversity

\section{Availability}

The majority of the rural population of Afghanistan depends on access to arable land for food production. However, as discussed in detail in Economic Development and Growth, only 12 percent of the national territory constitutes usable farmland, and land tenure in Afghanistan is very poorly regulated and non-transparent. Major causes of land tenure insecurity include:

\section{Lack of rule of law}

Overall lawlessness continues to tolerate commanderism, unpredictable declarations depriving ethnic groups of land, water and living rights, and the asset-stripping behavior of elites and militias.

\section{Lack of fair land ownership norms and of a single body of land tenure laws} Instability and ambiguity in land relations have been fostered by lack of fair land ownership norms and multiple cases of unresolved interests over the same plots of land. Land rights in Afghanistan are addressed by the various legal regimes, sometimes in contradictory ways.

\section{Limited capacity to respond to natural disasters}

See also Economic Development and Growth. 


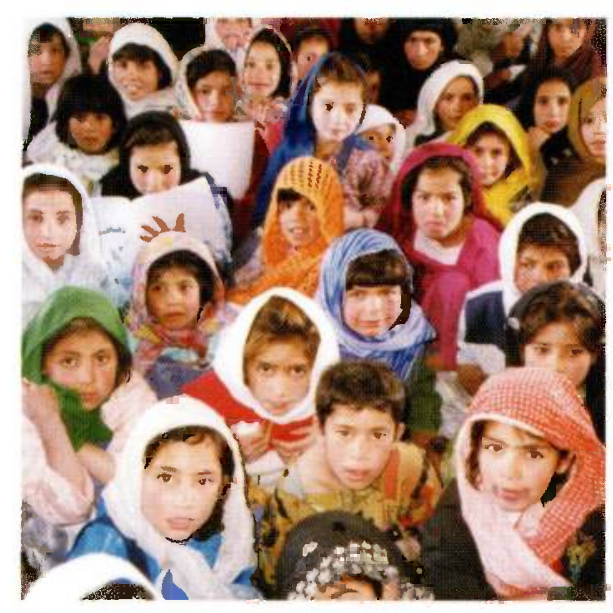

4. Unregulated water rights and decimated irrigation systems Unregulated water rights and decimated irrigation systems are vital to the sustenance and productivity of vineyards, orchards and cereal farms. A related issue is the critically uneven access to improved seed, fertiliser, manure, draught power and labour, because of competition over scarce resources and longstanding inequities in Afghan society.

\section{Access}

Even if available, for food to be considered adequate it must satisfy basic nutritional needs. Anaemia affects up to 65 percent of children under 5 and 70 percent of expectant mothers. Micronutrient deficiency symptoms result from a lack of foods rich in iodine, Vitamins $A$ and $C$ and iron/folic acid. ${ }^{137}$ Factors related to access contributing to this scenario include:

\section{Consequences of diminished livelihoods}

Poverty often prevents families from providing healthy meals to their members, especially children and women of childbearing age. A lack of income-generating opportunities thus has direct impact on the health of millions of Afghans. The lack of a free market policy in Afghanistan, while ensuring availability of commodities in large quantities across the country, has also contributed to reduce the purchasing power of families already suffering from lack of employment or of any income sources, given the absence of Government mechanisms to control prices.

\section{Lack of awareness of nutrition and the importance of dietary diversity and correct child care practices}

Women have higher energy, protein and micronutrient requirements when they are pregnant and nursing, and those who enter pregnancy malnourished or who do not gain sufficient weight during pregnancy are more likely to deliver low-birth-weight babies. These children then face a heightened risk of dying during the first week of life or of perpetuating the cycle of malnutrition across generations. Girls who are malnourished during childhood are more likely to be malnourished as adolescents, with a very high prevalence of iron deficiency. ${ }^{138}$ Limited knowledge of correct child care practices leads to inappropriate feeding, from shortened timing of breastfeeding to lack of provision of food during episodes of diarrhoea.

\section{Lack of dietary diversity}

Reliance on wheat as a staple dietary component and significant reduction in consumption of diversified, micronutrient-rich horticultural products have contributed to Afghans' impoverished diet. This relates closely to the low.purchasing power of millions of Afghans. It also results from the devastation of horticultural agriculture and irrigation systems. ${ }^{139}$

37 Findings from Protracted Relief and Recovery Operation 10233.0 in Afghanistan, World Food Programme 2003

138 WFP Gender Policy $2003-$ 2007, Enhanced Commitment I (http://www.wfp.org/eb/docs/2002/ wfp010654 4.pdf)

139 International Centre for Agricultural Research in the Dry Areas (ICARDA) 


\section{What Does Success Depend On?}

Given this strategic analysis, it appears challenging to create the necessary environment to achieve progress toward the MDGs, Millennium Declaration targets and rights of survival, livelihood, protection and participation. Full support must be given to national policies and priorities on social well-being, including:

\section{Education}

- Support to further improvements in girls' education, through more accessible schools; improved teaching-learning materials and classroom supplies; developing a network for community schools and introducing a bridging programme to mainstream education; and integration of the formal and non-formal education systems

- Support to institutional development, particularly development of managerial capacity in the Ministry of Education, including financial management. In addition, support to all interested stakeholders to build capacity in data collection and management through the Education Management Information System (EMIS) and related initiatives

- Support to establishing democratic governance in education, in terms of adopting clear, unambiguous education rules and regulations

- Support to promote cultural identity, civic education and peace development, through a revised curriculum and more effective teacher training. This can help develop a national culture of diversity and unity based on principles of tolerance, moderate Islamic ideals and national ownership

- Support to use of highly trained, experienced teachers who are returnees, by streamlining the difficult and costly accreditation procedure of the Ministry of Education. In addition, support for better pay for teachers, particularly as an incentive to encourage women to join the profession. Lastly, support to develop short- and long term plans to fulfil the requirement of in-service teaching training and its implementation

- Support to comprehensive policies on Early Childhood Development and a Plan of Action to systematically streamline the kindergarten programme

- Support to learning opportunities for youth/adolescents without access to formal education

- Support to modern, market-driven vocational, technical and non-formal education that promotes partnership arrangements with the private sector

\section{Health/Food}

- Support to implementation of the Basic Package of Health Services to ensure reductions in high maternal and infant mortality/morbidity as well as a narrowing of the current rural-urban gap

- Support to development of clear policies and human resource development aimed at increasing the number of qualified female health staff, particularly in rural areas, and at increasing the capacity of provincial health departments through gradual decentralisation

- Support to increased prioritisation of preventive health and hygiene

- Support to the promotion of HIV/AIDS and mental health awareness, which are currently not perceived as priorities, to foster preventive care

- Support to universal access to basic and comprehensive emergency obstetric care, along with proper antenatal and post-natal care for women 
- Support to a multisectoral approach to malnutrition, as defined in the Ministl $x_{\star}$ of Health Public Nutrition Policy and Strategy document, that develops inter-Ministerial planning and response mechanisms to link food security and health issues at the central and provincial levels

- Support to mechanisms for raising awareness, particularly for women, on a wide range of health-related issues as a means of reducing and/or preventing malnutrition

- Support to improvement of water management and sanitation, including continued repair and/or new construction, while ensuring environmental conservation

\section{Social Protection}

- Support to the role and function of existing social services, such as health clinics, schools and kindergartens to include social protection roles [see also Peace, Security and Justice]. Activities such as community building and social and family support are compatible with, or integral to, their core functions

- Support to orphanages and other institutions, which represent a major investment in facilities and staff and an expensive ongoing service for a small number of vulnerable and at-risk children, to be transformed into community-based child and family resource centres. These centres then could provide a wide range of programmes and services that reach into the community to protect a much larger number of children at risk and their families

- Support to further research into child abuse and exploitation to know how many children experience such suffering. ${ }^{140}$ In addition, support must be provided to more research on the psycho-social consequences of war and violence, particularly on children

\footnotetext{
140 What is known is that many children perform inappropriate. heavy or harmful work, both within the family and outside of it: many young girls are "sold" into early marriage; cultural practices exist of giving young girls to settle inter-group conflict; children, particularly boys, are being trafficked, both internally and across national borders; and an increasing number of children are being kidnapped.
} 


\section{International Context and Commitments}

\section{Right to education, health and food}

- International Covenant on Economic, Social and Cultural Rights

- Convention on the Rights of the Child and its Optional Protocols on the Involvement of Children in Armed Conflict and on the Sale of Children, Child Prostitution and Child Pornography

- Convention on the Elimination of All Forms of Discrimination Against Women

- Convention on the Elimination of All Forms of Racial Discrimination

- Universal Declaration of Human Rights

- General Comments 11 and 13 (education), 14 (health) and 12 (food) of the Committee on Economic, Social and Cultural Rights

- Protocol (to the Convention Against Transnational Organised Crime) to Prevent, Suppress and Punish Trafficking in Persons

- Agenda 21

- World Declaration on Education For All

- Beijing Platform for Action

- International Conference on Population and Development

- Cairo Declaration on Human Rights in Islam

- Copenhagen Declaration (health)

- Resolution 25 of the Commission on Human Rights

- Universal Declaration on the Eradication of Hunger and Malnutrition

- Rome Declaration of the World Food Summit

- General Assembly Resolution 56/155 on the Right to Food

- Committee on World Food Security, Voluntary Guidelines to Support the Progressive Realisation of the Right to Adequate Food in the Context of National Food Security

MDG targets for health, to which Afghanistan is committed, propose by 2015 to reduce by two-thirds the under-5 mortality rate (Target 5); to reduce, by three-fourths, the maternal mortality ratio (Target 6); to have halted and begun to reverse the spread of HIVIAIDS (Target 7); to have halted and begun to reverse the incidence of malaria and other major diseases (Target 8); and to halve the proportion of people without sustainable access to safe drinking water (Target 10 ).

\section{Significant Data Gaps}

\section{Education}

- Information on girls' and boys' enrolment, particularly in secondary schools, higher education institutions and non-formal education

- Need to assess quality of education and students' achievement

- Need for accurate information on nature and composition of the teacher body across all levels of schooling

- Lack of information on out-of-school children and youth

- Further research to ascertain complexity of reasons girls not in school, particularly in rural areas

\section{Health}

- Major data gaps on all health support networks, particularly extreme shortage of trained specialised personnel, including women; and on potentially disrupted social support networks at community level

- Mortality and morbidity data and study of burden of diseases

- Need for more information in particular on HIVIAIDS, mental health, tuberculosis, malaria, drug abuse, child abuse and kidnapping, disability, and access to and performance of safe water and sanitation facilities

- Research on health-seeking behaviour and socio-cultural and economic barriers to health services

\section{Food}

- Strategies for diversifying diet, including fortification, to address micronutrient deficiencies

- Effective strategies for improving the nutritional status among women of childbearing age

- Role of food security interventions for addressing malnutrition

- Piloting research for community-based strategies to address severe malnutrition

- Early warning systems, especially for emergencies like droughts

- Clearer picture of land ownership 
Areas of Cooperation 
Every person in Afghanistan deserves a life free from poverty and fear, conducted in security and dignity. But as the CCA analysis shows, millions of Afghans have no such rights, nor an equal opportunity to fully develop their human potential.

Ensuring human security means protecting vital rights and freedoms - freedom from want, freedom from fear, and freedom to take action on one's own behalf. This requires concerted efforts to develop norms, processes and institutions that systematically address insecurities. It also requires creating systems that give people the building blocks of survival, livelihood and decision-making. Because deprivation and insecurity are intimately intertwined, tackling both effectively demands an integrated approach.

Through protection and empowerment, human security demands building on and going beyond the MDGs, by addressing the full range of critical and pervasive threats facing people - security of the person; social and community security; economic and environmental security; governance and political security.

In Afghanistan, the United Nations System is well placed to undertake such efforts within the overarching framework of a human security approach. The concept of human security resonates deeply here, even as Afghanistan takes its first steps to rebuild after decades of violent conflict and chronic poverty. Diminished quality of life and dislocations in public services have emerged as sources of national instability. Hence, the well-being of the entire country may be at stake if the multiple and complex causes of these issues are not addressed.

In particular, millions of rural Afghan women experience the highest levels of human insecurity in nearly all thematic issues covered in the CCA. At the root of this insecurity is gender inequality - the cultural, social, economic and political barriers to realisation of basic human rights for Afghan women and girls.

The analysis of the development situation, provided in the previous chapters, indicates priorities for development cooperation in Afghanistan in the years to come. While each United Nations Agency in Afghanistan has its distinct mandate, some strategic goals and shared values consistent with global and national development agendas complement one another - and thus incorporate the roots of collaboration.

Combining these considerations with the diversity of mandates of the United Nations System yields three broad areas in which support for the transition of Afghanistan can be concentrated. These are:

- Human Rights and Peace Building

- Governance and Participatory Development

- Basic Social Services and Environmental Sustainability

The selected strategic areas for cooperation are not intended to be fully inclusive of all stakeholders' interventions, but they do represent an explicit common response. The main criteria for proposing these three areas of cooperation are: priority needs; potential for long-term impact on national goals and priorities; lessons learnt and good practices; and opportunities to strengthen both national capacities and international cooperation.

For each of these areas, joint efforts are necessary - a network of public, private and civil society actors who can help clarify and develop norms, embark on integrated activities, and monitor progress and performance. Such efforts can create a source of legitimacy that complements traditional structures. Strengthened efforts at data collection and analysis will be necessary in all areas to identify the numerous data gaps identified in the CCA. In all, unprecedented opportunities exist to address the desire for change that many Afghans 
possess, including through United Nations System participation in the upcoming PRSP process. During this process, United Nations strengths in normative standards, policy advice, capacity building and advocacy will be shared. The areas of cooperation will be. coherently reflected by individual United Nations organisations in their mandated activities within the UNDAF. Organisations can build on their strong field presence, impartiality and high credibility with Government and civil society, then act together to help conceptualise, implement and monitor country-owned development programmes and projects.

Turning to each area of cooperation, it is evident that the commitment of the United Nations System to poverty reduction is unwavering. In this regard, the impact of a failed national rebuilding process and inadequate enforcement of the rule of law will be devastating, rendering Afghanistan yet again vulnerable to violence, divisiveness and extreme instability. A major objective of United Nations assistance will be to establish "peace in development" in Afghanistan, through building capacities for preventing violent conflict, development frameworks supportive to peace-building, and wider peace-enabling environments.

The focus of Human Rights and Peace Building will not be on emergencies as such, but rather, on integrating longer-term peace-building into the full spectrum of conflict-related responses. This can include support to creating the knowledge, skills and values for a human rights culture; significantly improving gender equality; expanding counter-narcotics measures; enhancing the rule of law; and ensuring a more equitable allocation of resources, particularly through land reform that addresses the rights of returnees and IDPs. The United Nations also can provide a mechanism for reducing the severity of social conflict by helping to generate a framework for social policy that finds a place for both poverty and relative equity concerns, employing a series of internationally tested approaches consisting of a mix of poverty reduction, the eradication of discrimination, protection for the especially vulnerable, and improvement in working conditions. Building national ownership and national capacities, both within Government and civil society, will be emphasised, ensuring actionable results in both policies and programmes.

Overall, promoting civil society provides a channel for dispute resolution as well as Governance and Participatory Development. Good governance means different things to different people, but there is overall agreement that it is critical to have good governance. To political observers, good governance often means support for judicial and civil service reform, the strengthening of national and local parliaments and other governance institutions, the adoption of pro-poor policy frameworks, and the establishment of independent watchdog and advisory commissions. To the public, it means the eradication of corruption from daily life and a trust in the fairness of public decisions. To the economists, it means greater attention to the impact of institutions in market economies. To the religious, it means a polity fashioned along religious principles and edicts.

All of these concepts of governance can be accommodated within a durable structure of pluralist democracy grounded in civic rights. The latter also constitute a vehicle for ensuring minority rights. The United Nations System can assist both by helping to solidify the governance agenda as well as by supporting a number of initiatives to consolidate democracy in the course of the Afghan transition. In this context, the United Nations System will advane best-practice examples in the area of recovery and post-conflict reintegration. Assistance to NGOs in the enhancement of citizens' rights and entitlements will help their credibility and increase public participation in their activities. In the realm of economic security, the proper functioning of markets as well as development of growth that reaches the extreme poor and fairly distributes benefits is essential. A focus must be given to sudden economic downturns, natural disasters and the social impacts of crises. 
Finally, under Basic Social Services and Environmental Sustainabitity, the United Nations System will support measures essential to allow people to lead long, healthy and creative lives, to enjoy decent living standards and freedoms, and to possess dignity, self-respect and respect for others. Basic education and public information that provide knowledge, life skills and respect for diversity are particularly important for human security in Afghanistan. In their urgency, depth and impact, also critical are global infectious diseases, povertyrelated health and food security threats, and health deprivations arising from insecurity and violence. At the same time, support for access to land, credit and housing, especially for poor Afghan women, is necessary, as are strengthened social protection measures and population-related activities. Finally, human security recognises the linkages between environment and society; the United Nations System acknowledges that perceptions of the environment, and the way the environment is used, are historically, socially and politically constructed and must be addressed.

As the CCA analysis reveals, Afghanistan must accelerate its efforts urgently if the 2015 MDGs and targets are to be realised. But the Government cannot fulfil its objectives alone. In large part, its success will depend on the support of international and domestic partners, including the United Nations System. The CCA and its preparation bear testimony to the increased consultation and dialogue among the Government, the United Nations System and development partners on sustainable human development and human security in Afghanistan. Programming activities must all be designed with international human rights commitments and the Millennium Declaration in mind.

In the end, transitions create uncertainty. They tend to favour the present over the future. The United Nations System can do much to protect the future, supporting a rightsbased approach that moves the development agenda from the realm of charity to that of obligation. As it moves forward with development of the UNDAF, the focus on the poor and vulnerable - as well as on duty bearers - will be more deliberate. This new approach also will be seen during its engagement with the PRSP, which precedes the UNDAF. What this approach implies is a more concerted and explicit engagement of other domestic and international partners - local Governments and communities, NGOs and civil society, families, the business community, the media and academia alike. In so doing, the United Nations System can help Afghanistan stand firmly among the new democracies of the 21st Century. 


\section{CCA Statistical Indicator Framework}

N.B.: Italics denote proxy indicators

\section{A. Millennium Declaration And Conference Indicators}

Poverty headcount ratio (\% of population below national No Data poverty line) Caloric Deficiency Rate (Population below $2070 \mathrm{kcal} / \mathrm{capital}$

day; rural areas only)

Proportion of population below US\$1 (PPP) per day

Poverty gap ratio

Share of poorest quintile in national consumption

Gini coefficient

Underweight children under 5 years of age (\%)

energy consumption

Proportion of household income spent on food for the

poorest quintile

Net enrolment rate in primary education of 7 - to 12 -year-olds

Pupils starting grade 1 who reach grade $5(\%)$

Literacy rate of 15 - to 24 -year-olds (\%)

Adult literacy rate (age 15 and above, \%)

Ratio of girls to boys in primary education of 7 - to

12-year-olds

Ratio of girls to boys in secondary education

Ratio of girls to boys in tertiary education

Combined primary, secondary and tertiary gross enrolment

rate of 7- to 27-year-olds

Ratio of school attendance of orphans to school attendance

of non-orphans aged 10-14

Ratio of literate females to males 15- to 24-year-olds

Ratio of literate females to males (age 15 and above)

Women in wage employment in the non-agricultural sector (\%) 17

Proportion of seats held by women in national

parliament/loya jirga

Under-5 mortality rate (per 1,000 live births)

Infant mortality rate (per 1,000 live births)

One-year-old children immunised against measles

Children aged 9-59 months immunised against measles

Children below age 15 who are working

Children aged 7-12 years working at least half a day (4-12hrs)

for income in/out of household (\%)

Children aged 7-12 years do domestic chores at least half a

day (4-12hrs) for income in/out of household (\%)

Contraceptive prevalence rate

Married women under age 50 years currently not using a

method to delay pregnancy $(\%)$

Maternal mortality ratio (per 100,000 live births
49.0

No Data

No Data

20.4

2003

NRVA

No Data

No Data

No Data

$6 \%$ share in food consumption (NRVA 2003)

Da Afghanistan Bank estimate based on World Development Indicators CSO

See caloric deficiency rate above

\begin{tabular}{|c|c|c|}
\hline Total: $54.4, \mathrm{M}: 67, \mathrm{~F}: 40.5$ & 2003 & UNICEF/CSO MICS \\
\hline 49.0 & 2000 & UNICEF EFA \\
\hline \multicolumn{3}{|l|}{ No Data } \\
\hline Total: 28.7, M: 43.2, F: 14.1 & 2003 & UNICEF/CSO MICS \\
\hline 0.6 & 2003 & UNICEF/CSO MICS \\
\hline 0.325 & 2003 & UNESCO \\
\hline 0.208 & 2003 & UNESCO \\
\hline Total: 44.93, M: 59.34, F: 29.57 & 2002 & $\begin{array}{l}\text { CSO estimate on the basis } \\
\text { of available student and } \\
\text { population data }\end{array}$ \\
\hline
\end{tabular}

No Data

No Data

$0.326 \quad 2003 \quad$ UNICEF/CSO MICS

2002 UNCTAD

Minimum of $27 \% \quad 2004 \quad$ Constitution of Afghanistan

Total: 172 (Urban: 142, Rural: 183) 2003 UNICEF/CSO MICS

Total: 115 (Urban: 97, Rural: 121) 2003 UNICEF/CSO MICS

$44 \quad 2002 \quad$ UNCTAD

Total: 76 (Urban: 83.7, Rural: 73.2) $2003 \quad$ UNICEF/CSO MICS

No Data

Total: $6.8(M: 9, F: 4.5)$

UNICEF/CSO MICS

Total: 15.4 (M: 10.7, F: 20.6)

2003 UNICEF/CSO MICS

No Data

Total: 89.7 (Urban: 79.0, Rural: 93.9) 2003 UNICEF/CSO MICS 
Proportion of births attended by skilled health personnel (\%) Total: 14.3 (Urban: 34.8, Rural: 6.9) 2003 UNICEF/CSO MICS HIV prevalence among 15- to 24-year-old pregnant women No Data Condom use rate of the contraceptive prevalence rate

Condom use at last high-risk sex No Data No Data

Percentage of population aged 15-24 with comprehensive No Data correct knowledge of HIV/AIDS

HIVIAIDS prevalence $\quad<0.01$

Prevalence and death rates associated with malaria

Proportion of population in malaria risk areas using effective malaria prevention and treatment measures

Population using insecticide-treated nets $(\%)$
Under-5-year-olds appropriately treated for malaria (\%)
Prevalence and death rates associated with tuberculosis

Tuberculosis cases detected and cured under directly observed treatment short course (DOTS) (\%)

Unemployment rate (\%)

Employment to population of working age ratio

32

Informal sector employment as percentage of total employment

Proportion of population using solid fuels

Traditional fuel consumption (\% of total energy use)

Carbon dioxide emissions per capita (metric tons)

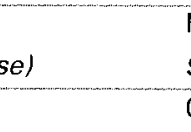

\section{$<0.01$}

Prevalence rate: $4.2 \%$ Death rate: $8 / 100,000$ No Data

5

\section{0}

Prevalence ratio: $667 / 100,000$

Death ratio: 92/100,000

84

32

No Data

No Data

No Data

97

0.046

Carbon dioxide emissions (thousand metric tons)

Energy use ( $\mathrm{kg}$ oil equivalent) per \$1 GDP (PPP)

Land covered by forest (\%)

Ratio of area protected to maintain biological diversity to surface area

Population with sustainable access to an improved water source, urban and rural areas (\%)

Households with safe drinking water from pump/protected spring (\%)

Urban population with sustainable access to sanitation (\%)

Urban households having a sanitary latrine (\%)

Households with access to secure tenure (Kabul only, \%)

Number of persons per room, or average floor area per person

Overall households having a sanitary latrine (\%)

Overall population with access to improved sanitation

Overall population with access to improved sanitation

Seizures of opiates (kilogrammes)

Area under illicit cultivation of opium poppy (hectares)

Prevalence of drug abuse

\section{6}

No Data

2.1

No Data

13

Total: 40.2

(Urban: 61, Rural: 31.2)

25

86.8

48-60

No Data

Total: 67.1 (Urban: 86.8 , Rural: 58.6)

12

12

5581.615

80,000

0.6

\begin{tabular}{l}
2003 \\
2000 \\
\hline 2000 \\
2002 \\
\hline 2003 \\
\hline 2001
\end{tabular}

2003

2000

2002

2003

2001
2004

2002 Ministry of Health $\mathrm{WHO}$

2000

2002

2002

2002

WHO

WHO

$2001 \quad$ WHO

$2003 \quad$ IRC

2002 CSO Statistical Yearbook UN-DESA / UN Statistical Division

UNFCCC

$2000 \quad$ FAO

2000 CSO Statistical Yearbook

2003 UNICEF/CSO MICS

2000 UNICEF-WHO

2003 UNICEF/CSO MICS

2004 UN-Habitat

UNICEF/CSO MICS

WHO-UNICEF

WHO-UNICEF

UNODC

UNODC

Prevalence of abuse

as percentage of the

population aged 15-64

(UNODC) 


\section{B. Conference And Concention Indicators on Governance, Democracy, Justice Administration And Security of Person}

First presidential election in October 2004. First parliamentary elections scheduled for 2005.

Periodicity laid down in Constitution of 2004.

\begin{tabular}{|c|c|c|c|}
\hline $\begin{array}{l}\text { Number of independent NGOs/CSOs and employers' and } \\
\text { workers' organizations operating in the country }\end{array}$ & No Data & & \\
\hline Existence of independent broadcasting and print media & Yes & & \\
\hline Legal guarantees for independent judiciary & Yes & 2004 & Constitution \\
\hline Procedural guarantees for fair trial & Yes & 2004 & Criminal Procedure Code \\
\hline $\begin{array}{l}\text { Availability of free legal assistance for the criminal defence } \\
\text { of poor people throughout the country }\end{array}$ & Yes & 2004 & Criminal Procedure Code \\
\hline $\begin{array}{l}\text { Recognition in law of the right to seek judicial remedies } \\
\text { against state agencies/officials }\end{array}$ & Yes & 2004 & Gonstitution \\
\hline Number of complaints of extra-judicial executions & No Data & & \\
\hline Number of persons granted asylum/refugee status & No Data & & \\
\hline Number of refugees that have returned & 3.6 million & 2004 & UNHCR \\
\hline $\begin{array}{l}\text { Strengthened support to displaced persons for their return } \\
\text { and reintegration }\end{array}$ & Yes & & \\
\hline Number of Internally Displaced Persons that have returned & 700,000 & 2004 & UNHCR \\
\hline IDP Caseload (May 2004) & 165,000 & 2004 & UNHCR \\
\hline \multicolumn{4}{|l|}{ C. Contextual Indicators } \\
\hline Population size (million) & 24.5 & 2003 & UNICEF/CSO MICS \\
\hline Population structure & $\begin{array}{l}\text { Pashtun } 38 \% \text {, Tajik } 25 \% \text {, Hazara } \\
19 \% \text {, minor ethnic groups (Aimaks, } \\
\text { Turkmen, Baloch, and others) } 12 \% \text {, } \\
\text { Uzbek } 6 \%\end{array}$ & 1979 & CSO \\
\hline Sex ratio (female to male) & 1.04 & 2003 & $\begin{array}{l}\text { Calculated based on } \\
\text { UNICEF/CSO MICS data }\end{array}$ \\
\hline Total fertility rate (per woman) & 6.26 & 2003 & UNICEF/CSO MICS \\
\hline Life expectancy at birth (years) & $\mathrm{M}: 45, \mathrm{~F}: 44$ & 2002 & CSO \\
\hline GNP per capita (US\$ and PPP) & No Data & & \\
\hline Non-opium GDP per capita (US\$) & 219 & 2003 & SAF \\
\hline External debt (US\$) as percentage of GNP & No Data & & \\
\hline Total debt as percentage of GDP & 9.4 & 2003 & World Bank \\
\hline Decadal growth rate of GNP per capita (US\$) & No Data & & \\
\hline GDP Annual Growth rate (\%) & 15.7 & 2002 & World Bank \\
\hline Gross domestic savings as percentage of GDP & -18.6 & 2003 & World Bank \\
\hline
\end{tabular}




\begin{tabular}{llcc}
\hline Indicators & Available Data & Year & Remarks \\
\hline & & No Data & \\
\hline Ratio of total trade (exports plus imports) over GDP & 68.7 & 2003 & World Bank \\
\hline Imports of goods and services as \% of GDP & 12.4 & 2003 & World Bank \\
\hline Exports of goods and services as \% of GDP & 1.06 & 2003 & Da Afghanistan Bank \\
\hline Share of foreign direct investment inflows in GDP (\%) & & 2003 & Wstimate \\
\hline Budget deficit as percentage of GDP & 52.9 & Bank \\
\hline Percentage of public expenditure on basic social services & No Data & 2002 & CSO \\
\hline Public expenditure on education (as \% of GDP) & 1.6 & 2002 & CSO \\
\hline Public expenditure on health (as \% of GDP) & 0.5 & 2003 & World Bank
\end{tabular}

\section{Selected Indicatiors Used For Monitoring Millennium Declarations Goal 8}

Proportion of bilateral ODA of OECD/DAC donors that No Data

is untied

ODA received in landlocked countries as proportion of No Data

their GNIs

Per-capita ODA received in Afghanistan (US\$)

Proportion of total developed country imports from

562002

UN-DESA / UN Statistical

Division

Afghanistan (by value and excluding arms), admitted

No Data

free of duties

Average tariffs imposed by developed countries on No Data

agricultural products and textiles and clothing from

Afghanistan

Proportion of ODA received to help build trade capacity

(million US\$

Debt relief committed under HIPC initiative, US\$

2002

UN-DESA / UN Statistical

Division

0

Afghanistan is not yet considered under the HIPC initiative, as it has still to develop an (I)PRSP.

Debt service as percentage of exports of goods and services

No Data

Proportion of ODA provided as debt relief

No Data

Unemployment rate of 15-to-24-year-olds, each sex and total

Unemployment rate of 16-to-25-year olds (\%)

No Data

Proportion of population with access to affordable essential

26

$50-79$

2003

IRC

drugs on a sustainable basis $(\%)$

Personal computers in use per 100 population No Data

Internet users per 100 population

No Data 


\begin{tabular}{llll}
\hline Indicators & Available Data & Year Remarks
\end{tabular}

\section{E. Country Specific Thematic Indicators}

GDP (US\$ billion), non-drug-related

GDP (USS billion) drug-related

GDP per capita (US\$)

Share of agriculture in GDP (\%)

Population living in rural areas (\%)

Annual population growth rate $(\%)$

Population under age 18 (as \% of total)

Population aged 65 and above (as $\%$ of total)

Population with physical disabilities (\%)

Unemployment among people with disabilities (\%)

Number of abducted children in the last 12 months

Literacy rate among demobilized child soldiers (age group

14-18 years) (\%)

Population with access to the BPHS (\%)

BPHS facilities providing basic reproductive health

services (\%)

Female-headed households (\%)

Land/property disputes in all complaints received by AIHRC

between June 2003 and May 2004 (\%)

Arable land to total land

Ex-combatants having undergone full DDR programme $(\%)$

Geographical distribution of prosecutors

Geographical distribution of judges

\section{Women judges among all judges (\%)}

Women prosecutors among all prosecutors (\%)

Permanent employment in the public service (all levels),

according to sex $(\%)$

Voter turnout in presidential elections October 2004 (as proportion of total registered voters)

Rural households that have experienced reduced water

quality/quantity in the past 12 months (\%)

Participation by rural households in food-for-work

programmes in the previous 12 months (\%)

Participation by rural households in cash-for-work

programmes in the previous 12 months (\%)

Rural households benefiting from relief food distribution in

the previous 12 months (\%)

$\begin{array}{lll}4.6 & 2003 & \text { World Bank } \\ 2.4 & 2003 & \text { SAF }\end{array}$

207

47.2

80

2.5

57.3

5.2

4-5

84

Total: 269, M: 246, F: 23

Indicators

World Bank

CSO/UNIDATA estimates

UNICEF/CSO MICS

2003 UNICEF/CSO MICS

2003 UNICEF/CSO MICS

2004 UNDP/UNOPS CDAP

2003 IRC

2004 UNICEF $195 \%$ of all cases happened in only one province)

2004 Afghanistan New

Beginnings Programme

2003 Ministry of Health/CDC/

UNICEF

2002 MSH HANDS

3.3 (Urban: 5 , Rural: 2.5 )

-

36 Confiscation of land

2003 UNICEF/CSO MICS

17 Destruction of property

$12 \quad 2003$ AREU

18.8

$44 \%$ in Kabul

Oct. 2004 ANBP

2003 SAF

$30 \%$ in provincial capitals

$26 \%$ in districts

$31 \%$ in Kabul 2003 SAF

$23 \%$ in provincial capitals

$46 \%$ in districts

3.12003 SAF

5.2

2003 SAF

Centre-M: 71, F: $29 \quad 2002 \quad$ CSO

Provinces - M: 83, F: 17

$66 \%$ overall $2004 \quad$ JEMB

(of this, $40 \%$ are women, $60 \%$ men)

$60 \quad 2003$ NRVA

$34 \quad 2003 \quad$ NRVA

$<20 \quad 2003 \quad$ NRVA

13

2003 NRVA 


\section{Sources}

AIHRC and UNAMA Joint Verification of Political Rights; First Report 15 June-7 July 2004.

AIHRC and UNAMA Joint Verification of Political Rights; Second Report 8 July-24 August 2004.

AKDN (2004) Survey Results from the Rural Education Support Programme in Baghlan.

Alden Wily, L. (2004) Rural Land Conflict and Peace in Afghanistan; AREU.

Andersson, N. et al. Mine Smartness and the Community Voice in Mine Risk Education: Lessons from Afghanistan and Angola; in: Third World Quarterly; Vol. 24 (2003); No.5.

AREU Situational Analysis, Teacher Education and Professional Development in Afghanistan (not yet published).

AREU and UNSECOORD Briefing Paper Minimal Investment, Minimal Results: The Failure of Security Policy in

Afghanistan, June 2004.

Atmar, H. and J. Goodhand (2002) Afghanistan: The Challenge of "Winning the Peace"; in: Van Tongeren, P.; Searching for Peace in Central and South Asia: An Overview of Conflict Prevention and Peace-Building Activities.

Bassiouni, C. Statement of the United Nations Independent Expert on Human Rights in Afghanistan; 21 August 2004.

Bruns, B. et al. (2003) Achieving Universal Primary Education by 2015: A Chance for Every Child; report published by The World Bank.

Centre for Strategic and International Studies (2004) The Road Ahead: Issues for Consideration at the Berlin Donor

Conference for Afghanistan.

Centres for Disease Control and UNICEF (2002) Maternal Mortality in Afghanistan: Magnitude, Causes, Risk Factors and

Preventability.

FAO (2003) Grazing Land Encroachment - Mission to Daste-e Laili.

Ghai, Y. (2003) Unitary or Federal - A False Choice?; Decentralisation of State Powers in Afghanistan; New York University, Centre for International Cooperation.

Guimbert, S. (2004) Structure and Performance of the Afghan Economy; World Bank - South Asia Working Paper Series.

Harpviken, K. et al. (2002) Afghanistan and Civil Society; commissioned by the Norwegian Ministry of Foreign Affairs Human Rights Watch "All Our Hopes Are Crushed - Violence and Repression in Western Afghanistan"; 5 November 2002. Human Rights Watch "Killing You Is an Easy Thing for Us - Human Rights Abuses in Southeast of Afghanistan"; 29 July 2003.

International Campaign to Ban Landmines (2003) Landmine Monitor Report 2003: Toward a Mine-Free World.

International Crisis Group; "Elections and Security in Afghanistan" 30 March 2004.

Internews (2004) Afghan Media Directory, 1st Edition.

IRC (2003) Afghanistan: Labour Market Information Survey.

Journal of the American Medical Association Theme Issue on Violence and Human Rights, No. 292, 4 August 2004.

Khalizad, Z.; "Democracy Bubbles Up" Wall Street Journal; 25 March 2004.

Malikyar, H. and B. Rubin (2002) Center-Pèriphery Relations in the Afghan State: Current Practices, Future Prospects; New York University, Centre for International Cooperation.

Medica Mondiale "Women and girls in detention in Kabul Welayat"; 5 March 2003.

Ministry of Agriculture and Animal Husbandry (2004) Policy and Strategy for the Forestry and Range Management Sectors;

Discussion Paper No. 4.

Ministry of Education (2003) National Education Curriculum Framework Document.

Ministry of Education Submission to 1383 National Development Budget.

Ministry of Rural Rehabilitation and Development and World Bank (2004) Rural Poverty in Afghanistan: Initial Insights from the National Risk and Vulnerability Assessment 2003.

National Democratic Institute for International Affairs' Pre-Election Delegation to Afghanistan Statement of 18 August 2004. Nojumi, N. (2004) The Prospect of Justice and the Political Transition of Civil Society: The Recovery Process of Afghanistan: in: Asia Program Special Report No. 122 - Political Transition in Afghanistan: The State, Islam and Civil Society, Woodrow Wilson International Centre for Scholars.

Office of the High Commissioner for Hurhan Rights (2004) Country Profile of Afghanistan and the International Human Rights System.

Office of the High Commissioner for Hunan Rights (2004) Country Profile of Afghanistan and the International Human Rights System - Annexes.

Pain, A (2004) The Impact of the Opium Poppy Economy on Household Livelihoods: Evidence from the Wakhan Corridor and Khustak Valley in Badakhshan (Draft); study for AKDN. 
Rights and Democracy (2002) Women's Rights in Afghanistan - Report on Rights and Democracy's Mission to Afghanistan. Rubin, B. (2003) Summary of Papers on Anti-Corruption Measures in the Constitution of Afghanistan; New York University, Centre for International Cooperation.

Special Rapporteur on Independence of Judges and Lawyers Civil and Political Rights, Including the Questions of Independence of the Judiciary, Administration of Justice and Impunity; Addendum: Situations in specific countries or territories; Document E/CN.4/2003/65/Add.1 (25 February 2003).

Special Rapporteur on Violence Against Women, Its Causes and Consequences Integration of the Human Rights of Women and the Gender Perspective: Violence Against Women - Toward an Effective Implementation of International Norms to End Violence Against Women; Document E/CN.4/2004/66 (26 December 2003)

The Constitution of Afghanistan (1382)

Islamic Republic of Afghanistan and international agencies (2004) Securing Afghanistan's Future: Accomplishments and the Strategic Path Forward

Tufts University, Feinstein International Famine Center (2004) Human Security and Livelihoods of Rural Afghans 2002-2003 UN-DESA/UN-Statistics Division (2004) Progress of the Least Developed Countries on the Millennium Development Goals UNDP (2004) Opening Doors to Opportunity: Afghanistan's Millennium Development Goals

UNEP (2003) Afghanistan - Post-Conflict Environmental Assessment

UNESCO et al. Education For All 2000 - Assessment for Afghanistan

UN-HABITAT (2003);Preliminary Study of Land Tenure-Related Issues in Urban Afghanistan, with Special Reference

to Kabul City,

UNHCR; Returnee Monitoring Report 2002-2003.

UNICEF Rapid Assessment of Learning Space 2002.

UNICEF (2003) Report on a National Assessment of the Situation of Children Deprived of Parental Care in Institutions in Afghanistan.

UNICEF and Central Statistics Office (2004) Afghanistan - Progress of Provinces: Multiple Indicator Cluster Survey 2003.

UNODC (2003) Community Drug Profile \#5: Assessment of the Problem of Drug Use in Kabul City.

UNODC (2004) World Drug Report 2004.

UNODC and Counter Narcotics Directorate (2003) Afghanistan Opium Survey 2003.

Usmani, F. (15 April 2002) Afghanistan Country Profile: Reproductive Health.

Wardak, A. Building a post-war justice system in Afghanistan; in: Crime Law and Social Change, Vol. 41 (2004), No. 4.

WFP (2003) Findings from Protracted Relief and Recovery Operation 10233.0 in Afghanistan.

WFP Gender Policy 2003-2007.

WHO (2003) Shaping the Future - World Health Report 2003.

World Bank (2004) Afghanistan: Statè Building, Sustaining Growth, and Reducing Poverty - A Country Economic Report (Draft).

World Bank (2004) Poverty, Vulnerability and Social Protection in Afghanistan (Discussion Draft).

World Bank World Development Indicators 2003.

Zakhilwal, O. and A. Niazi "The Warlords Win in Kabul"; The New York Times; 21 June 2002.

\section{Websites}

Centre for Economic and Social Rights The Right to Food (www.cesr.org)

Ministry of Education Achievements (http://www.moe.gov.af/achievements.asp) 


\section{Major Findings of the Common Country Assessment of the Islamic Republic of Afghanistan}

\section{Area: Governance and Institutional Development \\ Key issues}

- Democratic accountability and the rights of the citizen

- Participation in political processes and social inclusion, including gender equality and civil society partnerships

- Corruption

- Public administration reform

- Decentralisation and devolution

- The positive role of the media

\section{Underlying causes}

- Challenges to credibility of political processes

- Challenges to separation of powers

- Lack of capacity within civil society to monitor Government and hold it accountable for its acts

- Consequences of the lack of a human rights culture

- Lack of policy, regulatory and legal frameworks, as well as efficient enforcement

- Absence of an integrated local governance framework

- Consequences of gender inequality

- Low level of salaries in the public sector and delays in payment

- Politicisation of the public administration institutions and absence of a merit-based system

- Financial dependence of the media

- Climate of fear among journalists

\section{Root causes}

- Underdeveloped human rights culture, along with lack of democracy, state-building and civil society participation

- Young governance structures still in process of establishment and/or early stages of development, and unable to curb political insecurity

- Shortage of human resources that can propel democratic reforms

- Wide variations in socio-economic indicators, by gender, region and rural-urban divide

- Weakened social infrastructure

- Socio-cultural traditions that result in widespread marginalisation based on gender, social status or ethnicity

\section{Area: Peace, Security and Justice}

\section{Key issues}

- Explosive remnants of war

- Continued power and influence of non-statutory armed forces under commanders and warlords, along with the persistence of incidents of armed violence

- Contested allocation of resources, in particular land and water

- Cultivation of poppy

- Dysfunctional formal.justice system and preference for traditional justice mechanisms

- Social violence and lack of social protéction

\section{Underlying causes}

- Slow progress on implementation of Disarmament, Demobilisation and Reintegration (DDR)

- Traditional widely dispersed authority, including lack of central Government control over natural resources

- Insufficient and inadequate law enforcement capacity, and shifts in traditional decision-making mechanisms

- Weakened conflict resolution mechanisms

- Lack of awareness of basic rights and the legal system, impeding access to justice 
- Low level of capacity/resources of the formal justice system and lack of coherent policies

- Lack of awareness of risk related to landmines and UXO

- Lack of a legal and regulatory framework for landmines and UXO

- Lack of institutional capacity for drug control, along with lack of adequate engagement of poppy farmers in eradication plans

- Consequences of diminished livelihoods; high and increasing indebtedness or need for credit, leading to increased vulnerability

- The shortcomings of traditional justice mechanisms in safeguarding human rights in a situation of monopoly of such mechanisms for many years

- Lack of clarity of the transitional legal framework

- Insufficient capacity of the correctional system

- Lack of redress for violations in the absence of a formal legal system

- Consequences of socio-cultural traditions, including those that do not discourage social violence, particularly against women

\section{Root causes}

- Underdeveloped human rights culture, along with lack of traditions of democracy, state-building and civil society participation

- Young governance structures still in process of establishment and/or early stages of development, and unable to curb political insecurity

- Shortage of human resources that can propel democratic reforms

- Wide variations in socio-economic indicators, by gender, region and rural-urban divide

- Weakened social infrastructure

- Socio-cultural traditions that result in widespread marginalisation based on gender, social status or ethnicity

\section{Area: Economic Development and Growth}

\section{Key issues}

- Employment

- Distributive justice

- Environment and natural disaster management

\section{Underlying causes}

- Lack of an enabling environment, including policy, legislative and regulatory frameworks

- Lack of support services, including key infrastructure, and market access

- Lack of access to capital and finảncial services

- Lack of advanced entrepreneurial skills, knowledge and technology

- Consequences of socio-cultural traditions and lack of opportunities (illiteracy, little or no capital), that prevent women, the landless, and vulnerable groups including returnees/IDPs, widows, people with disabilities, street working children, children without parental care, and former child soldiers and war-affected children from participating in many types of economic activities

- Unequal distribution of employment, reflecting biases based on social status, gender or ethnic group

- Ambiguity and high insecurity in land ownership and land tenure rights that marginalise numerous sections of the population, based on social status, gender and ethnicity

- Ambiguous legal status of ownership and access to natural resources

- Competing land'usage (agriculture, human settlements, forests/rangeland, wetlands)

- Limited capacity of Govérnment to prepare for and mitigate natural disasters

- Negative impact from war, drought, increasing population, human settlements, over-exploitation and landmines

\section{Root causes}

- Underdeveloped human rights culture, along with lack of longstanding traditions of democracy, state-building and civil society participation

- Culture of unsustainable resource use that must be reversed

- Shortage of human resources that can propel economic reforms 
- Wide variations in socio-economic indicators, by gender, region and rural-urban divide

- Weakened social infrastructure

- Socio-cultural traditions that result in widespread marginalisation based on gender, social status and ethnicity

- Obsolete industrial and agricultural techniques and practices that harm the environment

\section{Area: Social Well-Being}

\section{Key issues}

- Availability of/access to education

- Availability of/access to health

- Availability of/access to food

\section{Underlying causes}

- Poor quality of services (outdated curriculum, lack of essential teaching-learning materials, limited accountability and lack of clear relations in Government at the provincial level, limited community involvement)

- Lack of skilled staff, particularly women, resulting in poor institutional capacity to plan and manage programmes; lack of training; and shortages of physical infrastructure, equipment and supplies

- Lack of awareness of education issues

- Lack of awareness of health and food issues

- Consequences of diminished livelihoods

- Consequences of socio-cultural traditions

- Degraded and limited road infrastructure

- Limited capacity of Government to prepare for and mitigate natural disasters

- Lack of fair land ownership norms, as well as lack of a single body of land tenure laws

- Unregulated water rights and decimated irrigation systems

- Lack of dietary diversity

- Reported discrimination against some ethnic groups

\section{Root causes}

- Underdeveloped human rights culture, along with lack of traditions of democracy, state-building and civil society participation

- Wide variations in socio-economic indicators, by gender, region and rural-urban divide

- Weak social infrastructure

- Socio-cultural traditions that result in widespread marginalisation based on gender, social status or ethnicity

- Young governance structures in process of establishment and/or early stages of development, and unable to curb political insecurity

- Shortage of human resources that can propel social reforms

- Culture of unsustainable resource use that must be reversed 
Annex B

\section{International Agreements Concluded Between Afghanistan and the United Nations}

Title

\section{Status of Major International Human Rights Instruments for Afghanistan}

International Convention on the Elimination of All Forms of Racial Discrimination

1983

International Covenant on Economic, Social and Cultural Rights, 1966

International Covenant on Civil and Political Rights, 1966

Optional Protocol to the Covenant on Civil and Political Rights, 1966

1983

Second Optional Protocol to the Covenant on Civil Political Rights Aiming at the Abolition of the Death Penalty, 1989

Convention on the Elimination of All Forms of Discrimination against Women (CEDAW)

Optional Protocol to the CEDAW

Convention Against Torture and Other Cruel, Inhuman or Degrading Treatment or Punishment

Convention on the Rights of the Child (CRC)

Optional Protocol to the CRC on the Involvement of Children in Armed Conflict

1983

$\mathrm{N} / \mathrm{A}$

N/A

2003

N/A

1987

1994

Optional Protocol to the CRC on the Sale of Children, Child Prostitution and Child Pornography

2003

International Convention on the Suppression and Punishment of the Crime of Apartheid, 1973

2002

Convention on the Prevention and Punishment of the Crime of Genocide, 1948

$07 / 1983$

Slavery Convention, 1926, and Protocol Amending the Slavery Convention, 1953

$03 / 1956$

$08 / 1954$

Supplementary Convention on the Abolition of Slavery, the Slave Trade, and Institutions and Practices

$11 / 1966$

Similar to Slavery, 1956

Convention on the Suppression of the Traffic in Persons and of the Exploitation of the Prostitution of Others, 1950

$05 / 1985$

Geneva Convention for the Amelioration of the Condition of the Wounded and Sick in Armed Forces in the Field, 1949

Geneva Convention for the Amelioration of the Condition of Wounded, Sick and Shipwrecked Members of*Armed

$09 / 1956$

Forces at Sea, 1949

Geneva Convention Relative to the Treatment of Prisoners of War, 1949

$09 / 1956$

Geneva Convention Relative to the Protection of Civilian Persons in Time of War, 1949

\section{Status of International Labour Instruments for Afghanistan}

\section{Fundamental Conventions}

C.98 Right to Organise and Collective Bargaining Convention, 1949

$\mathrm{N} / \mathrm{A}$

C. 105 Abolition of Forced Labour Convention, 1957

C.29 Forced Labour Convention, 1930 $05 / 1963$

C. 111 Discrimination (Employment and Occupation) Convention, 1958

$\mathrm{N} / \mathrm{A}$

C. 87 Freedom of Association and Protection of the Right to Organise Convention, 1948

$10 / 1969$

C. 138 Minimum Age Convention, 1973

C. 100 Equal Remuneration Convention, 1951

C. 182 Worst Forms of Child Labour Convention

$\mathrm{N} / \mathrm{A}$

$\mathrm{N} / \mathrm{A}$

$08 / 1969$

N/A

\section{Other Conventions}

C. 4 Night Work (Women) Convention, 1919

$06 / 1939$

C. 13 White Lead (Painting) Convention, 1921

$06 / 1939$

C. 14 Weekly Rest (Industry) Convention, 1921

$06 / 1939$

C. 41 Night Work (Women) Convention (Revised), 1934

C. 45 Underground Work (Women) Convention, 1935

$05 / 1937$

$01 / 1957$

C.95 Protection of Wages Convention, 1949

C. 106 Weekly Rest (Commerce and Offices) Convention, 1957 
C. 137 Dock Work Convention, 1973

C.139 Occupational Cancer Convention, 1974 $05 / 1979$

C. 140 Paid Educational Leave Convention, 1974 $05 / 1979$

C. 141 Rural Workers' Organisations Convention, 1975 $05 / 1979$

C.142 Human Resources Development Convention, 1975

\section{Status of Other Major International Conventions}

Convention on Biological Diversity, 1992

$09 / 2002$

United Nations Convention to Combat Desertification, 1994

$11 / 1995$

United Nations Framework Convention on Climate Change, 1992

$09 / 2002$

Rome Statute of the International Criminal Court, 1998

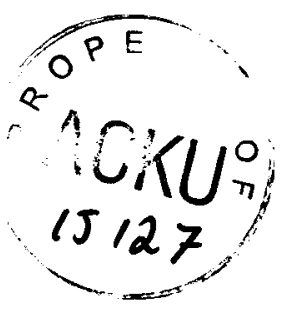

